\title{
Decadal Seismicity before Great Earthquakes-Strike-Slip Faults and Plate Interiors: Major Asperities and Low-Coupling Zones
}

\author{
Lynn R. Sykes
}

Lamont-Doherty Earth Observatory of Columbia University, Palisades, New York, USA

Email: sykes@ldeo.columbia.edu

How to cite this paper: Sykes, L.R. (2021) Decadal Seismicity before Great Earthquakes-Strike-Slip Faults and Plate Interiors: Major Asperities and Low-Coupling Zones. International Journal of Geosciences, 12, 784-833.

https://doi.org/10.4236/ijg.2021.129044

Received: August 4, 2021

Accepted: September 11, 2021

Published: September 14, 2021

Copyright $\odot 2021$ by author(s) and Scientific Research Publishing Inc. This work is licensed under the Creative Commons Attribution International License (CC BY 4.0).

http://creativecommons.org/licenses/by/4.0/

\begin{abstract}
Decadal forerunning seismic activity is examined for very large, shallow earthquakes along strike-slip and intraplate faults of the world. It includes forerunning shocks of magnitude $\mathrm{Mw} \geq 5.0$ for 21 mainshocks of $\mathrm{Mw} 7.5$ to 8.6 from 1989 to 2020. Much forerunning activity occurred at what are interpreted to be smaller asperities along the peripheries of the rupture zones of great mainshocks at transform faults and subduction zones. Several great asperities as ascertained from forerunning activity agree with the areas of high seismic slip as determined by others using geodetic, mapping of surface faulting, and finite-source seismic modeling. The zones of high slip in many great earthquakes were nearly quiescent beforehand and are identified as the sites of great asperities. Asperities are strong, well-coupled portions of plate interfaces. Different patterns of forerunning activity on time scales of up to 45 years are attributed to the sizes and spacing of asperities (or lack of). This permits at least some great asperities along transform faults to be mapped decades before they rupture in great shocks. Rupture zones of many great mainshocks along transform faults are bordered either along strike, at depth or regionally by zones of lower plate coupling including either fault creep forerunning activity, aftershocks and/or slow-slip events. Forerunning activity to transforms in continental areas is more widespread spatially than that adjacent to oceanic transforms. The parts of the San Andreas fault themselves that ruptured in great California earthquakes during 1812, 1857 and 1906 have been very quiet since 1920; moderate to large shocks have been concentrated on their peripheries. The intraplate shocks studied, however, exhibited few if any forerunning events, which is attributed to the short period of time studied compared to their repeat times. The detection of forerunning and
\end{abstract}


precursory activities for various time scales should be sought on the peripheries of great asperities and not just along the major faults themselves. This paper compliments that on decadal forerunning activity to great and giant earthquakes along subduction zones.

\section{Keywords}

Earthquakes, Strike-Slip Faults, Transform Faults, Intraplate, Prediction, Plate Coupling, Asperities

\section{Introduction}

Great earthquakes have occurred at shallow depths along active transform faults and subduction zones and within the interiors of lithospheric plates. They are particularly important to understand since many have caused extensive destruction and loss of life. Much new seismic and geodetic information has become available for great earthquakes that occurred globally during the last several decades. Here I study 21 mainshocks of magnitude Mw 7.5 to 8.6 that occurred from 1989 to 2020 along 11 strike-slip faults, 8 plate interiors and two in Tibet that may be classified as occurring in either intraplate regions or along slow-moving block boundaries. Emphasis is given to the spatial and in some cases the temporal patterns of activity of moderate to large forerunning events that preceded them in the previous decades. The rupture zones and forerunners of three older earthquakes in California and Guatemala are also described. It is surprising how little has been written about decadal preceding events, which I call forerunning earthquakes to distinguish them from foreshocks of shorter-time duration. The first aim of this paper is simply to describe the spatial distribution of forerunning events to a large number of mainshocks.

A second aim is to use forerunning shocks to map great asperities that were clearly definable, as well as those that were not, in the years to decades before they subsequently ruptured in large, great and giant shocks. Understanding forerunning seismic activity and where it occurs with respect to both the centroids of slip in mainshocks and their regions of high displacements is emphasized. A third aim is to ascertain the implications of this work for risk reduction and shorter-term prediction of large earthquakes. This paper on strike-slip and intraplate mainshocks is a companion paper to [1] that examined decadal activity prior to mainshocks along subduction zones of the world.

Very large mainshocks and their forerunning events are described in terms of the rupture of asperities of various sizes, i.e., strong, well-coupled portions of plate interfaces. Some parts of plate boundaries consist of great asperities that are well coupled, i.e., largely locked, during the slow process of stress buildup to very large earthquakes. Other parts of plate boundaries, so called low-coupling zones (LCZ), often are identified as the sites of either fault creep, smaller asperities and moderate-size forerunning activity and aftershocks. Much forerunning 
activity as well as several slow-slip events described in the literature occurred in LCZ on the peripheries of great asperities. I describe forerunning cumulative seismic moment before one great strike-slip earthquake and how it changed with time.

In the past, most shorter-term precursory seismic activity was identified only after the occurrence of large earthquakes. Typically, it has been difficult to distinguish it from other seismic events that happen during the long periods of stress buildup to large earthquakes.

Mogi [2] described rupture in the lab of two quite different substances: homogeneous pine resin and three inhomogeneous rocks. The rupture of pine resin at high stress was not preceded by small forerunning seismic events whereas failures of those rocks were. The presence of inhomogeneities seems to be essential, at least in principle, to the occurrences of forerunning, precursory and aftershock activities not only in the lab but also at larger scales at plate boundaries.

More study of the distribution of strong and weak regions along and near major faults is needed not only to understand the physics of earthquakes but also whether long-term earthquake prediction is either possible or unlikely for specific faults. Strong regions that are more difficult to break are called asperities in the rock mechanics and seismological literatures. I use the terms asperities and plate coupling extensively. Some parts of plate boundaries remain locked, i.e., well-coupled during stress accumulation; others are sites of poorer coupling, moderate-size shocks, slow earthquakes, and fault creep. Some information about the physical and geological factors that govern strong and weak asperities is examined here briefly.

Others have analyzed the detailed distribution of large displacement (high slip) over the main rupture zones for many of the mainshocks examined here. They used seismic observations, data from the Geodetic Positioning System (GPS) and observations of surface faulting. They found that areas of high displacements were typically smaller than the sizes of aftershock zones.

A main contribution here is to map the distributions of forerunning strike-slip and intraplate earthquakes and to compare them with areas of high slip as computed by others. Most previous work has focused on individual large earthquakes and not on what can be ascertained by examining many of them worldwide. Relatively little attention has been paid to either the depths of forerunning decadal activity or if locations change with time.

Most very large earthquakes have occurred where plate coupling is high as reported in the literature. Rupture zones of great earthquakes are often bordered by zones of poorer plate coupling either along strike, downdip, updip or adjacent to them along nearby faults. Some of the clearest examples of forerunning activity to large earthquakes are sought with the hope that better knowledge gained from them will permit less well-defined cases to be interpreted better.

How can great asperities be identified beforehand if they do not rupture until the time of a great or giant shock? I find that earthquakes of moderate to major size in the decades before very large events mostly occurred near the peripheries 
of great asperities that later broke in great mainshocks. Shocks of moderate to major size can be used to map great asperities that are mostly quiet seismically before they rupture in mainshocks up to decades later. Precursory seismic and geodetic changes to great events should be sought on the peripheries of great asperities and not just along great faults themselves. Some claims that large earthquakes do not have precursors result from sampling only the faults that ruptured in great events. Many were looking in the wrong places.

This study builds upon previous work on great earthquakes, seismic gaps, forerunning activity and aftershocks by Fedotov [3], Mogi [4] [5], Sykes [6], Kelleher et al. [7] and others. Seismic gaps are segments of active plate boundaries that have not been the sites of large earthquakes for decades to hundreds of years. Those early studies typically used the extent of aftershock zones to map the rupture zones of great earthquakes. They did not have access to either GPS data, very long-period centroid locations of earthquakes, information on slow-slip events or finite-fault slip computations of sub-areas of high slip. Forerunning earthquakes of magnitudes as small as 5.0 are used in this paper. This permits many smaller events to be used to map the approximate rupture zones of many coming individual great mainshocks up to decades ahead of time.

One of the major findings of this paper is that the spatial distribution of forerunning earthquakes differs between oceanic and continental transform faults. Forerunning activity was found to be very concentrated for oceanic transforms and more widespread near continental transform faults. Little to no forerunning activity on a time scale of a few decades was found for the intraplate earthquakes studied. This is attributed to the need to include much longer periods of analysis for intraplate areas where strain buildup likely is slower than for most active plate boundaries.

The distributions of forerunning activity, great and moderate-size asperities, differences in plate coupling, and velocity strengthening and weakening materials can be considered as the building blocks or the architecture of seismic activity along and near strike-slip faults and subduction zones. Some may be useful for more detailed predictions or forecasts of large earthquakes.

\section{Methods}

Giant earthquakes are defined as those of seismic magnitude 8.5 or larger on the moment magnitude scale, $\mathrm{Mw}$, and great shocks as those of $7.7 \leq \mathrm{Mw}<8.5$. Mw and its corollary seismic moment, Mo, are needed to quantify the very large dimensions and magnitudes of great and giant earthquakes. Seismic moment, Mo in $\mathrm{N}-\mathrm{m}$, is related to $\mathrm{Mw}$ by

$$
\log \mathrm{Mo}=1.5 \mathrm{Mw}+9.1
$$

I define major shocks as those of $7.0 \leq \mathrm{Mw}<7.7$ and moderate-size earthquakes as with $5.0 \leq \mathrm{Mw}<7.0$. I examine earthquakes of $\mathrm{Mw} 5.0$ and greater and focus on shallow events on or near plate boundaries of the transform-fault type as well as on earthquakes within lithospheric plates, so-called intraplate shocks. 
Sykes [1] found that $69 \%$ of shallow earthquakes worldwide of $M w \geq 7.7$ were located at subduction zones, $7 \%$ involved normal-faulting and most of the rest occurred with strike-slip mechanisms either along transform plate boundaries or within lithospheric plates.

Locations, magnitudes and seismic moments of earthquakes shallower than 70 $\mathrm{km}$ along transform faults and within lithospheric plates were obtained from the Global Centroid Moment Tensor (GCMT) catalog since it started in 1976 [8] [9]. The centroids of slip are plotted and emphasized here rather than points where slip initiated. GCMT locations and their magnitude, $\mathrm{Mw}$, utilize some of the largest and longest-period seismic waves. The types of GCMT focal mechanisms in the figures are distinguished in terms of thrust, normal, strike-slip and reverse faulting. GCMT solutions have improved over time and have been extended to events as small as $\mathrm{Mw} 5.0$ [10].

Older locations and magnitudes are from the Bulletin of the International Seismological Centre and the 1992 catalog of Pacheco and Sykes [11]. The computer program GeoMapApp [12] was used for bathymetry and topography. Calculations of slip distributions in individual large earthquakes are taken from the literature as identified in the captions.

Uncertainties exist in the relative and absolute locations of the centroids of the shocks analyzed in this paper as well as in computations by others of areas of high slip in mainshocks. For the of areas of high slip in mainshocks, I used results that included whenever possible local and distant seismic data, geodetic observations, and mapping of rupture at the earth's surface. Relative locations likely can be improved by applying double-difference methods.

I added zones of computed high slip for large earthquakes. Those computations, often called finite-fault rupture models, map variations in slip during large mainshocks. In the figures I plot two contours of high slip from sources in the literature along with forerunning activity and centroids of mainshocks. The point where rupture initiated, the epicenter as determined from short-period data, is plotted as well for mainshocks.

After the start of the GCMT database in 1976, I needed to have many years of forerunning activity for an adequate analysis of a subsequent large shocks. Hence, the mainshocks studied here were limited to the period 1989 to August 2020 (Table 1). Results for three older great earthquakes are included as well.

\section{Results}

\subsection{Asperities, Earthquakes and Low-Coupling Segments}

The greatest earthquakes along strike-slip faults, which are taken here to break the largest asperities, typically occur at depths of a few to $15 \mathrm{~km}$ but sometimes as great as $25 \mathrm{~km}$. Transform plate boundaries at depths greater than about 15 to $25 \mathrm{~km}$ move without earthquakes. I show that great asperities are largely or totally locked during periods of slow stress buildup to mainshocks whereas smaller asperities, mostly on their peripheries, rupture in forerunning earthquakes of 
moderate to large size. Slow-slip seismic events occur in low-coupling zones between great asperities as well as updip and downdip of them. The mainshocks examined within plates, however, were preceded by few, if any, forerunning shocks going back to 1976. Extending the record well back in time may be needed to map any patterns of forerunning events for intraplate regions since they are characterized by show stress accumulations and very long-repeat times.

Scholz ([15], p. 73) interprets earth materials along much of the shallowest part of plate boundaries at depths of a few kilometers as in the velocity-strengthening regime of rock mechanics Rocks below those where great earthquakes and great asperities are found are taken to be in the velocity-weakening regime.

Table 1. Earthquakes studied.

\begin{tabular}{|c|c|c|c|c|c|c|c|}
\hline Earthquake & Date & $\begin{array}{c}\text { Latitude } \\
\text { GCMT }\end{array}$ & $\begin{array}{l}\text { Longitude } \\
\text { GCMT }\end{array}$ & $\begin{array}{l}\text { Depth } \\
\text { km }\end{array}$ & $\begin{array}{l}\text { Magnitude } \\
\text { Mw }\end{array}$ & $\begin{array}{l}\text { Figure } \\
\text { Number }\end{array}$ & $\begin{array}{l}\text { Long-Term Slip } \\
\text { Rate, } \mathrm{mm} / \mathrm{a}\end{array}$ \\
\hline Calilfornia, southern & $1857 \operatorname{Jan} 9$ & 35.7 & -120.3 & 14 & 7.9 & 33 and 34 & 33 \\
\hline California, northern & 1906 Apr 18 & 38.0 & -123.0 & 12 & 7.8 & 1 and 32 & 28 \\
\hline Guatemala & 1976 Feb 4 & 15.1 & -89.78 & 16 & 7.5 & 30 and 31 & $<21$ \\
\hline Macquarie Ridge & 1989 May 23 & -52.15 & 160.41 & 15 & 8.0 & 4 & 27 \\
\hline Luzon, Phillipines & 1990 July 16 & 15.97 & 121.23 & 15 & 7.7 & 16 and 17 & $\sim 9$ to 17 \\
\hline Balleny region & 1998 Mar 25 & -62.99 & 148.94 & 29 & 8.1 & 22 & \\
\hline Ceram Sea & 1998 Nov 29 & -2.03 & 125.00 & 16 & 7.7 & 25 and 26 & \\
\hline Sumatra, Southern & 2000 Jun 4 & -4.73 & 101.94 & 44 & 7.8 & 14 and 15 & \\
\hline Indian Ocean, South & 2000 Jun 18 & -13.47 & -97.17 & 15 & 7.9 & 23 & \\
\hline Qinghai, China & 2001 Nov 14 & 35.80 & 92.91 & 15 & 7.8 & 20 and 21 & 12 \\
\hline Alaska, Denali Fault & 2002 Nov 3 & 63.22 & -144.89 & 15 & 7.8 & 7 and 8 & 10 \\
\hline Macquarie Ridge & 2004 Dec 23 & -49.91 & 161.25 & 28 & 8.1 & 5 & \\
\hline Sichuan, China & 2008 May 12 & 31.44 & 104.10 & 13 & 7.9 & 18 and 19 & $\sim 4$ \\
\hline Sumatra, off Northern & 2012 Apr 11 & 2.35 & 92.82 & 46 & 8.6 & 27 and 28 & \\
\hline Sumatra, off Northern & 2012 Apr 11 & 0.90 & 92.31 & 55 & 8.2 & 27 and 28 & \\
\hline Southeast Alaska & 2013 Jan 5 & 55.69 & -134.97 & 14 & 7.5 & 9 & 52 \\
\hline Pakistan & 2013 Sept 24 & 26.70 & 65.04 & 12 & 7.8 & 2 & $<38$ \\
\hline Scotia Sea & 2013 Nov 17 & -60.49 & -45.32 & 24 & 7.8 & 6 & 12 \\
\hline Sumatra, off Southwest & 2016 Mar 2 & -4.75 & 94.22 & 37 & 7.8 & 29 & \\
\hline New Zealand & 2016 Nov 13 & -42.03 & 173.85 & 19 & 7.8 & 11 to 13 & 35 \\
\hline Kommandorsky Islands & $2017 \mathrm{Jul} 17$ & 54.13 & 169.78 & 23 & 7.8 & 10 & 51 \\
\hline Cayman Trough, west & 2018 Jan 10 & 17.56 & -83.86 & 16 & 7.5 & 3 & 21 \\
\hline Alaska, Gulf & $2018 \operatorname{Jan} 23$ & 56.22 & -149.12 & 34 & 7.9 & 24 & \\
\hline Cayman Trough, east & $2020 \operatorname{Jan} 28$ & 19.33 & -79.55 & 24 & 7.7 & 3 & $\sim 16$ \\
\hline Slip Rates from references & plus DeMets & et al. & {$[13]$} & and Field & et al. & {$[14]$} & \\
\hline
\end{tabular}




\subsection{A Model of Slip and Asperities-The San Andreas Fault, California}

Figure 1 illustrates some of the patterns of forerunning activity before several large strike-slip earthquakes within continents, in this case numerous prior shocks in a broad area near the coming rupture zone of the great 1906 San Francisco earthquake. Surrounding activity was then low from 1920 until about 1954. Most of the 1906 rupture zone along the San Andreas fault itself was quiet in the decades prior to 1906; forerunning activity occurred along other faults including strike-slip faults in the San Francisco Bay area. The four nearby dots northeast of San Francisco Bay denote some of the largest prior shocks. They occurred on or near mapped thrust faults [16]. Plate motion in the area includes a modest component of convergence in addition to strike-slip faulting. Those two types of faulting are partitioned spatially.
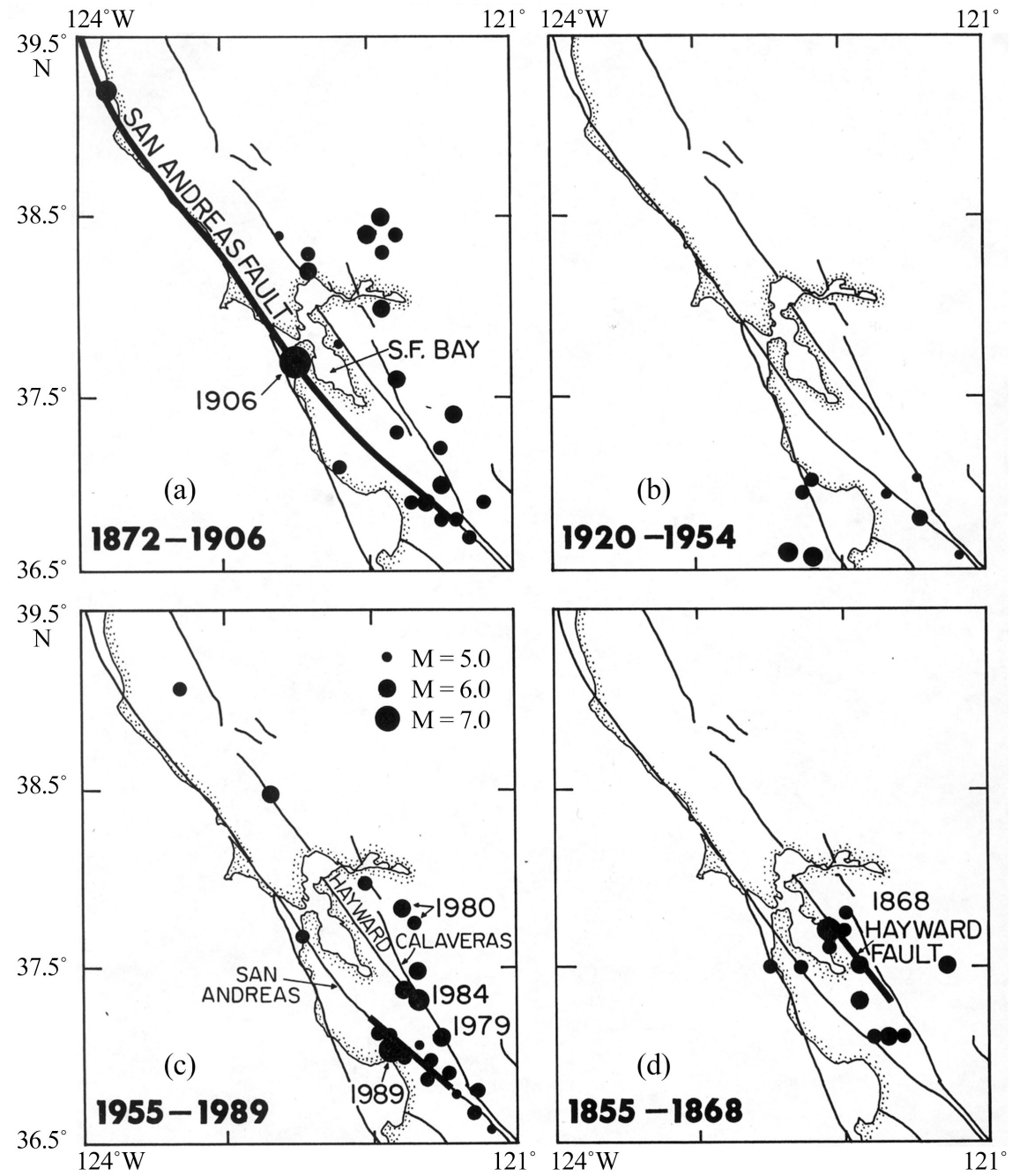

Figure 1. Forerunning activity of magnitude 5 and greater (solid dots) in the greater San Francisco Bay area, California from 1872 until the great 1906 earthquake (upper left). Three other time windows are illustrated. Largest solids dots denote epicenters of the 1868, 1906 and 1989 mainshocks. Heavy solid lines show rupture zones of mainshocks along San Andreas fault in 1906 and 1989 and the Hayward fault in 1868 from [16]. 
Several of the examples to follow show similar patterns of forerunning activity for continental areas. I find that forerunning activity and aftershocks for transform faults in oceanic areas typically are much more concentrated spatially than those in continental areas.

\subsection{Patterns of Forerunning Activity-Strike-Slip Faults}

\subsubsection{Pakistani Earthquake of 2013, Mw 7.7}

Figure 2 illustrates forerunning activity from 1976 until the occurrence of the southern Pakistani earthquake of 2013 in Balochistan province of Mw 7.7. Its mechanism involved strike-slip displacement with a small thrust component along the Hoshab fault, a part of the plate boundary that extends northeasterly near the eastern end of the Makran subduction zone. The GCMT epicenter of the main shock, a measure of its centroid location, is situated near the middle of the areas of large horizontal slip in 2013 (solid black and dashed lines) as determined by [17] from geodetic data and seismic-wave modeling.

Rupture in the mainshock initiated near the northeastern end of the zone of largest moment release at the short-period epicenter. Rupture progressed southwesterly [17]. It was followed by a smaller release of moment [17], probably in the smaller zone of slip along the northeastern end of surface rupture.

Most of the forerunning activity and many aftershocks of $\mathrm{Mw}>5.0$ were situated to the northeast of the two main zones of displacements in the mainshock, i.e., well off the rupture zones. Some of that activity may have occurred on sub-parallel faults to the one that broke in 2013. Most of the rupture zone can be considered as a great asperity along its southeastern end and a smaller asperity along its northeastern end. Each remained nearly quiet seismically for decades ahead of time until they ruptured in the Mw 7.7 event. This pattern is like that prior to the 1906 San Francisco event (Figure 1) and other transform faults within continental areas as well as along many subduction zones [1].

Barnhart et al. [18] mapped surface rupture of the 2013 mainshock using Landsat 8 satellite data with a spacing of $15 \mathrm{~m}$ resolution. They found that slip was not parallel to the direction of relative motion between the Arabian and Eurasian plates and hence, that compressional deformation must occur at other times either along either the Hoshab fault itself or in a broader surrounding zone.

In summary, most forerunning activity and aftershocks occurred at a distance from the two main rupture zones of the 2013 mainshock. The two rupture zones can be regarded as major asperities that accumulated stress in the preceding decades and released it suddenly in 2013. Searches for shorter-term foreshock activity to the 2013 and other strike-slip mainshocks within continents should include broad areas of forerunning activity like that in Figure 2 and not just single zones of surface rupture in past great earthquakes. Concentrating just on the main fault itself may well miss prior activities that may be useful for intermediate and short-term predictions. 


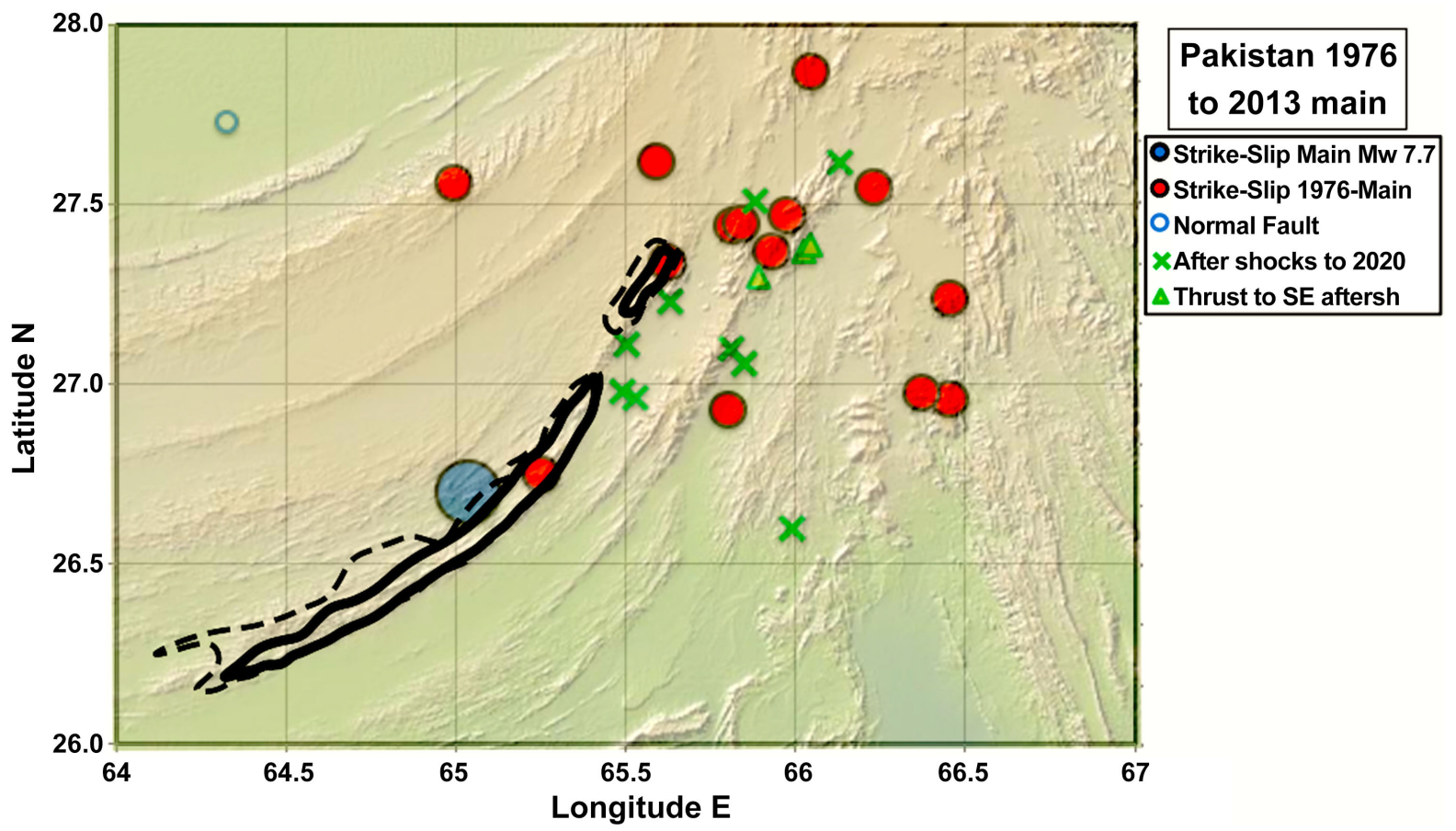

Figure 2. Locations and mechanisms of earthquakes of $\mathrm{Mw} \geq 5.0$ from 1976 through the Pakistani mainshock (large blue circle) in 2013 of Mw 7.7. Heavy solid and dashed lines enclose regions of computed slip greater than 5 and $2 \mathrm{~m}$ in the mainshock from [17].

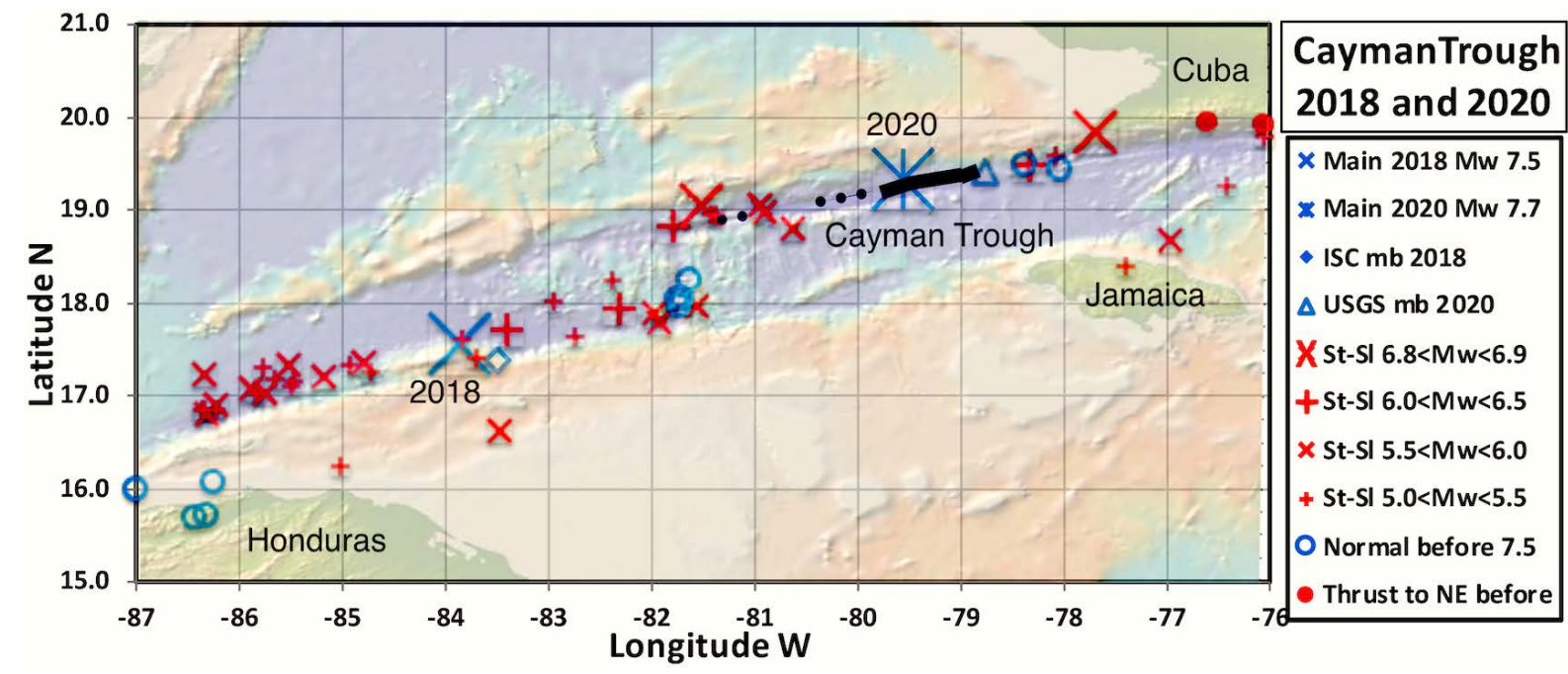

Figure 3. Forerunning activity from 1976 until two mainshocks of 2018 and 2020 of Mw 7.5 and 7.7. The Cayman spreading center is located near the normal faulting events in the center of the figure at $81.8^{\circ} \mathrm{W}$. The deep Cayman trough is about $100 \mathrm{~km}$ wide and is shown in purple. Sea floor to the north and south of the Cayman trough is shallower than that in normal oceans. Solid and dotted black lines indicate computed slip greater than 6 and $4 \mathrm{~m}$ in the 2020 mainshock from [19].

\subsubsection{Earthquakes along Cayman trough of 2018 and 2020, Mw 7.5, Mw 7.7}

Two large strike-slip earthquakes ruptured transform faults on the two sides of the Cayman spreading center (Figure 3) in 2018 (Mw 7.5) and 2020 (Mw 7.7). The well-defined spreading center, which is about $100 \mathrm{~km}$ in length from north 
to south, spreads at about $75 \%$ of the long-term rate of relative movement of about $21 \mathrm{~mm} / \mathrm{yr}$. between the North American and Caribbean plates. The Swann transform fault to the west of the spreading center, the site of the 2018 mainshock, takes up nearly the full plate motion. Each of the two transform faults at the eastern ends of the Cayman spreading center are active. The 2020 mainshock broke the northern most active of the two, the Oriente transform, which passes off the coast of southeastern Cuba.

Rupture in the 2020 mainshock proceeded westward toward the Cayman spreading center from its short-period epicenter. No forerunning activity occurred for about $100 \mathrm{~km}$ on either side of the centroid location of the 2020 mainshock and along that part of the Oriente transform fault for which [19] computed slip was greater than $6 \mathrm{~m}$ (Figure 3). That area is also notable for an absence of reported earthquakes as small as magnitude, mb, 4.5 since 1920. Clearly, that absence of forerunning activity defines a great asperity along that transform. Some slip as great as $4 \mathrm{~m}$ farther west along the Oriente transform closer to the Cayman spreading center was reported [19]. While it experienced five forerunning shocks in Figure 3, whether the area of $4 \mathrm{~m}$ slip coincided with them is uncertain. A reanalysis of the locations of those earthquakes is needed.

Abundant forerunning activity in Figure 3 also took place at distances great than $100 \mathrm{~km}$ from the centroid of the 2018 mainshock along the Swann transform. Some forerunning activity to the east, however, occurred close to the centroid. Again, those small forerunners need to be relocated. The 2018 mainshock ruptured westward from that area into the region of no forerunning activity in Figure 3. The latter was the site of no shocks of mb 4.5 or greater since 1920 . No estimate of detail slip is known to the author for the 2018 mainshock. Hence, it is difficult to estimate the distribution of large asperities for the relatively small shock of Mw 7.5.

In summary, forerunning activity did not occur within $100 \mathrm{~km}$ of the centroid of the 2020 mainshock and little within $100 \mathrm{~km}$ of the 2018 event. The region of computed slip greater than $6 \mathrm{~m}$ in the 2020 main event was not the site of forerunning shocks; it is identified as a great asperity. The seismic activity along the two oceanic transforms occurs along two narrow zones, a very different pattern than that seen in Figure 1 and Figure 2 for continental transform fault zones. Forerunning activity did not occur perpendicular to the zone of high slip in the 2020 mainshock.

\subsubsection{Macquarie Ridge Earthquake of 1989, Mw 8.0}

The Macquarie Ridge, which extends from southern New Zealand to a plate triple junction north of Antarctica, has been the site of many great strike-slip and thrust earthquakes, including the strike-slip mainshock of Mw 8.0 of 1989. Eighty percent of the slip in that mainshock occurred along the plate boundary [20] close the short-period epicenter (Figure 4), more concentrated than reported for many other great strike-slip events. The centroid of the 1989 mainshock (GCMT) was situated near the regions of computed large slip. Forerunning events and aftershocks largely occurred outside those slip zones. 


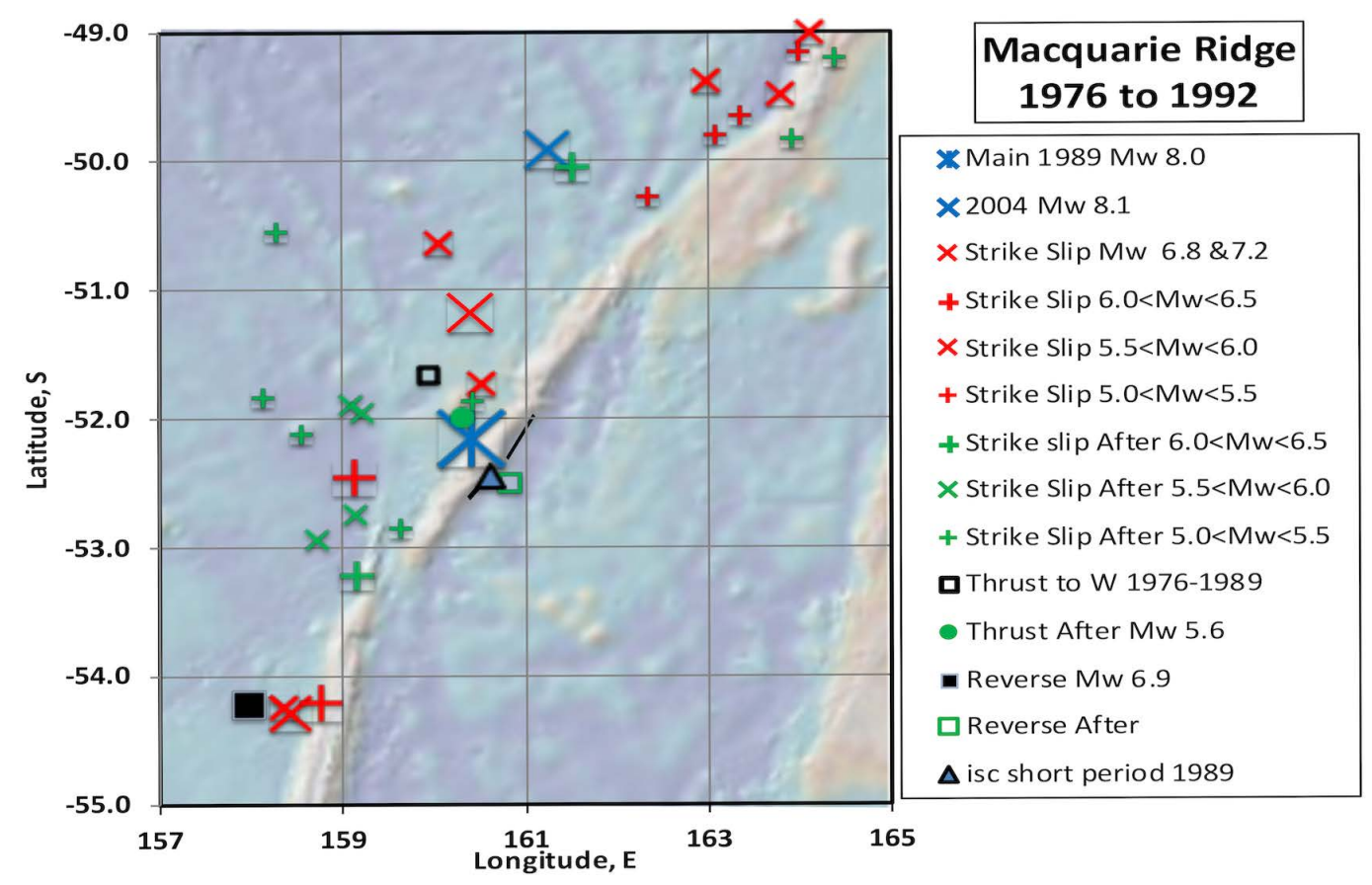

Figure 4. Forerunning and aftershock activity for the Macquarie Ridge mainshock of 1989 of Mw 8.0. Largest blue symbol in center denotes centroidal location of mainshock. Solid black lines indicate short region in which $80 \%$ of its computed displacement occurred after [20].

In summary, the zone of largest computed displacement in the 1989 mainshock was nearly quiescent for forerunning and aftershock activity. Thus, it appears to have been a major asperity that built up stress for many decades before it ruptured in 1989.

\subsubsection{Intra-Plate Earthquake West of Macquarie Ridge in 2004, Mw 8.1} The strike-slip mainshock of 2004 of Mw 8.1 occurred about 75 to $125 \mathrm{~km}$ to the northwest of the plate boundary along the Macquarie Ridge. Neither of its two fault planes is nearly parallel to the strike of the Macquarie Ridge, indicating it likely was an intraplate earthquake shock. Hayes et al. [21] comment on the presence of activity to the northwest of the plate boundary, as in Figure 4 and Figure 5, and relate that deformation to the slow growth of a new plate or block as the ratio of strike-slip to reverse motion along that part of the plate boundary changed over the past few million years. Similar activity, however, does not extend southeast of main plate boundary.

Nearby forerunning activity to the 2004 mainshock in Figure 3 and Figure 4 took place closer to the plate boundary than to its centroid. It may have had little if any relationship to the coming 2004 mainshock. To my knowledge, no one has published a detailed slip distribution for the 2004 event. I consider the mapped distribution of high-frequency radiation by [22] a relatively poor representation of detailed slip.

In summary, the 2004 mainshock occurred well to the northwest of the plate boundary in an area of little forerunning activity. It likely was an oceanic intraplate event. A detailed mapping of slip is needed. 


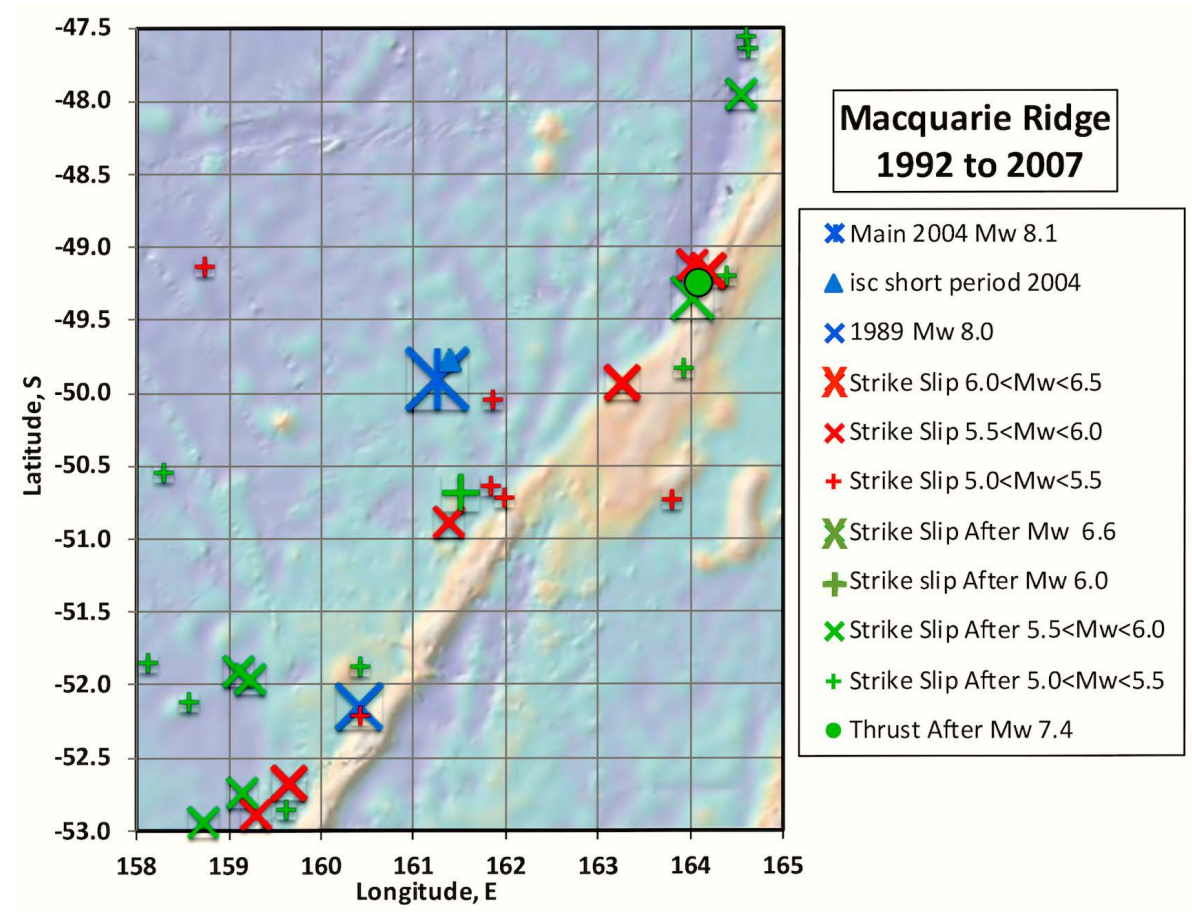

Figure 5. Forerunning and aftershock activity to the Macquarie Ridge mainshock of 2004 of Mw 8.1. Largest blue symbol denotes centroid location of 2004 mainshock.

\subsubsection{South Scotia Sea Earthquake of 2013, Mw 7.8}

A great earthquake in 2013 of $\mathrm{Mw} 7.8$ occurred along a transform fault that bounds the southern margin of the Scotia Sea just to the north of the South Orkney Islands in the southernmost Atlantic Ocean. Long-term plate motion is slow, about $6.4 \mathrm{~mm} / \mathrm{a}$, along that boundary between the Scotia and Antarctic plates [23]. It occurred well to the west of the southern end of the Scotia subduction zone (not shown).

Rupture started at the short-period epicenter (Figure 6) and proceded easterly. Slip in the mainshock as computed by Ye et al. [23] was larger than $5 \mathrm{~m}$ in the two zones enclosed by solid black lines. They also computed slip in the earlier 2003 shock of Mw 7.6 to its east, which broke a small part of the eastern region that ruptured more than $5 \mathrm{~m}$ in 2013. Since the centroid of the 2013 mainshock is located west of much of the slip computed by [23], at least one of those estimates is problematic.

The centroid calculations for the 2013 and 2003 mainshocks indicate mainly strike-slip motion with a normal-faulting component on east-west striking faults that dip $44^{\circ}$ and $36^{\circ}$ south under the region of shallower ocean water in Figure 6.

All of the forerunning strike-slip activity prior to the 2013 mainshock was located well to either the east or west of its centroid and outside the computed zones of high slip. A single earthquake of Mw 5.7 with a thrust mechism occurred in 1991 between the two zones of highest slip. Two of the largest forerunning events, those of $\mathrm{Mw} 6.9$ and 6.0, occurred one and four days before the 2013 mainshock. The north-south extent of seismic activity is somewhat broader than that for the two Cayman transforms in Figure 3. 


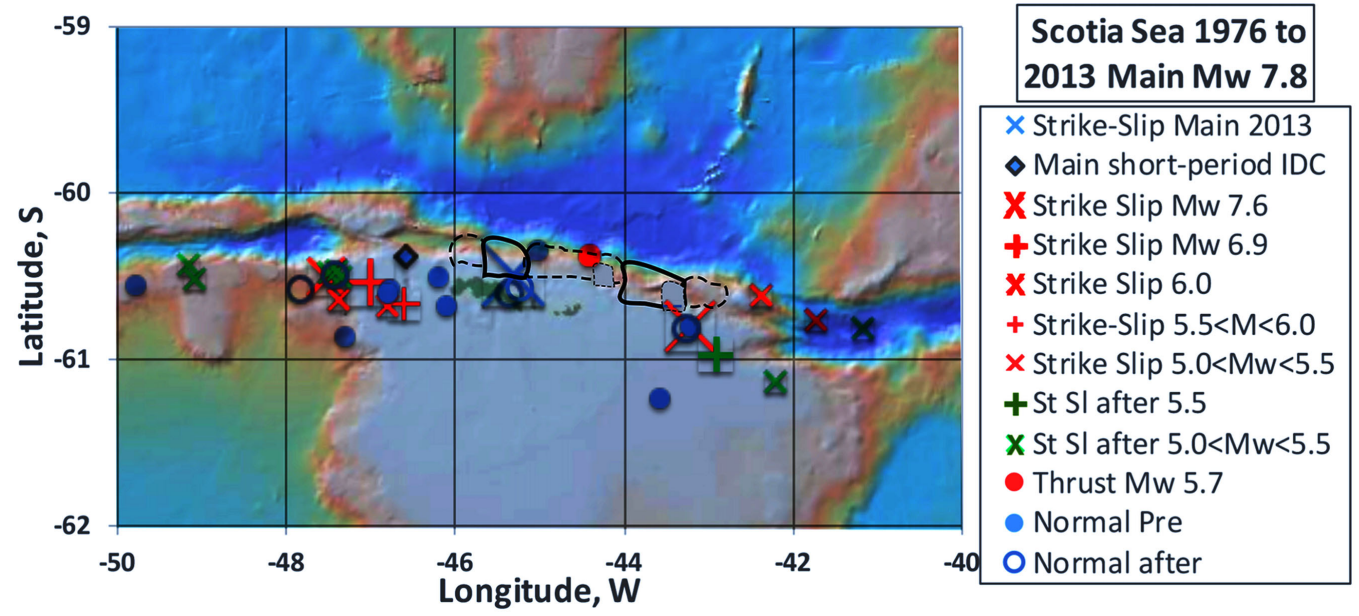

Figure 6. Forerunning activity from 1976 until mainshock in 2013 of Mw 7.8 (large blue X) and aftershocks until 2021.1. Computed slips in 2013 larger than 5.0 and $2.5 \mathrm{~m}$ are shown as solid and dashed black lines from [23]; slip zones between 2.5 and $5.0 \mathrm{~m}$ in the earlier 2003 event of Mw 7.6 are indicated by the two small gray areas surrounded by dots.

In summary, forerunning strike-slip activity to the 2013 mainshock occurred outside the regions of high computed slip and within what are interpreted as either one or two major asperities. Seismic moment release increased in the 10 years before the mainshock compared to that from 1976 to 2003. Foreshocks occurred within four days of the 2013 event. The 2013 shock took place along a plate boundary with low long-term slip rate.

\subsubsection{Earthquake in Central Alaska of 2002, Mw 7.8}

The 2002 mainshock of Mw 7.8 ruptured the surface of the Denali and Totschunda faults in central Alaska for about $340 \mathrm{~km}$ mainly with strike-slip displacement. The Denali fault has largest long-term slip rate of faults within continenal Alaska with the exception of the Fairweather fault in southeast Alaska. The 2002 mainshock was preceded ten days earlier by a foreshock of Mw 6.6 (large red X in Figure 7) just to the western end of rupture in the the mainshock [24]. Rupture started at the small black diamond in Figure 7 and proceeded easterly and then southeasterly. It subsequently jumped to the Totschunda fault, where slip was smaller. Rupture did not extend farther southeastward along the continuation of the Denali fault.

Eberhart-Phillips et al. [24] state that the long-term slip rate for that part of the Denali fault that broke in 2002 was about $10 \mathrm{~mm} / \mathrm{a}$, about $1 / 7$ of the rate for the relative motion of the Pacific and the North American plates. The long-term rate for the part of the Denali fault to the southeast that did not rupture in 2002 is about 2 to $3 \mathrm{~mm} / \mathrm{a}$; that for the Totschunda fault, about $5 \mathrm{~mm} / \mathrm{yr}$.

Rupture in the mainshock was mainly strike slip but with a small compressional component. Most aftershocks occurred at depths less than $10 \mathrm{~km}$, an indication of shallow slip in 2002 [24]. Except for the foreshock, only one small forerunning earthquake occurred within $150 \mathrm{~km}$ of the rupture zone of the mainshock. The same result can be seen for events as small as Ms 4.5 in Figure 7 
and Figure 8. A few aftershocks took place on or close to the rupture zone (Figure 8). Some aftershocks smaller than magnitude 5.0 along and near the rupture zone are shown in [24].

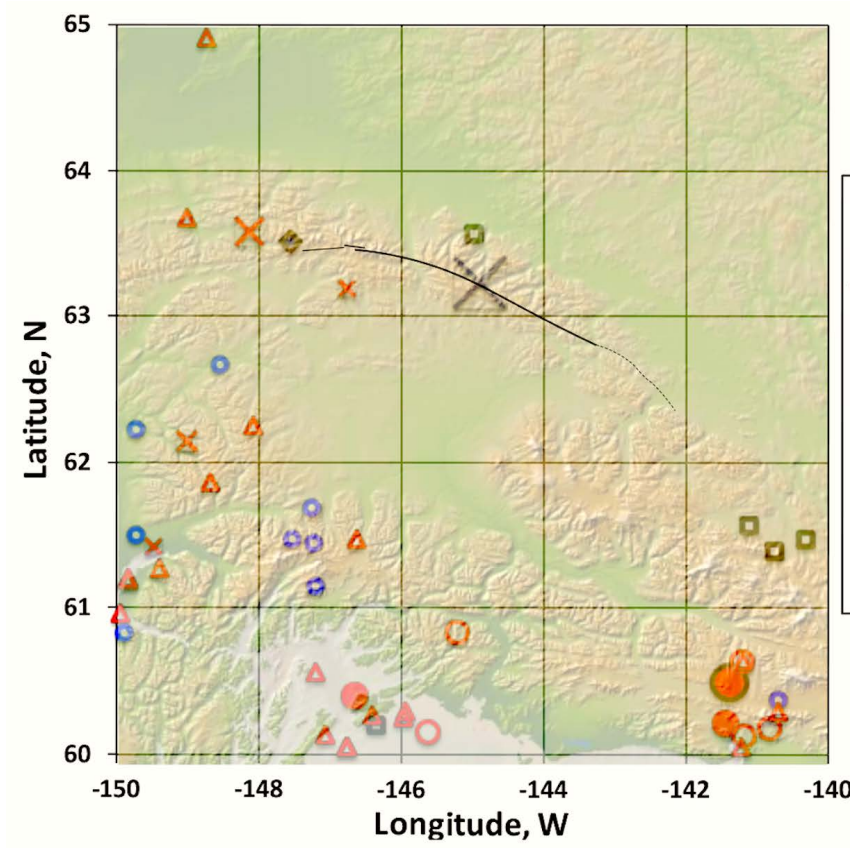

\section{Denali Fault Alaska 1976 to 2002 Main Mw 7.8}

X Strike-Slip Main 2002

- Main short-period IDC

X Strike-Slip 6.6

$\mathbf{X}$ Strike-Slip $5.5<\mathrm{M}<6.0$

$\times$ Strike Slip $5.0<\mathrm{Mw}<5.5$

O Thrust $\mathrm{Mw}=7.4$

- Thrust $5.5<\mathrm{Mw}<6.0$

O Thrust $5.0<\mathrm{Mw}<5.5$

- Normal Fault

- Reverse Fault

$\Delta M s>4.5 \mathrm{IDC}$

Figure 7. Activity of $\mathrm{Mw}>5.0$ from 1976 until the mainshock of 2002 (large black X). Calculated co-seismic slip larger than $4 \mathrm{~m}$ (solid black line) along the Denali fault and 2 to 4 $\mathrm{m}$ along its western end and the Totschunda fault (dashed lines) are from [24]. Triangles are events of Ms > 4.5 from the International Seismological Centre plotted at their short-period epicentral locations.

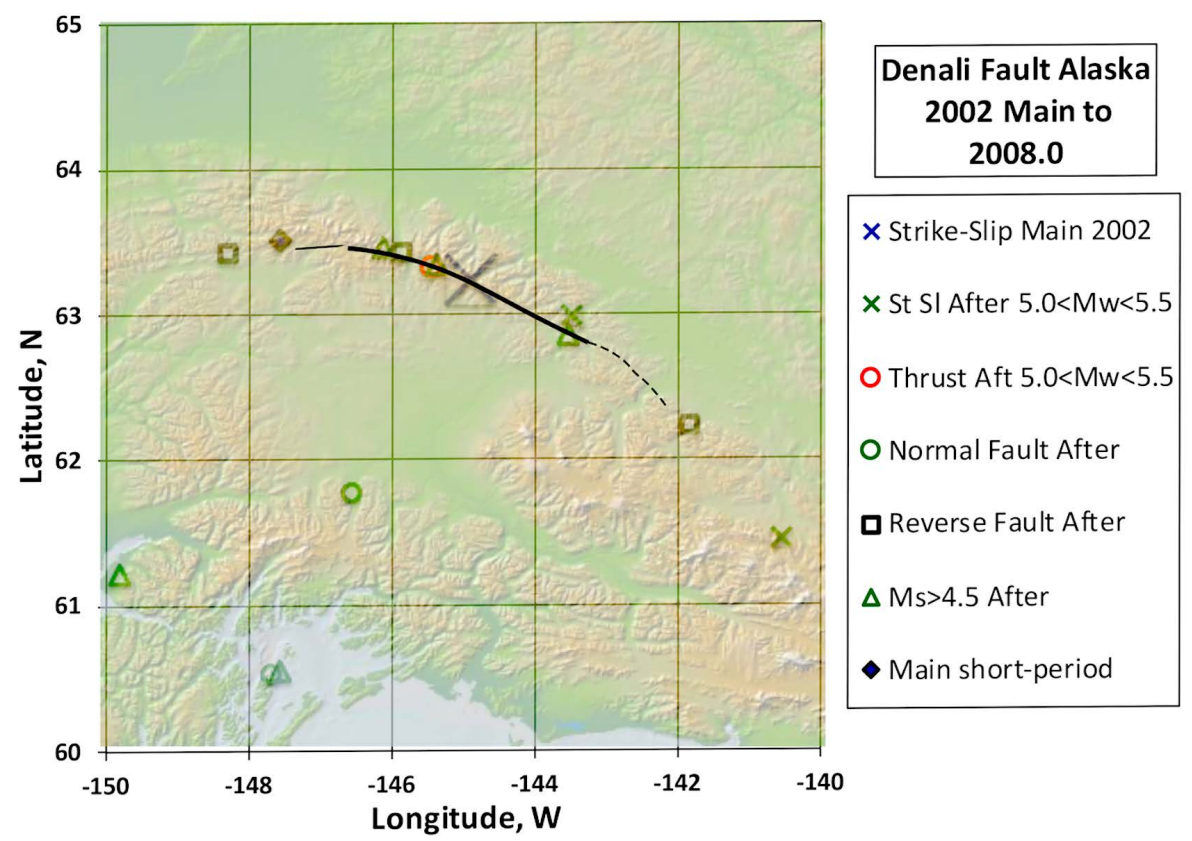

Figure 8. Aftershocks from Alaska mainshock of 2002 through 2007. Symbols same as previous figure. 
In summary, the coming rupture zone of the mainshock was surrounded by a large region with very low forerunning activity. It can be interpreted as a major asperity. The few forerunners indicate, however, that they could not have been used ahead of time to map the size of the coming mainshock with much accuracy.

\subsubsection{Earthquake of 2013 off the Coast of Craig, Southeast Alaska, Mw 7.5}

The strike-slip earthquake of 2013, Mw 7.5, occurred off the coast of southeast Alaska along the Queen Charlotte-Fairweather fault system, which forms the boundary between the Pacific and North American plates. The mainshock was situated at the boundary between continental and oceanic lithosphere. It is one of the smallest earthquakes along a transform-fault that is examined here. A small number of forerunning events of magnitude 4.5 and greater took place south of the centroid of the mainshock. All but one of them occurred outside of the zones of computed displacements larger than $2 \mathrm{~m}$. The location of the centroid to the north of those computed contours suggests rupture extended somewhat farther to the northwest.

In summary, the 2013 mainshock occurred along a transform plate boundary off the coast of southeast Alaska. The region of high computed slip and the centroid location were largerly quiet for forerlunning events; they define a major asperity that broke in the mainshock of 2013. Forerunning and aftershock activity took place in a narrow zone along strike, similar to the patterns after the two mainshocks along the transform faults bordering the Cayman Trough in Figure 3.

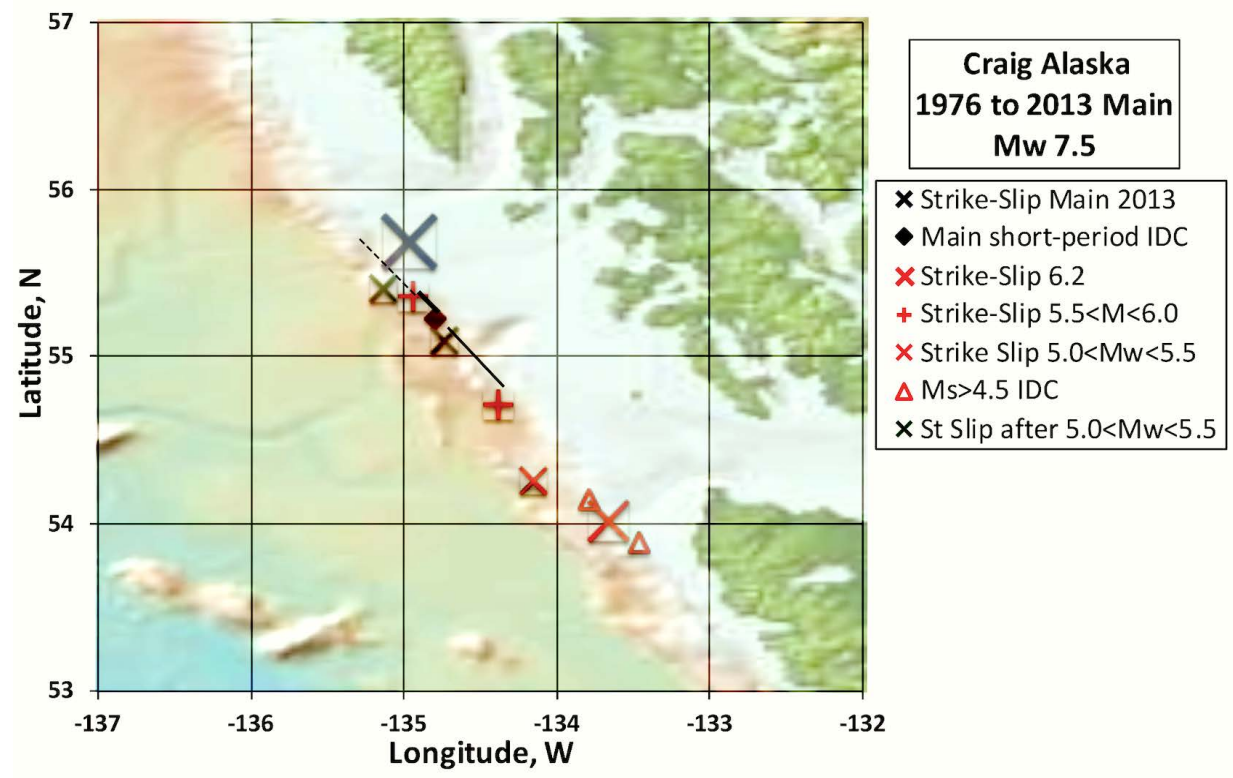

Figure 9. Forerunning activity and aftershocks of the Craig, southeastern Alaska mainshock (large black X) of 2013, Mw 7.5. Solid line indicates computed displacement greater than $4 \mathrm{~m}$; dashed line, 2 to $4 \mathrm{~m}$ from [25]. 


\subsubsection{Strike-Slip Earthquake of 2017 along Komandorsky (Commander) Islands, Mw 7.8}

The great earthquake of 2017 in the westernmost Aleutian Islands involved strike-slip motion between the North American and Pacific plates. Plate motion changes from nearly perpendicular convergence south of mainland Alaska to very oblique convergence, i.e. nearly along-strike motion, in the westernmost Aleutians. Plate motion then changes abruptly from near total strike-slip motion near the 2017 rupture zone to underthrusting farther west beneath Kamchatka. Using GPS data from the Komandorsky Islands and Kamchatka, Kogan et al. [26] concluded that plate motion in the westernmost Aleutians is partitioned into strike-slip motion along a Bering fracture zone (transform fault) to the north of the Komandorsky Islands and along-strike motion on a shallow-dipping interface to their south. They found that model fit the GPS data best with two zones of major long-term plate motion that are separated and partitioned by a narrow Komandorsky block or sliver. About $2 / 3$ of the total plate motion occurs along the Bering fault between the North American plate to its north and the Komandorsky sliver to its south (computed plate motion in the western Aleutians is nearly the same if a distinct Bering plate is analyzed instead of using the North American plate).

Lay et al. [27] computed slip as a function of length along strike for the 2017 mainshock. Slip extended a great distance, nearly $400 \mathrm{~km}$ with smaller slip in a zone about $100 \mathrm{~km}$ along strike near the centroid of the mainshock (Figure 10). Rupture progressed mainly to the southeast from the short-period epicenter but with a minor region of slip to its northwest [27]. The locations of forerunning activity are difficult to correlate with the well-separated patches of computed high slip. Forerunning activity occurred southeast of the region of highest slip in Figure 10 including a thrust event of Mw 6.2 just off the southeastern corner of Figure 10. A forerunning event 45 days before the mainshock of $\mathrm{Mw} 6.7$ took place about $40 \mathrm{~km}$ to the northeast of the rupture zone. Other forerunning activity occurred, however, near the three zones of computed slip of 1.7 to $3.7 \mathrm{~m}$ and in the broad zone near the centroid. Foreshocks of magnitude larger than 4 occurred within 12 hours of the mainshock near its short-period hypocenter [27].

The 2017 mainshock took place in what had long been regarded as a major seismic gap that ruptured in great shocks in 1849 and 1958 somewhere in the Komandorsky Islands [6]. The 2017 event may have broken in 1929 in an earthquake of Mw 7.8 [11] but its depth and mechanism are uncertain. The subduction zone to the east of the 2017 rupture broke in the giant Rat Island earthquake of $\mathrm{Mw} 8.7$ between $170^{\circ}$ and $180^{\circ} \mathrm{E}$ [6] [11]. Since displacement in 2017 was largely strike-slip, it is not surprising that it produced only a small tsunami.

In summary, the 2017 mainshock broke a known long-standing seismic gap in the westernmost Aleutian Islands. Computed slip in 2017 was complex along strike. Several of the larger forerunning shocks occurred outside of the coming rupture zone. Other forerunning activity took place, however, near the three zones than experienced moderate slip of 1.7 to $3.7 \mathrm{~m}$. 


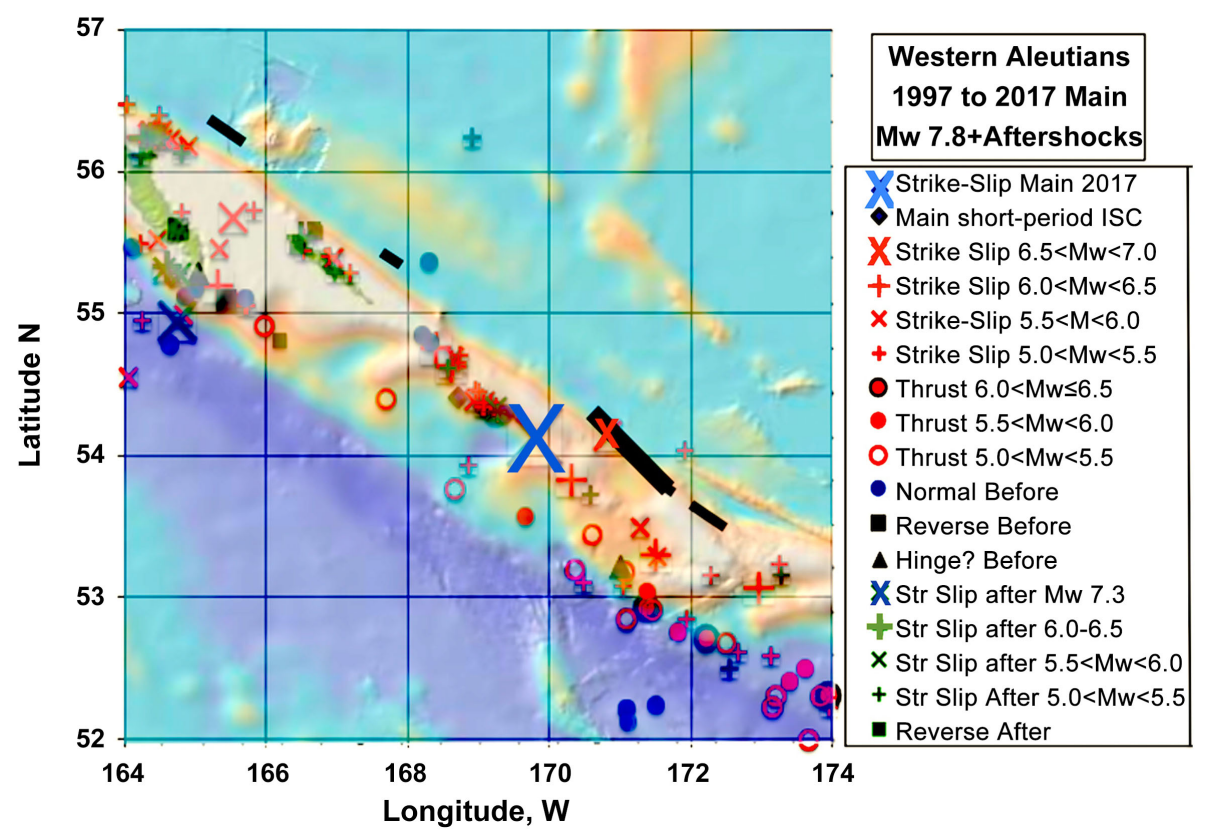

Figure 10. Forerunning activity (in red) from 1997 until the mainshock of 2017, Mw 7.8 (large blue X), and aftershocks through 2020. Computed slips larger than 3.7 and $1.7 \mathrm{~m}$ are shown as thick and thinner solid lines from [27].

\subsubsection{Kaikoura New Zealand Earthquake of 2016, Mw 7.8}

The great Kaikoura earthquake on the South Island of New Zealand in 2016 (Figure 11) was unusual in that it ruptured many faults at the surface and several offshore [28]. They form part of the boundary between the Pacific and Australian plates. The GCMT mechanism of the main shock involved strike-slip motion with a significant component of thrusting. Forerunning activity in Figures 11 and 12 also involved strike-slip and thrust mechanisms. Rupture during the mainshock started at its southwestern end at the short-period hypocenter and progressed northeasterly. The largest pre-event at the southwestern corner of Figure 11 near Christchurch of Mw 7.0 was far enough away from the rupture zone of the 2016 mainshock that it likely should not be regarded as precursory to it.

Figure 11 indicates faults that ruptured at the surface as well as regions of significant uplift and subsidence as determined from GPS and tide-gauge data. Forerunning strike-slip activity in Figure 12, an enlarged view, was concentrated well outside the centroid of the mainshock as well as outside the region of the highest measured uplift (Figure 11). A large region centered near the centroid is inferred to be a great asperity that was largely devoid of forerunning activity.

Four forerunning thrust mechanisms were concentrated south of the centroid just offshore near the region that experienced uplift between 2.5 and 5.0. $\mathrm{m}$ in Figure 11. [28] [29] [30] and others deduce that thrusting faulting occurred on and offshore and was a significant contribution to the total moment release and to the generation of a sizable tsunami. [31] attributes the complex distribution of 


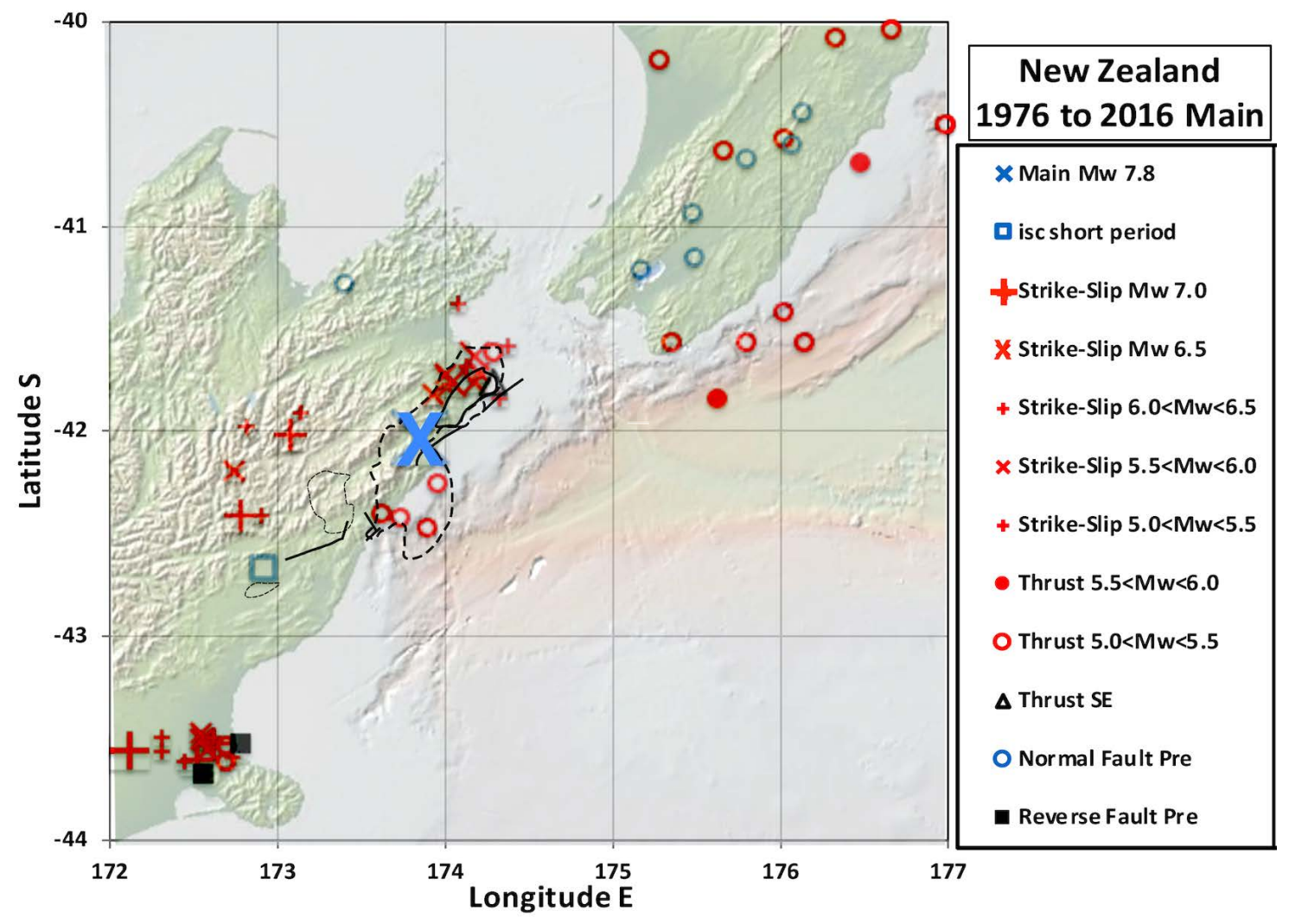

Figure 11. Forerunning activity from 1976 until the mainshock of 2018, Mw 7.8 (large blue X). Faults that ruptured during mainshock are shown as black lines from [28]. Vertical uplift larger than 5.0 and $2.5 \mathrm{~m}$ is shown as solid and enclosed dashed lines. Downward vertical motion larger than $2.5 \mathrm{~m}$ is depicted as thin dotted lines from [29].

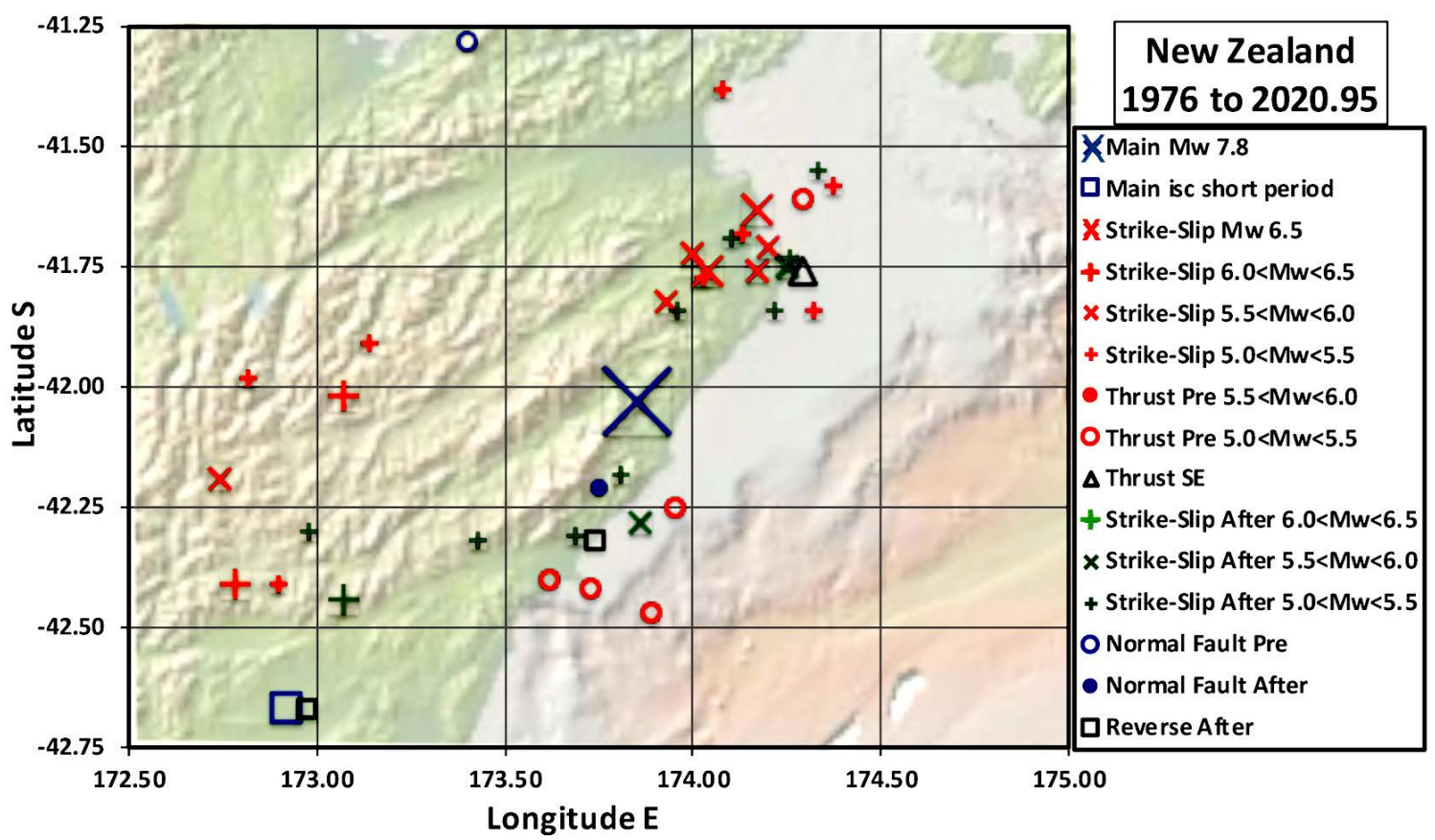

Figure 12. Enlarged view of forerunning activity from 1976 until New Zeal.and mainshock of 2018, Mw 7.8 (large blue-black X). Aftershocks are included. 
rupture and the number of faults that broke the surface to locking of the megathrust below. The large size of the region that nearly lacked forerunning activity is in accord with that hypothesis.

Forerunning strike-slip activity to the northeast of the centroid took place on or close to the Clarence and Atwatere faults. They did not experience surface faulting during the mainshock [28] [29]. Cumulative seismic moment is shown for that area in Figure 13. It is domated by two shocks in 2013 of Mw 6.5. Afterhocks in that area, however, contributed little to the total forerunning seismic moment release. The increase in cumulative moment in 2013 could be considered to be an intermediate-term precursor to the 2018 mainshock. The region of forerunning strike-slip activity to the west of the centroid, however did not exhibit a significant increase in moment release with time.

In summary, the 2018 mainshock involved displacements on a number of strike-slip and thrust faults. Most forerunning activity occurred outside the region of highest computed slip in the mainshock and well away from its centroid. This suggests that the large size of that quiet region was controlled by a great asperity, perhaps on the downgoing plate interface at depth. Precursory activity took place in 2013 on or near the Clarence and Atwatere faults, which did not experience faulting at the surface during the mainshock.

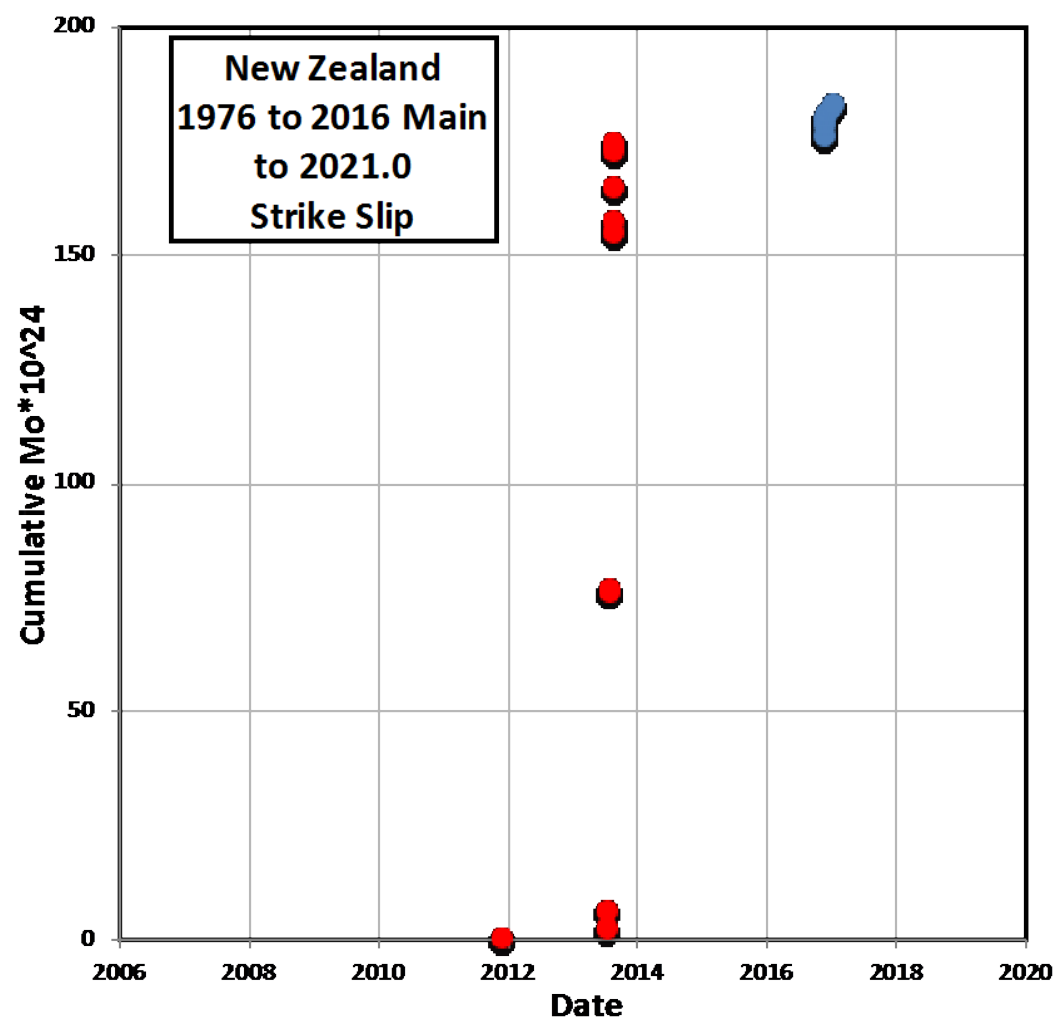

Figure 13. Cumulative seismic moment as a function of time (area $41.5^{\circ}$ to $42.0^{\circ} \mathrm{S}, 173.5^{\circ}$ to $175.0^{\circ} \mathrm{E}$ ) to north of centroid of mainshock near the Clarence and Atwatere faults. Aftershocks are shown in blue but mainshock is not included in moment accumulation. 


\subsubsection{Mainshock of 2000, Mw 7.8, Southern Sumatra, Indonesia}

The 2000 earthquake near Enggano Island offshore of Sumatra was unusual in that it was largely a strike-slip event below the forearc of the Sumatran subduction zone. Abercrombie [32] calculated that its moment release consisted of a large strike-slip sub-event within the subducting Indian-Australian plate followed by at least 35\% thrust release on the plate interface. The 2000 mainshock was located near the southeastern end of the rupture zone of the giant shock of 1833. In 2007 a giant earthquake of Mw 8.5 [1] rebroke the 1833 area just to the northwest of the 2000 rupture zone. The thrust sub-event of 2000 ruptured southeasterly away from the 1833 shock.

Most of the forerunning events in Figure 14 had thrust mechanisms. Its large strike-slip sub-event occurred along the $\mathrm{N} 19^{\circ} \mathrm{E}$ oriented nodal plane of the GCMT solution with a length of 50 to $100 \mathrm{~km}$ [32]. Three small forerunning strike-slip shocks occurred within $100 \mathrm{~km}$ of the centroid of the 2000 mainshock. Whether any of them took place along the strike-slip sub-zone is unclear. Several aftershocks with strike-slip mechanisms took place to the southeast of the centroid of the mainshock (Figure 15) but most mechanisms of after events involved thrust faulting.

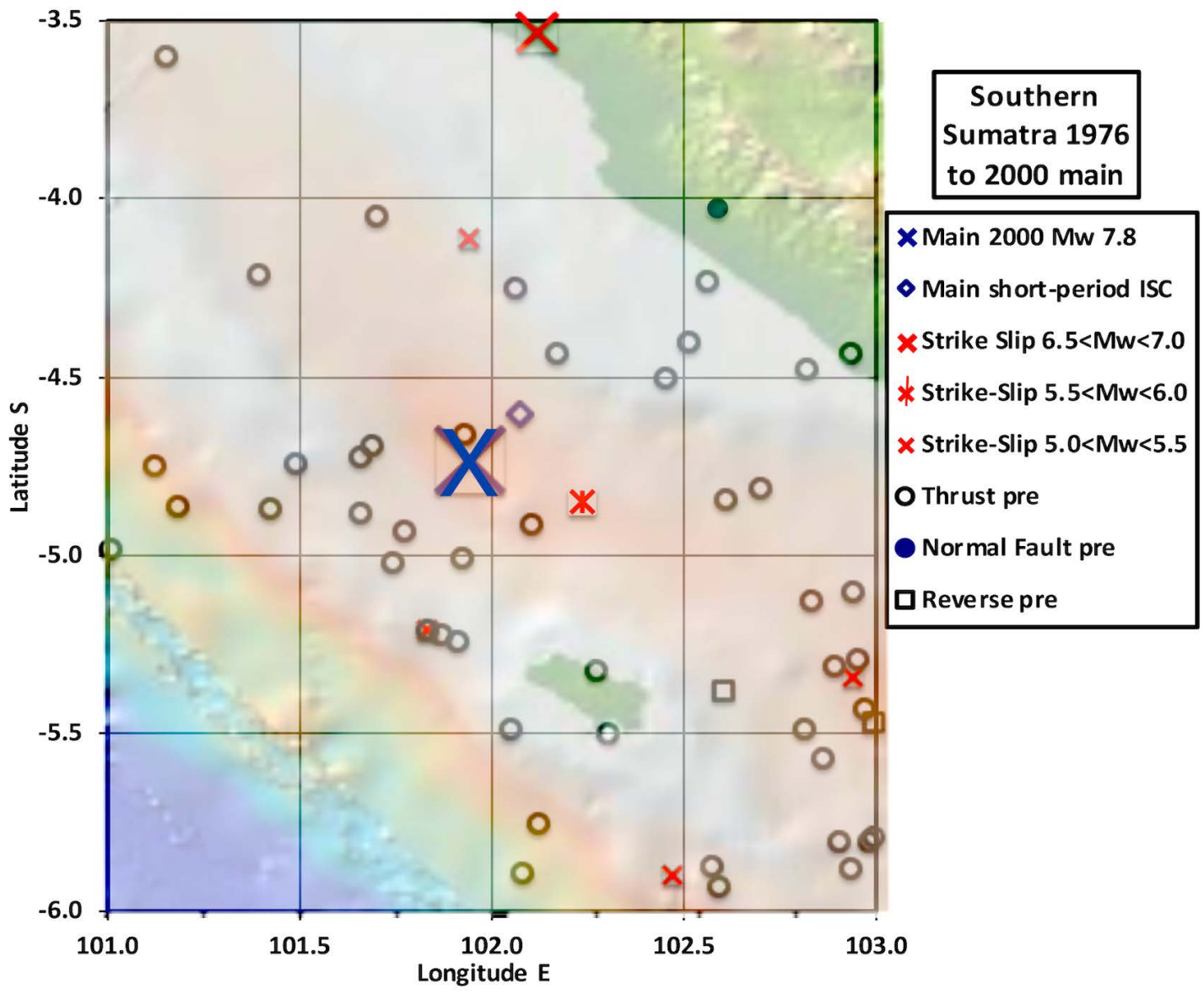

Figure 14. Forerunning activity from 1976 until 2000 south Sumatran, Indonesian mainshock of Mw 7.8 (large blue-black X). 


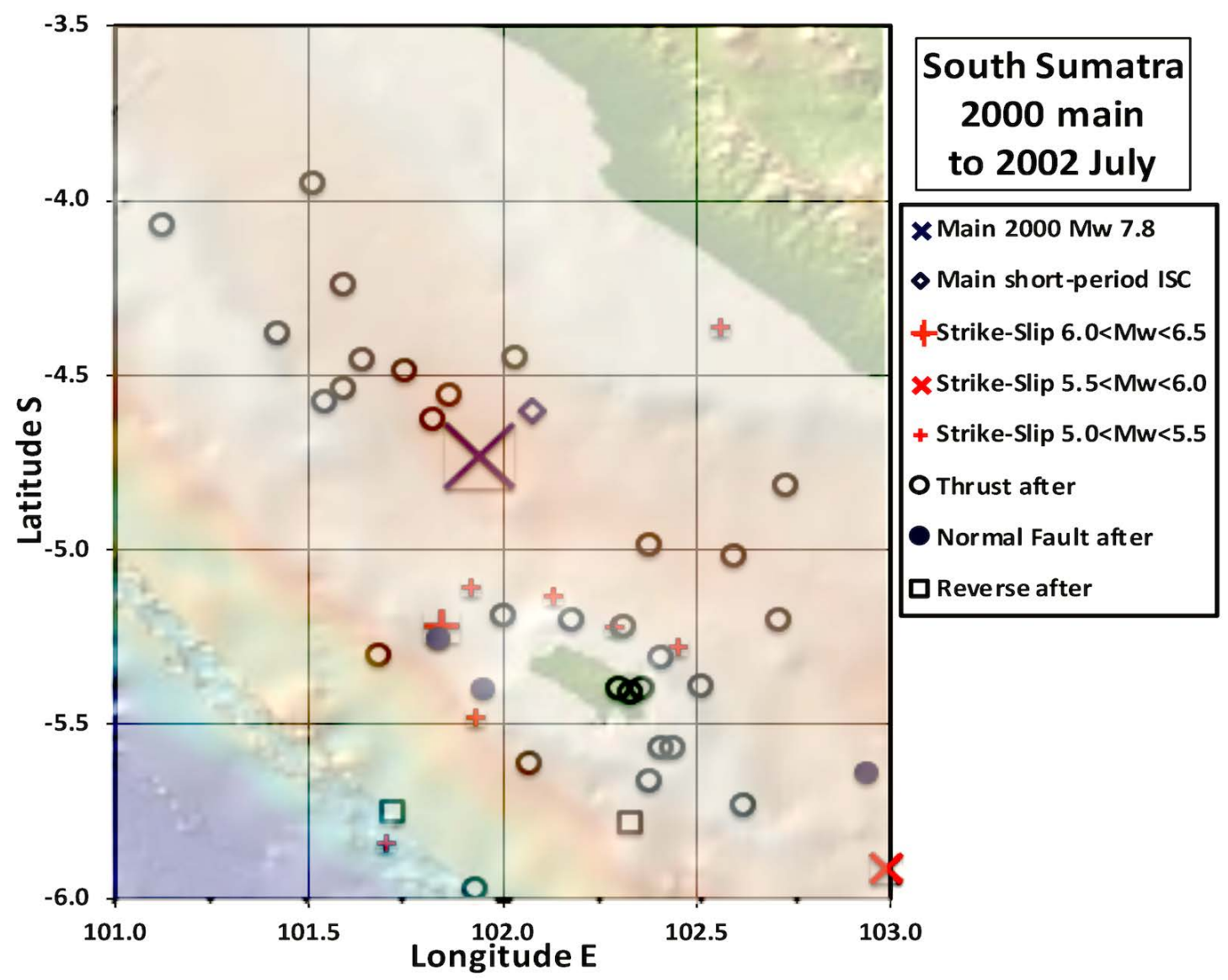

Figure 15. After activity from 2000 southern Sumatra, Indonesian mainshock of Mw 7.8 (large blue-black X) until July 2002.

In summary, the 2000 mainshock was unusual in releasing seismic moment mainly along a strike-slip fault of steep dip within the downgoing India-Australian plate beneath the forearc of the Sumatran subduction zone. Few of these forerunning shocks involved strike-slip faulting. Most forerunning events and aftershocks involved thrust events. Hence, the size of the coming rupture zones of the 2000 mainshock could not be ascertained from the forerunning activity studied here. The 2000 shock was small compared to the giant thrust earthquake that broke the adjacent zone to the northwest in 2007 and the previous giant event of 1833.

\subsubsection{Earthquake of 1990 in Luzon along Philippine Fault System, Mw 7.7}

The 1990 mainshock of Mw 7.7 with a strike-slip faulting mechanism ruptured a part of the Philippine fault system in central Luzon, Philipines. The Philippine Islands form part of the complex boundary between the large Philippine Sea and Eurasian plates. The Philippine fault system, which is within that region, is one the major strike-slip faults of the world, similar in many ways to the San Andreas in California and the Alpine fault in New Zealand [33]. In a plate tectonic framework, the series of left-lateral faults that make up the Philippine system 
connect the easterly subducting Manila trench to the northwest with the westerly subducting Mindanao (Philipine) trench to its southeast and the East Luzon trench to its east (Figure 16 and Figure 17). In that sense, the Phillipine fault system is similar to the Alpine fault system of New Zealand that connects oppositely-dipping subducting zones to its north and south.

Surface displacement was observed along a significant part of the 1990 rupture zone (Figure 16). Silcock and Beavan [34] estimated an average slip of 5.5 to 6.5 $\mathrm{m}$ along the well-mapped part of the fault and 4 to $5 \mathrm{~m}$ about 40 to $50 \mathrm{~km}$ farther north beyond the end of mapped surface rupture. They favor a faulting depth of at least $20 \mathrm{~km}$ along the central part of the rupture. Velasco et al. [35] used short and long-period seismic data to deduce that the largest slip (10 to $15 \mathrm{~m}$ ) occurred about $25 \mathrm{~km}$ northwest of the short-period epicenter, beyond which slip decreased gradually as the rupture propagated into a restraining bend. The centroid of the mainshock is located about $20 \mathrm{~km}$ east of the surface break, probably a systematic location error.

The 1990 rupture zone likely did not dip easterly since the fault planes of the GCMT solution are nearly vertical. Hence, only one of the forerunning events in Figure 16 is located within $30 \mathrm{~km}$ of the 1990 rupture zone; none occurred along that zone itself. Thus, the rupture zone can be regarded as a major asperity that

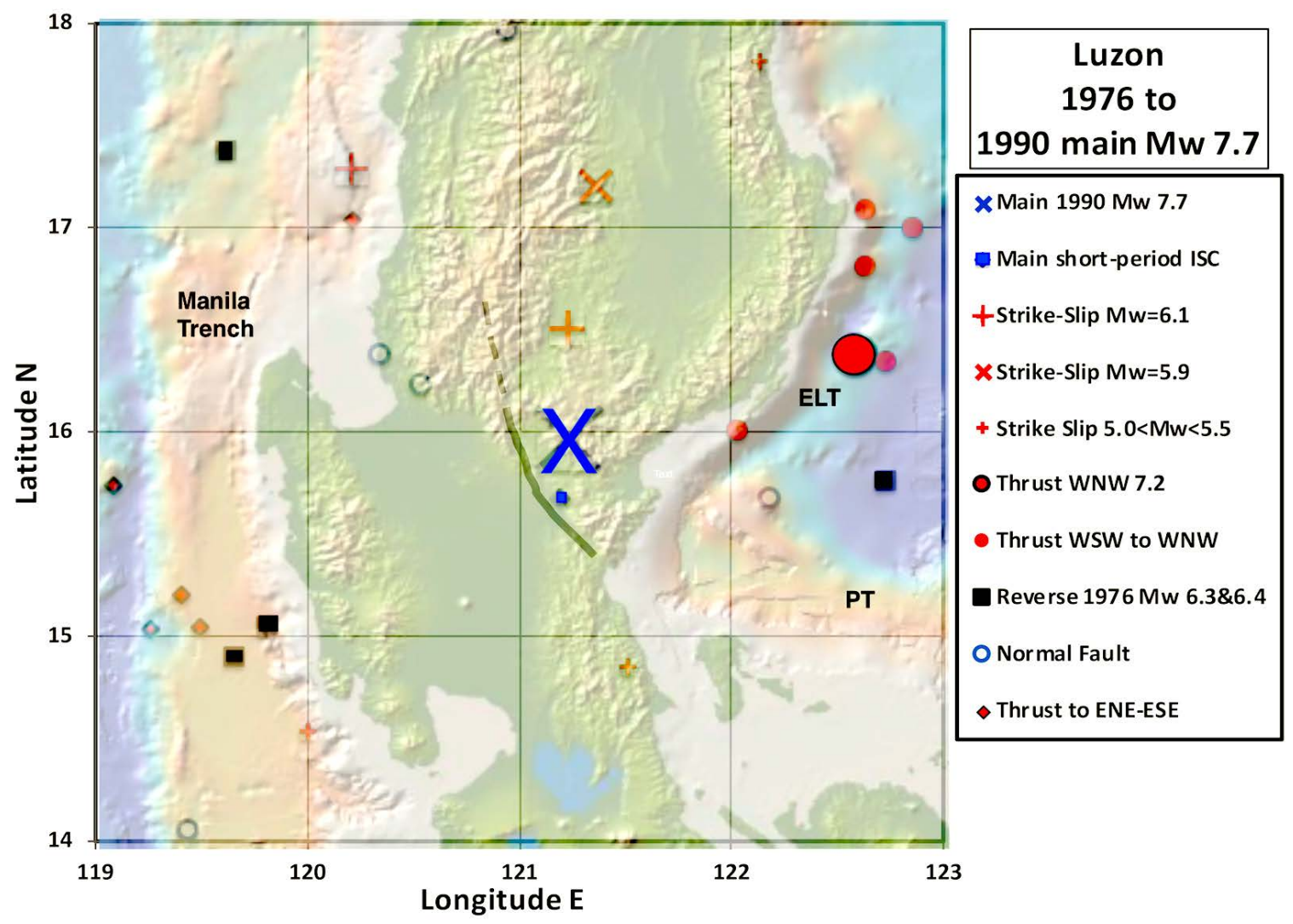

Figure 16. Forerunning seismic activity between 1976 and the 1990 Luzon, Philippines mainshock (large blue X). Mapped surface rupture shown by solid line and inferred northern extension indicated by dashed line from [34]. PT is Philippine (Mindanao) trench; ELT, the East Luzon trench. 


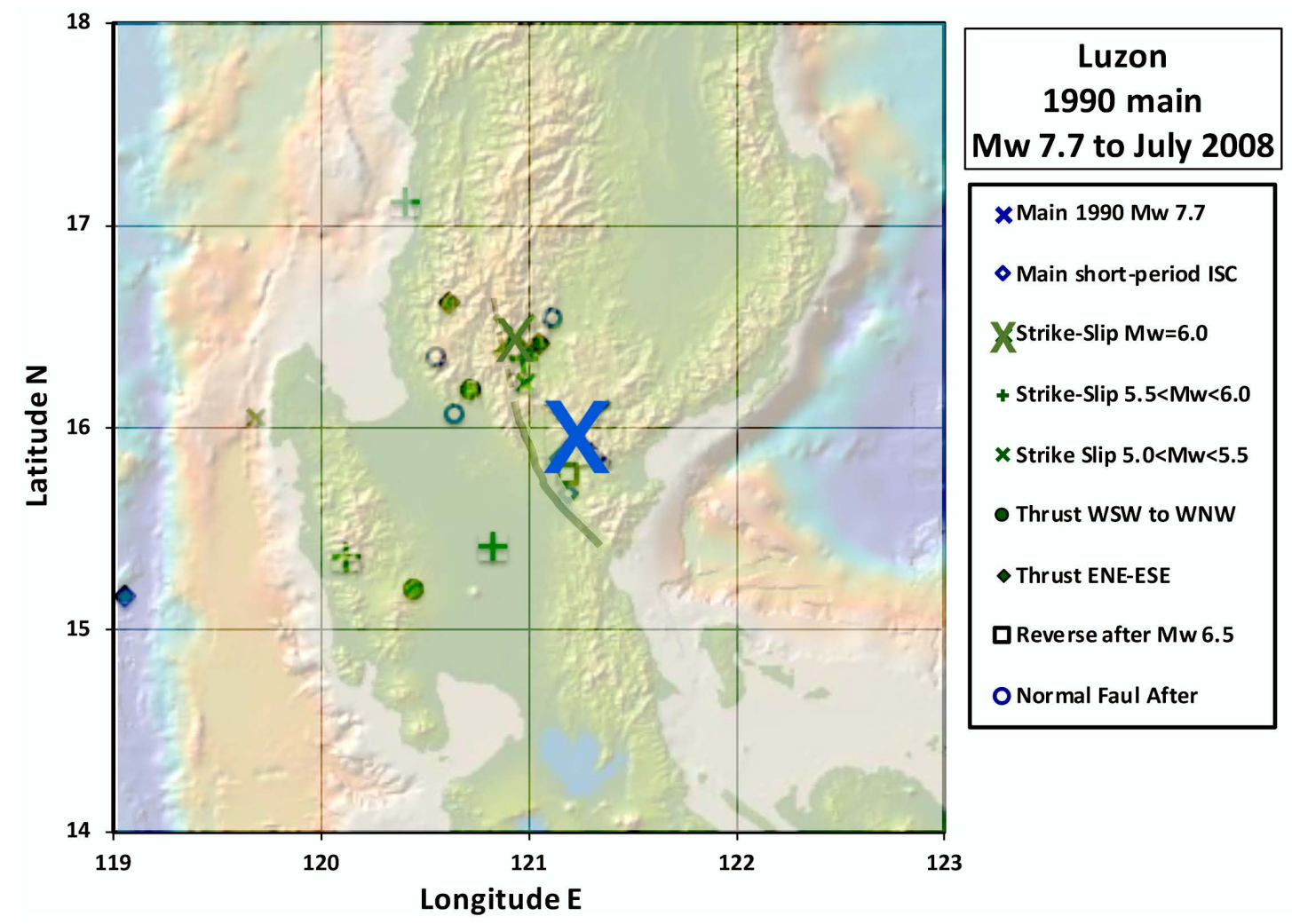

Figure 17. Seismic activity from 1990 Luzon, Philippines mainshock (large blue X) until July 2008. Faults same as in previous figure.

was quiet at the $\mathrm{Mw}>5.0$ level for at least 13 years before it broke in 1990. Forerunning activity occurred well to its west and east along the three trenches but I do not take them to be causally related to the coming 1990 event. Several aftershocks were located within $20 \mathrm{~km}$ of the rupture zone (Figure 17). More accurate locations are needed to ascertain if those events took place either on or east of the rupture zone.

A shock of Mw 7.6 occurred on or close to the trace of Philippine fault farther south of the 1990 rupture zone in 1937 near $14.57^{\circ} \mathrm{N}, 121.68^{\circ} \mathrm{E}$. The subduction zones associated with the Manila, Philippine and East Luzon trenches have been the sites of several known shocks of surface-wave magnitude larger than 7.0 within the area of Figure 16 since 1900. None of them, however, was larger than Ms 7.6. How much slow slip or creep occurs along them is uncertain.

The most recent historical earthquake to break the central Luzon section of the Philippine fault occurred in 1645 [36]. From fault trenching, Daligdig [37] finds six or seven past events broke the 1990 zone including that of 1645 . He dated a previous event as 1190 to 1390 A.C.E. and estimated an average recurrence interval of 300 to 400 years.

In summary, the rupture zone of the 1990 mainshock was quiet for nearby forerunning earthquakes of $\mathrm{Mw}>5.0$ from 1976 until its occurrence. It can be regarded as a major asperity. Not much forerunning activity was observed, however. 


\subsection{Patterns of Forerunning Activity-The Tibetan Plateau}

Two great earthquakes are described in China-the first in 2008 on the east side of the Tibetan plateau and another within it in 2001. The long-term slip rate for the faults on which they occurred (Table 1) is small compared to that of many plate boundaries but larger than that for many intraplate regions.

\subsubsection{Wenchuan China Earthquake of 2008, Mw 7.9}

The Wenchuan mainshock of 2008, Mw 7.9, broke about $285 \mathrm{~km}$ of the Longmen Shan fault zone in Sichuan Province, China. That rupture zone took place along the boundary between the east side of the Tibetan Plateau and the western side of the Sichuan basin [38]. It caused nearly 90,000 deaths, left millions homeless and caused huge monetary losses [38]. Earthquake mechanisms (Figure 18 and Figure 19) indicate that slip on the fault system during the mainshock and aftershocks consisted of segments with strike-slip and reverse displacements. Similar co-seismic displacements at the surface occurred along various parts of the rupture zone [38].

Another historic earthquake like 2008 has not been identified since 2300 BCE. Trenching after the 2008 mainshock revealed a paleoseismic event at three sites with an age of 2300 to 3300 years BCE [39]. Wang et al. [40] estimate a long-term slip rate for the Longmen Shan fault zone of about $4 \mathrm{~mm} / \mathrm{a}$. Thus, the 2008 rupture zone is not a fast-slipping plate boundary but is better described as the boundary between two major lithospheric blocks or subplates.

Rupture in the mainshock started at the short-period epicenter (Figure 18) near the southwestern end of the rupture zone and broke to the northeast. Nakamura et al. [41] used broadband seismic waves recorded at large distances to deduce the distribution of slip in the mainshock. They concluded that major fault slip of dip about $33^{\circ}$ occurred along a southwestern segment and about $60^{\circ}$ along a northeastern zone. They also found two main asperities: one about 40 $\mathrm{km}$ and the other about $170 \mathrm{~km}$ along strike from the short-period epicenter (near $\left.31^{\circ} \mathrm{N}\right)$. Using data from strong-motion stations, Zhang [42] found that major slip, interpreted as a strong asperity, occurred 20 to $50 \mathrm{~km}$ northeast of the short-period epicenter, like the location of the first asperity of [41] and the location of the centroid of the mainshock (Figure 18).

None of the forerunners to the mainshock in Figure 18 occurred near its centroid nor the zones of large slip as deduced by [41] [42]. All forerunners took place within the Tibetan plateau at a distance from the faults that ruptured in 2008 and none within the Sichuan basin. Since the number of forerunners of $\mathrm{Mw}$ $\geq 5.0$ was small, events of surface wave magnitude $\mathrm{Ms} \geq 4.5$ are included in Figure 18 and Figure 19. Xue et al. [44] concluded there was a background seismicity gap of $M \geq 5.0$ earthquakes and a gap of local magnitude $>4.0$ close to the Longmen Shan fault zone and its vicinity prior to the 2008 mainshock. They also report, "The seismic activity obviously strengthened and a doughnut-shaped pattern of $M \geq 4.6$ earthquakes was formed in the middle and southern part of the North-South seismic zone after the 2005 Dayao, Yunnan, earthquake". Those 


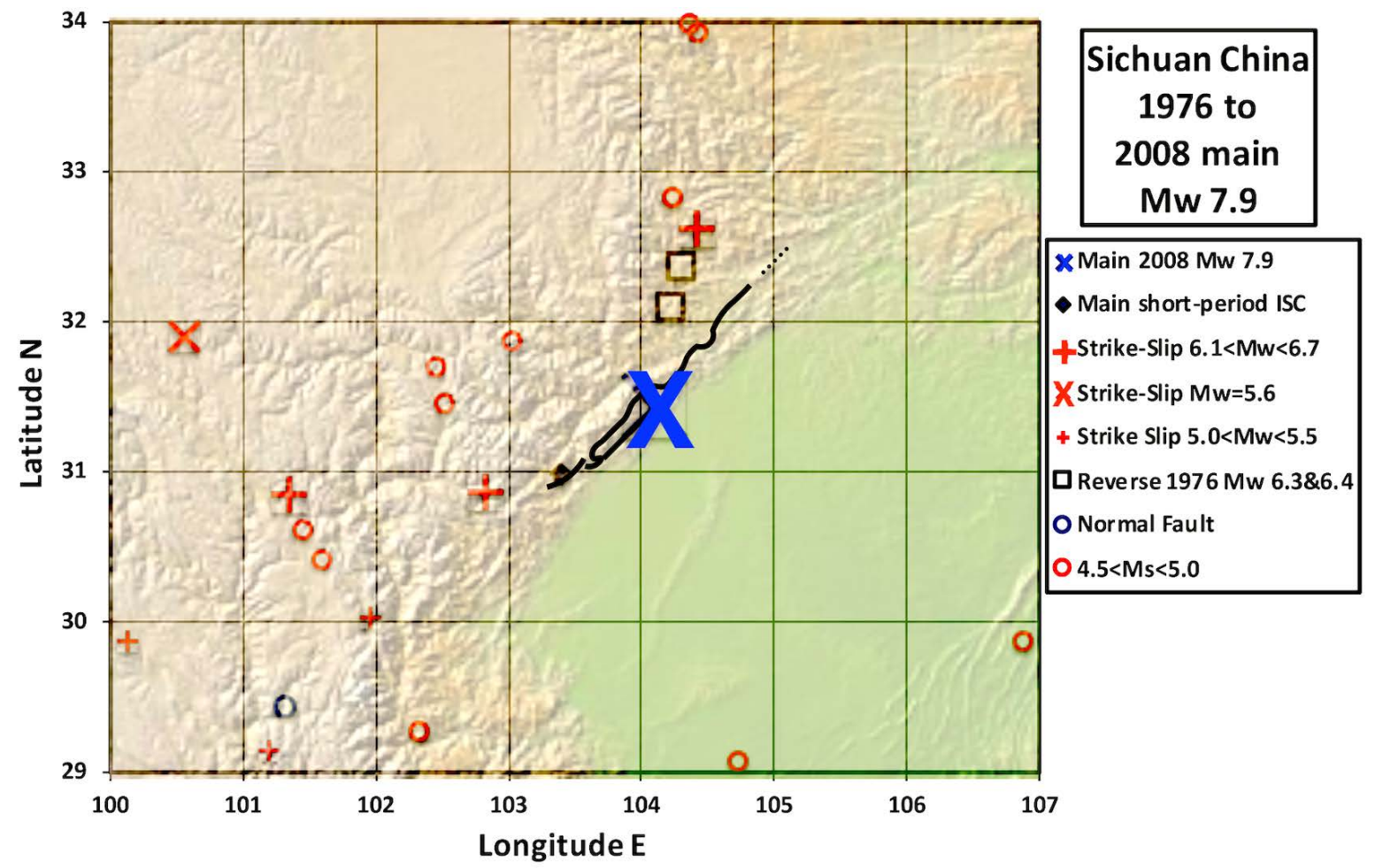

Figure 18. Forerunning activity to Sichuan, Chinese earthquake of 2008, Mw 7.9 (large blue X). Surface ruptures in the mainshock are from [43]. In addition to events of $\mathrm{Mw} \geq 5.0$ from the GCMT catalog, shocks of Ms $\geq 4.5$ from the Bulletin of the International Seismological Centre (ISC) are shown. The ISC symbols are short-period locations. The Tibetan plateau is shown in tan; the Sichuan basin, in green.

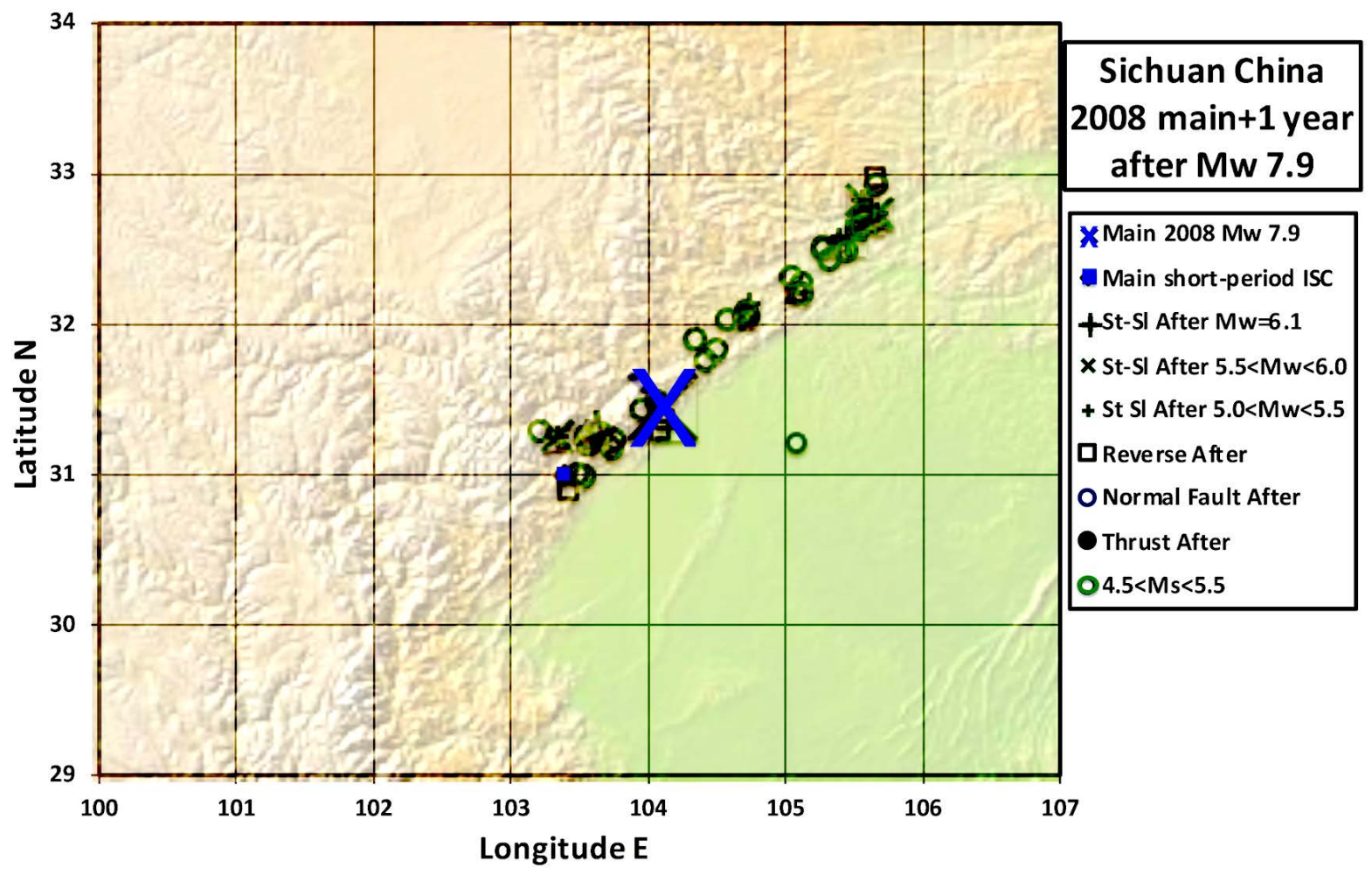

Figure 19. Aftershocks within one year of the 2008 Sichuan mainshock of Mw 7.9. Symbols same as previous figure. 
statements agree with the results in Figure 18. They do remark, however, "A quiescent area with $M \geq 7.0$ has been formed in the middle of the [extensive] North-South seismic zone since 1988, and the Wenchuan earthquake occurred just within this area". My sense is that the 2008 rupture zone was quiet at least since 1976 and that it did not suddenly become quiescent. Since activity of $M>7$ came and went elsewhere in central and western China, it may well not have been a long-term precursor to the 2008 mainshock since it occurred so far away. My conclusion is that very large asperities that break in great and giant events remain quiescent for moderate and large forerunning events for many decades and do not suddenly become quiescent part way through their cycle of stress buildup.

In summary, forerunning activity to the 2008 mainshock did not occur near its zones of major slip but surrounding it at a distance within the Tibetan plateau. That pattern is like the forerunning one to the 1906 California earthquake (Figure 1). A great asperity likely was present near its long-period GCMT centroid and the 2008 rupture zone. The 2008 mainshock took place along the boundary between the Tibetan Plateau and the Sichuan basin, the site of a well-mapped fault zone and a long-term seismic gap. The location of the 2008 rupture zone had not been the site of a similar great shock for 4300 to 5300 years. Since the fault zone has a low long-term rate of slip, it may be regarded as an intraplate earthquake, albeit one in a more active region than the interiors of many lithospheric plates.

\subsubsection{Great Strike-Slip Earthquake in Qinghai Province, Western China, 2001, Mw 7.8}

One of the largest earthquakes along a strike-slip fault of the last 100 years occurred in western China in 2001 of Mw 7.8. It is of particular importance in the Uniteld States since it was comparable in size and rupture length to the San Francisco earthquake of 1906. Surface rupture in 2001 extended about $426 \mathrm{~km}$ (Figure 20 and Figure 21) along the Kunlun Mountain fault system [45] [46] [47] [48]. It is one of the major fault zones along which Tibet is moving easterly as it is being squeezed by the surrounding Indian and Eurasian plates.

Slip started at the short-period epicenter near $90.5^{\circ} \mathrm{E}$ and propagated largely unilaterally to the east. A small amount of slip occurred to its west. Xu et al. [47] report the rupture zone was oriented $\mathrm{N} 100^{\circ} \pm 10^{\circ} \mathrm{E}$ on average, and slip in 2001 consisted of three main sections-a short westernmost strike-slip section, a short transtensional segment near the start of rupture and a long eastern strike-slip section. Most of the moment release occurred along the eastern segment. They and others subdivide that eastern section into several parts of which several sub-zones slipped more than $5 \mathrm{~m}$. They also report a reassessment of the maximum coseismic horizontal displacement of $7.6 \pm 0.4 \mathrm{~m}$ at a site just to the east of the centroid, which is consistent with independent measurements derived from interferometric synthetic aperture radar and seismology. 


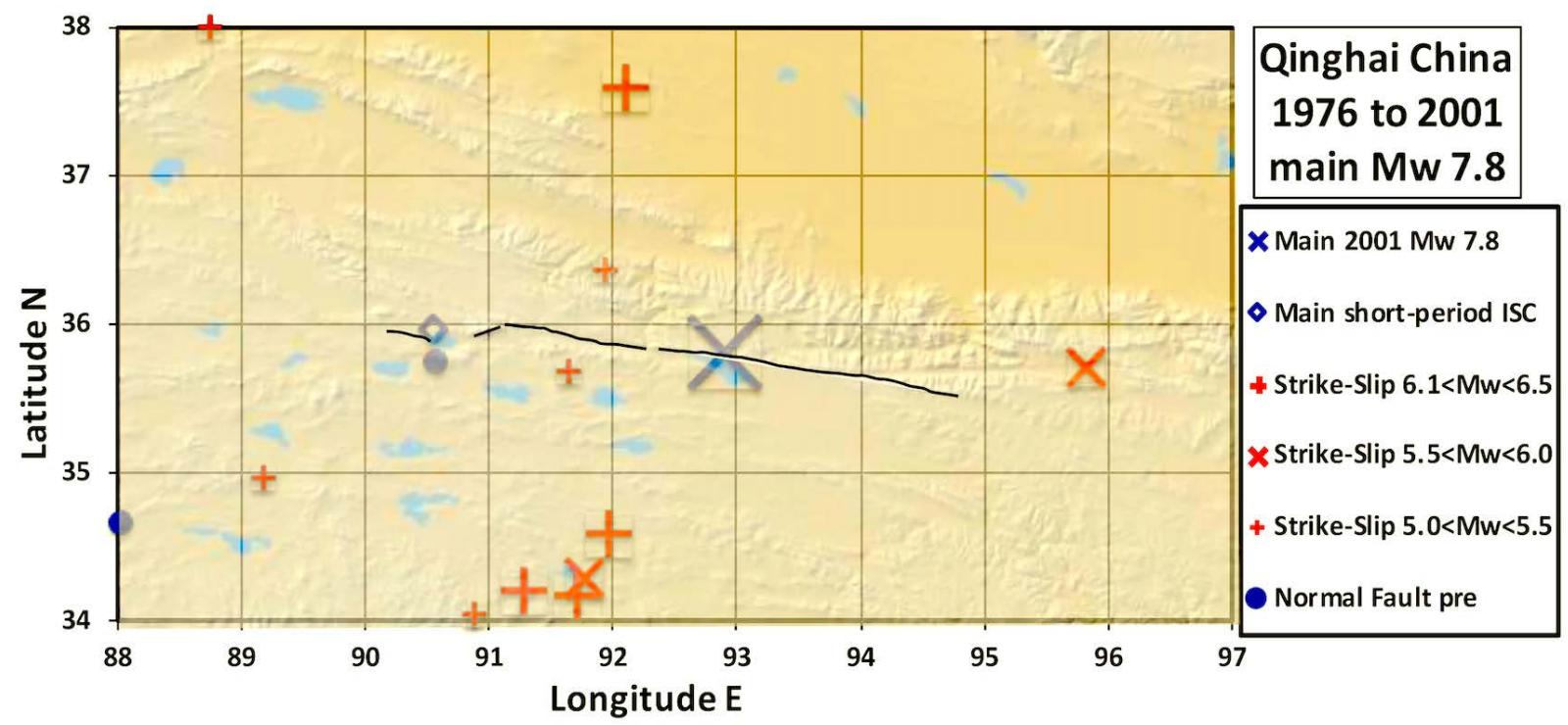

Figure 20. Forerunning activity from 1976 until the 2001 Kunlunshan mainshock of Mw 7.8 (large blue-black X). Surface faulting during mainshock is shown as black lines from [45] [46] [47] [48].

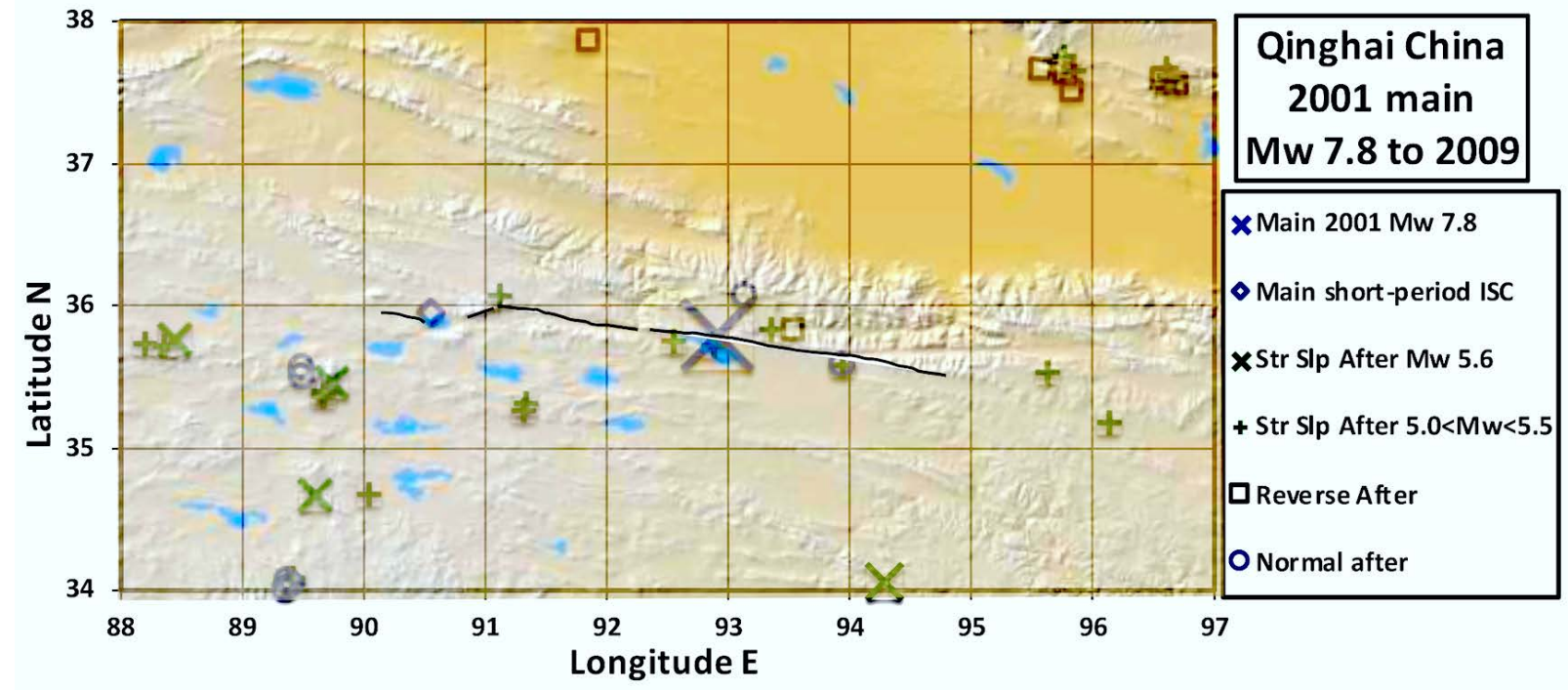

Figure 21. Aftershock activity from the 2001 Kunlunshan mainshock, Mw 7.8 (large blue-black X) through 2009. Surface faulting and references are the same as in the previous figure.

No forerunning shocks in Figure 20 were situated on the surface rupture, much of which can be considered to be the site of one or more major asperities. Seismicity recorded one year before the 2001 Kunlun earthquake by the China Seismic Net-work DMC (CSNDMC) indicated there was almost no activity in the rupture area of the 2001 event [48]. Several aftershocks occurred on or close to its surface rupture. Two strike-slip forerunnng events of Mw 5.4 and 5.3 took place in 1980 and 1989 within $50 \mathrm{~km}$ of the rupture zone. They need to be relocated by double-difference techniques to ascertain if they were either on or off the 2001 rupture zone. The distribution of forerunning seismicity at a distance from the rupture zone is similar to that prior to the 1906 California and 2013 
Pakistani earthquakes (Figure 1 and Figure 2).

Van der Woerd et al. [49] computed a mean Late Pleistocene-Holocene leftlateral slip-rate of $11.7 \pm 1.5 \mathrm{~mm} / \mathrm{a}$ for the Kunlun fault and estimated a repeat time for the 2001 rupture zone of about 800 to 1000 years. A shock in 1937 of Mw 7.5 took place east of the 2001 rupture zone. Two events in 1973 of Mw 7.4 [11] and one in 1997 of Mw 7.5 occurred along a branch of the Kunlun fault well to the west. The 2001 rupture zone was a seismic gap for at least the 135 years of instrumental seismology. I am not aware of any pre-instrumental earthquakes that were described using either historic data or paleoseismic studies.

In summary, forerunning activity after 1976 did not occur on or close to the mapped surface rupture zone of the 2001 giant earthquake. It consisted of one or more major asperites that were quiet before they broke in the mainshock. Could forerunning activity have been used ahead of time to define the approximate size of the forthcoming great earthquake? While forerunners were small in number, the Kunlun fault system has one of the fastest, if not the fastest, long term slip rates of faults along which Tibet is moving easterly with respect to surrounding regions. Future work could concentrate on other parts of the Kunlun fault system itself that have not ruptured for a long time, examining possible places where forerunning activity either occurs or not. Gathering paleoseismic data and searches for additional historic information are important in long-term assessments. More work could be done to examine events smaller than magnitude 5 as well as earthquakes before 1976 and to locate them using double-difference techniques.

\subsection{Patterns of Forerunning Activity for Intraplate Earthquakes}

\subsubsection{Antarctic Intraplate Earthquake Northwest of the Balleny Islands in 1998, Mw 8.1}

A great earthquake of Mw 8.1 occurred in 1998 within the oceanic part of the Antarctic plate (Figure 22) about $300 \mathrm{~km}$ from the nearest plate boundary. It took place in a remote region to the southeast of Australia, southwest of New Zealand and north of Antarctica. It is the largest known earthquake within the Antarctic plate. The two zones of high activity to the north and northeast of the 1998 centroid occurred along two transform faults of the Australian-Antarctic plate boundary. No forerunning activity occurred before the mainshock, likely because of very slow stress buildup to it and other intraplate events.

Rupture in the 1998 mainshock started at the short-period epicenter just to the east of its centroid and propagated $276^{\circ}$ west-northwesterly but along two separated zones of the same strike [50]. Higher moment release occurred in a first sub-event within $140 \mathrm{~km}$ of its initiation. It was followed by a second subevent between 210 and $270 \mathrm{~km}$. Hjörleifsdóttir et al. [51] showed, however, that a solution involving slip between and including those zones adequately fit both the long and short-period seismic data. All but two of the aftershocks occurred between 100 to $200 \mathrm{~km}$ of the centroid. Thus, a great asperity that broke in the 


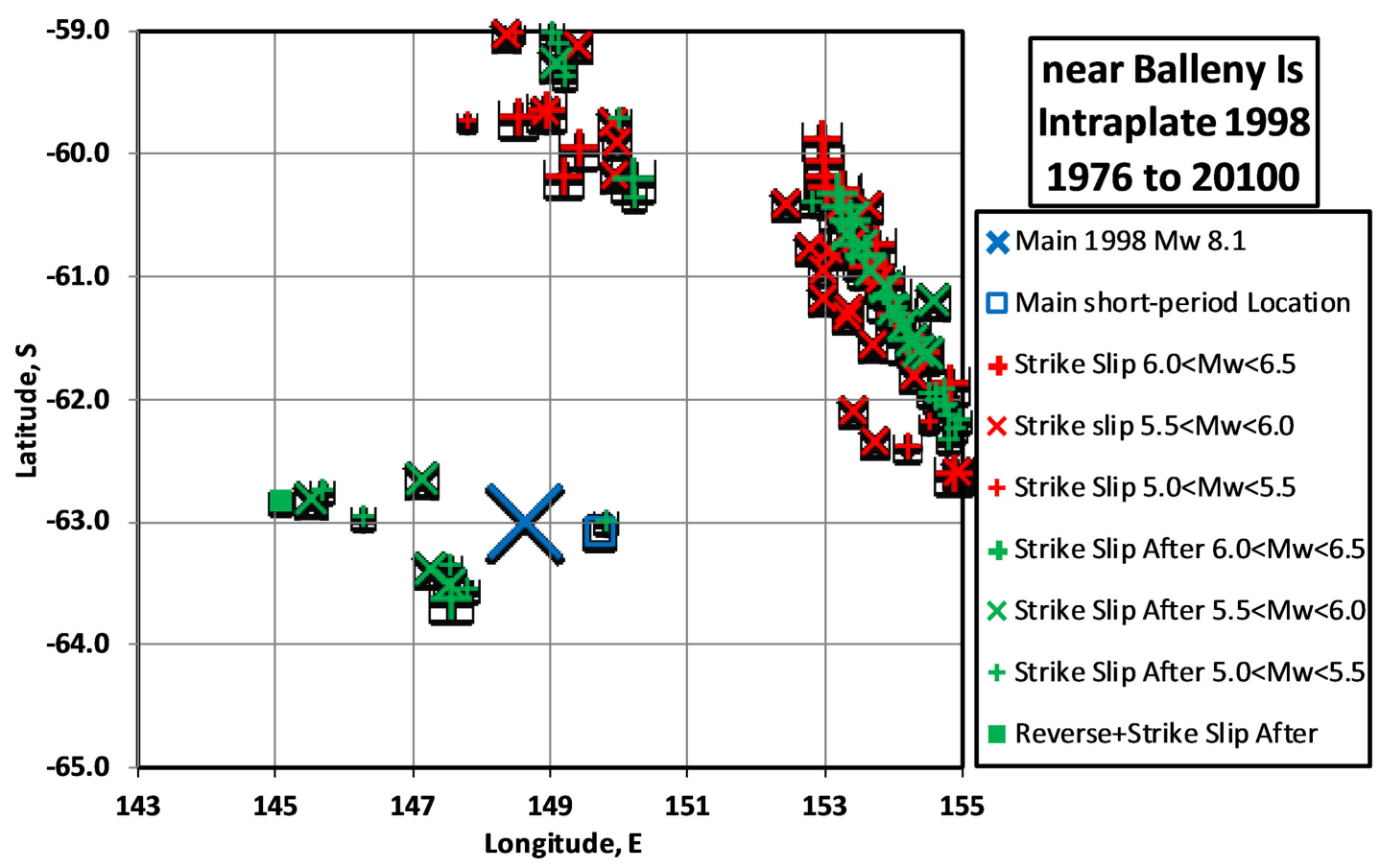

Figure 22. Forerunning and after activity to the of 1998 mainshock, a great intraplate earthquake (large blue X). The main plate boundary occurs well to the north and northeast where two major transform faults along the Australia-Antarctic plate boundary are active.

mainshock likely coincides with at least the first $100 \mathrm{~km}$ of slip in the first sub-event. The 1998 intraplate rupture zone likely has a long repeat time. Hence, it is not surprising that the relatively short period since 1976 was not enough to depict forerunning activity.

In summary, no forerunning activity occurred in the vicinity of the 1998 intraplate mainshock. Its rupture zone defines a great asperity.

\subsubsection{Earthquake within the Indian-Australian Plate in 2000, Mw 7.9}

A great strike-slip mainshock occurred within the Australian plate in the Indian Ocean during 2000. Like the previous event within the Antarctic plate, it was typified by a small number of events afterward but only one unlikely forerunning earthquake to it that was located about $250 \mathrm{~km}$ from its centroid (Figure 23). Robinson et al. [52] found that it consisted of two sub-events that ruptured the two nodal planes of the mechanism solution. Small aftershocks defined one plane striking about $345^{\circ}$. They report that the centroid of the mainshock occurred below a major seamount.

In summary, the great intraplate mainshock of 2000 was accompanied by only a few moderate-size events in the 20 years after its occurrence and one preceding shock 250 km away.

\subsubsection{Earthquake off the Coast of Kodiak Island, Alaska in 2018, Mw 7.9} A great mainshock occurred in the Pacific plate southeast of Kodiak Isand, Alaska in 2018 of Mw 7.9. Most of the activity before the mainshock, a predominantly strike-slip event, occurred to its northwest along the plate boundary as 


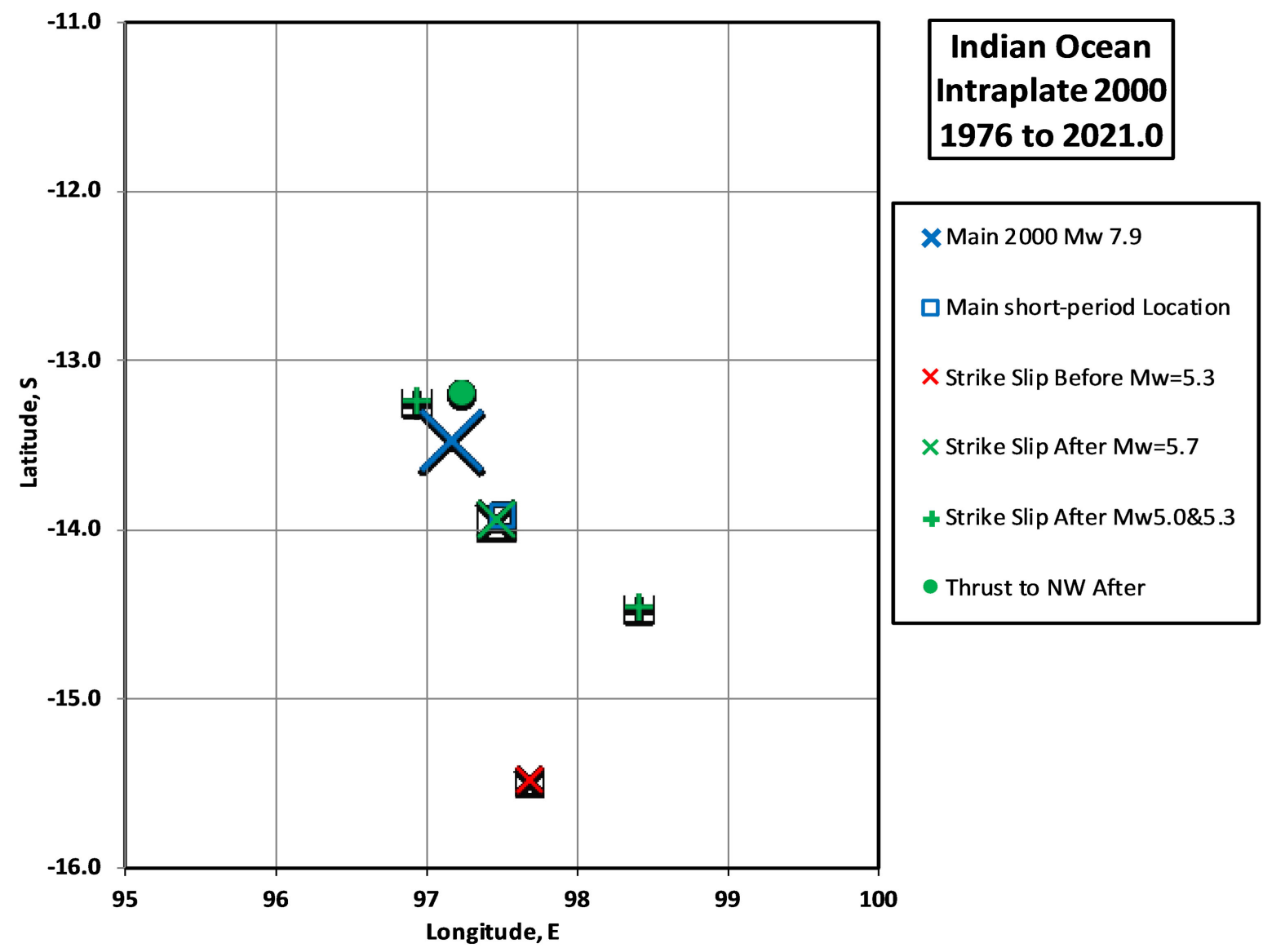

Figure 23. One forerunning and several after events to intraplate earthquake in the Indian Ocean mainshock of 2000, Mw 7.9.

thrust-faulting mechanisms (Figure 24). One forerunning thrust event occurred nearby within the Pacific plate and two strike-slip mechanisms were situated to the north of the coming mainshock along the plate boundary. That part of the plate boundary broke in the giant shock of 1964. Aftershocks occurred along a complex set of faults and those striking NE-SW were the sites of most of the moment release in the mainshock [53]. Otherwise, the rupture zone was devoid of forerunning events of $\mathrm{Mw} \geq 5.0$.

In summary, the 2018 mainshock was an intraplate event in the Pacific plate south of the Pacific-North American plate boundary. Its rupture zone, inferred to be a great asperity, was devoid of forerunning shocks of moderate and larger size.

\subsubsection{Ceram, Indonesian Earthquake of 1998, Mw 7.7}

The 1998 mainshock of Mw 7.7 beneath the south coast of the island of Ceram (Seram) in eastern Indonesia occurred in one of the most seismically and tectonically complicated areas of the world. Several large as well as a number of small plates interact nearby. Hall [54] describes the extensive geological and plate tectonic evolution of eastern Indonesia since the Jurassic. Plate motions changed in just the last $5 \mathrm{Ma}$. Ceram is part of the Banda arc, an eastern and 


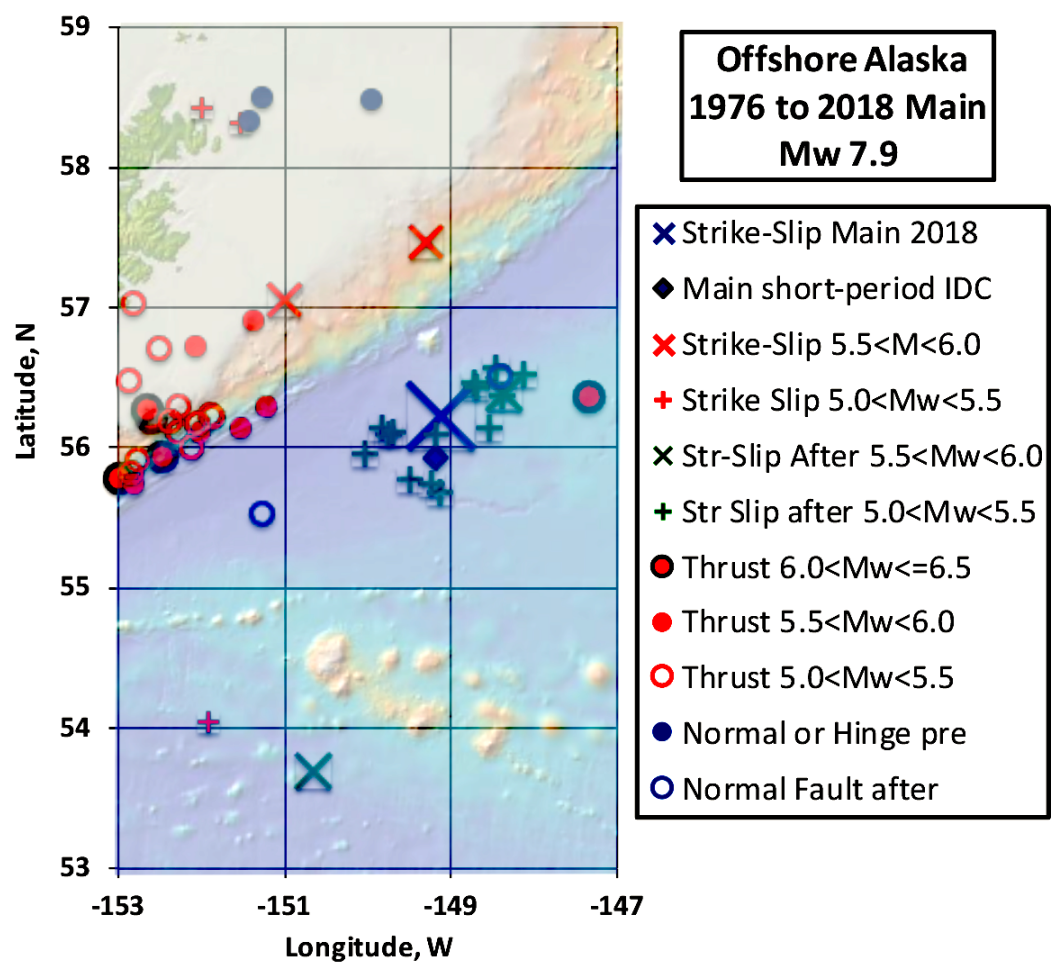

Figure 24. Forerunning activity in red from 1976 until mainshock of 2018, Mw 7.9, off the coast of Kodiak Isand Alaska (large blue X). Aftershocks are indicated in green.

northern extension of the Sunda arc, which changes strike nearly $180^{\circ}$. The "Bird's Head" region of northwestern New Guinea has converged upon Ceram and the Molucca Sea area to its north leading largely to the ceasing of subduction on the north side of Ceram along the Ceram trough. Plate motion is occurring today about $100 \mathrm{~km}$ to the north of Ceram.

Some deformation has occurred along the backarc of various parts of the former Banda subduction zone, including the south coast of Ceram where the 1998 mainshock was situated along the north side of the Banda Trough. Great earthquakes occurred farther to either the east or northeast of the 1998 shock on 30 September 1899 (Wikipedia referencing the work of Dutch Geologist R. D. M. Verbeek, 2021) and 1629 [55]. Whether they occurred along either the Ceram or the Banda troughs is uncertain.

The mechanism of the mainshock involved largely strike slip motion with a small component of extension. The two nodal planes of the 1998 centroid mechanism strike $92^{\circ}$ and $196^{\circ}$. Since the bathymetry just to the south of Ceram along the Banda trough (near the center of Figure 25) strikes nearly east-west, the choice of the $92^{\circ}$ nodal plane as the causitive fault in 1998 is appropriate. Two aftershocks in Figure 26 favor that choice but the distribution of forererunning activity is indecissive. Seven forerunning shocks took place within 100 $\mathrm{km}$ of either the centroid or its nearby short-period epicenter. The Bulletin of the International Seismological Centre located some shocks of Ms $>5$ along the northern side of the Banda trough since 1920 but not enough for it to be called a 
plate boundary. Left-lateral strike-slip deformation within the island of Ceram is like that in the 1998 GCMT mechanism [56]. That strike-slip motion pertains, however, to earlier geological deformation, which involved high-grade metamorphism. To my knowledge no one has computed a detailed distribution of slip for the 1998 mainshock.

In summary, the 1998 mainshock occurred along the Banda trough on the south side of the island of Ceram. It does not appear to be a plate boundary today and is located on the forearc side of the Banda arc. It is interpreted as an intraplate earthquake. Forerunning activity in Figure 25 would not have been a good guide to either the location of the coming 1998 mainshock or its magnitude.

\subsubsection{Three Great Intraplate Earthquakes off the Coast of Sumatra in 2012 and 2016}

Three great mainshocks occurred in the Wharton Basin of the eastern Indian Ocean off the west coast of Sumatra, Indonesia. Two took place about 2 hours apart in 2012 ( $\mathrm{Mw} 8.6$ and 8.2) and the other in 2016 (Mw 7.8). The Mw 8.6 earthquake is the largest strike-slip earthquake since the start of instrumental seismology. All three were intraplate strike-slip events whose rupture extended into the upper mantle (GCMT mechanisms, 2012; [57]). Meng et al. [57] attribute the large $\mathrm{Mw} 8.6$ event to high-stress drop, displacements along several faults and rupture penetrating into the uppermost mantle. They occurred in a

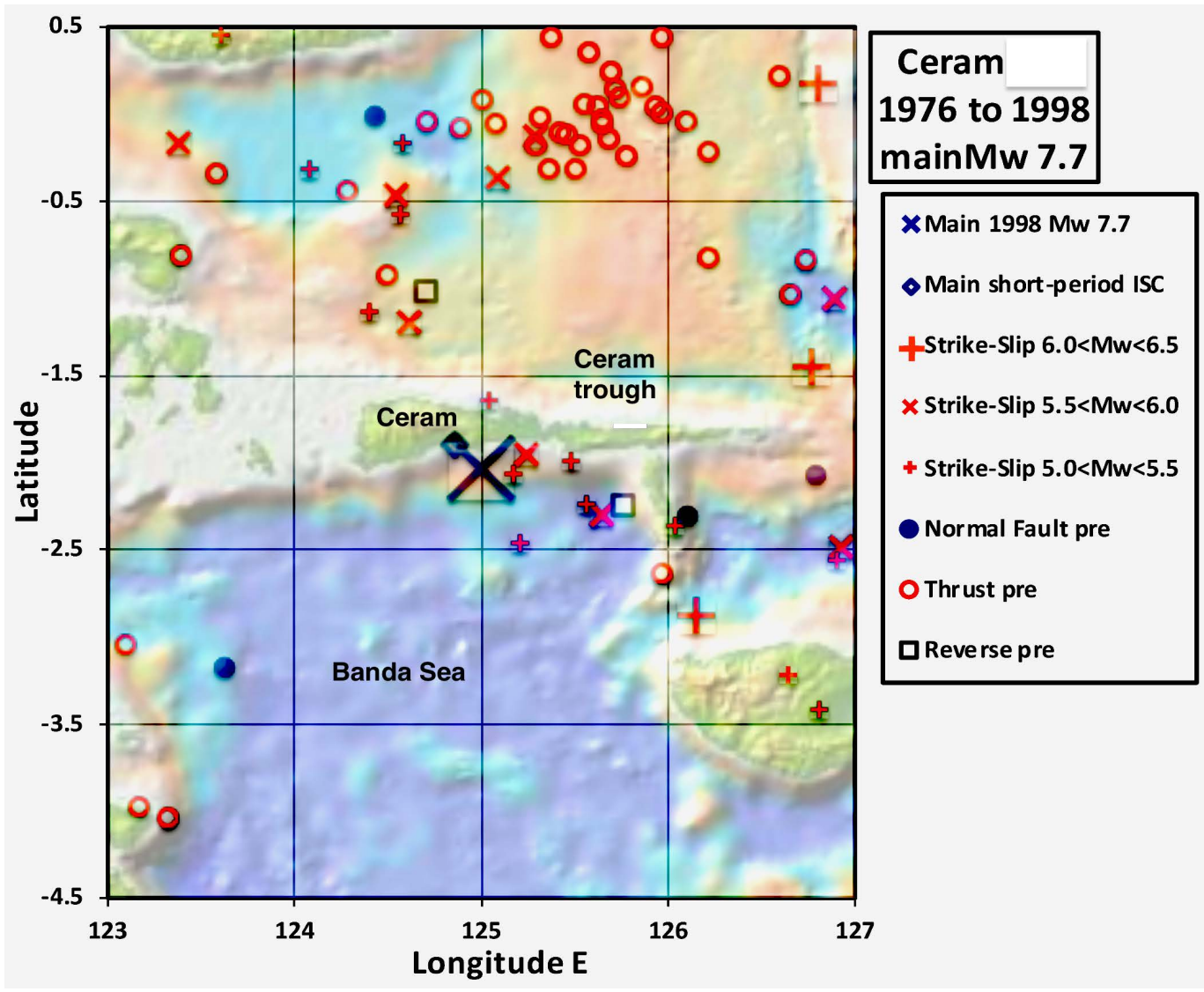

Figure 25. Forerunning activity from 1976 until the 1998 Ceram mainshock of Mw 7.7 (large dark blue X). 


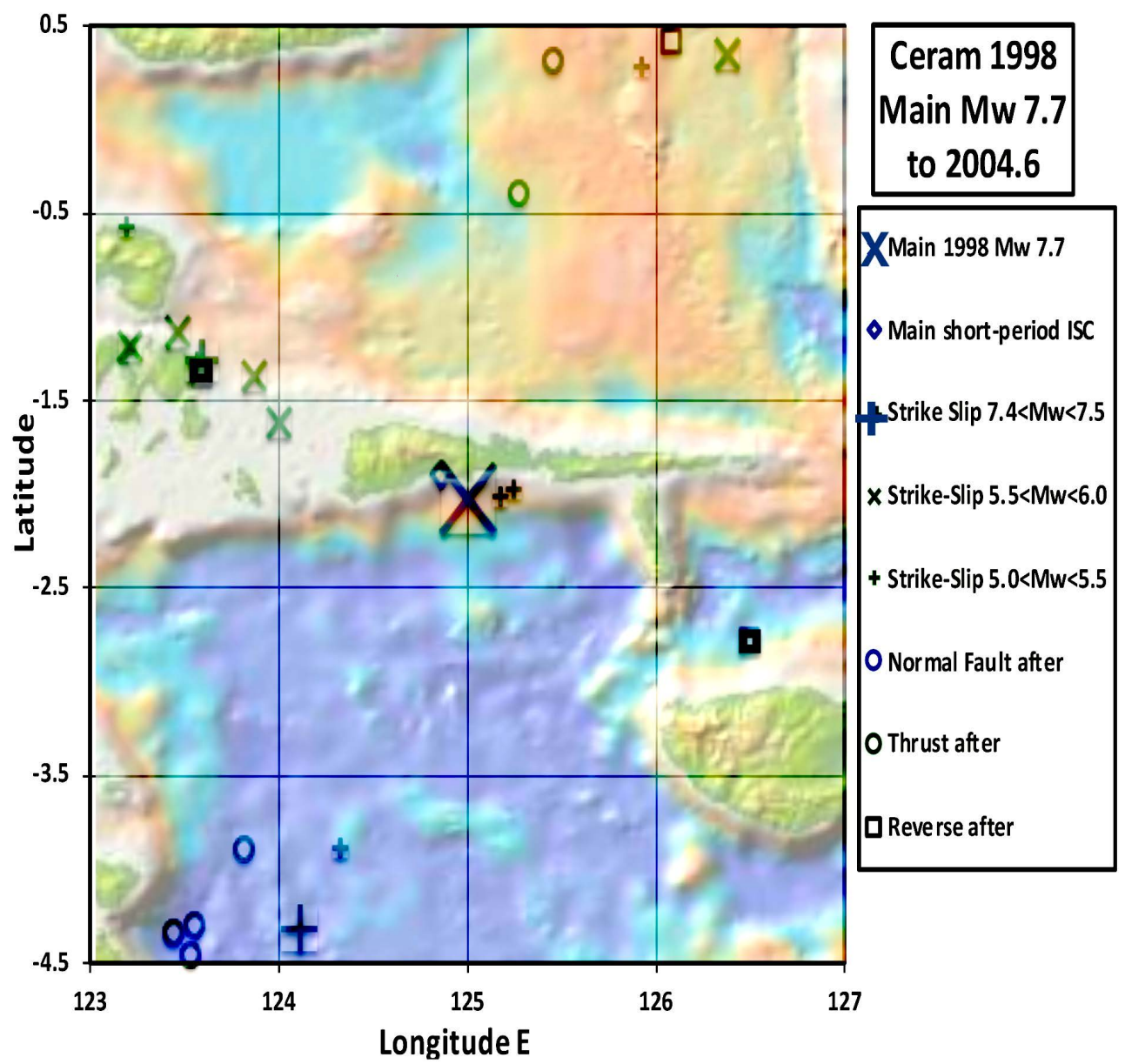

Figure 26. Seismic activity after the 1998 Ceram mainshock of Mw 7.7 (large dark blue X) until 2004.6.

broad zone separating the Indian and Australian plates [57] [58] in what may be developing as a distinct Capricorn plate. The 2012 mainshocks triggered slip worldwide [59].

Slip along six fault segments for the two events of 2012 (Figure 27 and Figure 28) was modelled by [60] [61]. Most forerunning shocks involved strike-slip motion and occurred between the northern two fault segments in Figure 27 and the coast of Sumatra. The multiple-segment rupture in 2012 was encouraged by the occurrence of two giant Sumatran thrust events in 2004 and 2005, which increased horizonal extensional stress in the area where most of the forerunning events occurred between their occurrence and 2012. Forerunning shocks were few from 1976 until the end of 2004 when the first giant Sumatran event occurred. The foreshocks close to the 2012 mainshocks were strike-slip events.

The six fault segments, which are nearly orthogonal, involved right-lateral motion along those striking ESE and left-lateral along those striking NNE. Rupture started near $93^{\circ} \mathrm{E}$ near the middle of the northern of the two long ESE-striking segments. The greatest moment release occurred there [61]. Rupture then spread to the two long NNE segments. Later displacement occurred nearly $200 \mathrm{~km}$ farther west along the Ninety-East Ridge near the left side of Figure 27. 


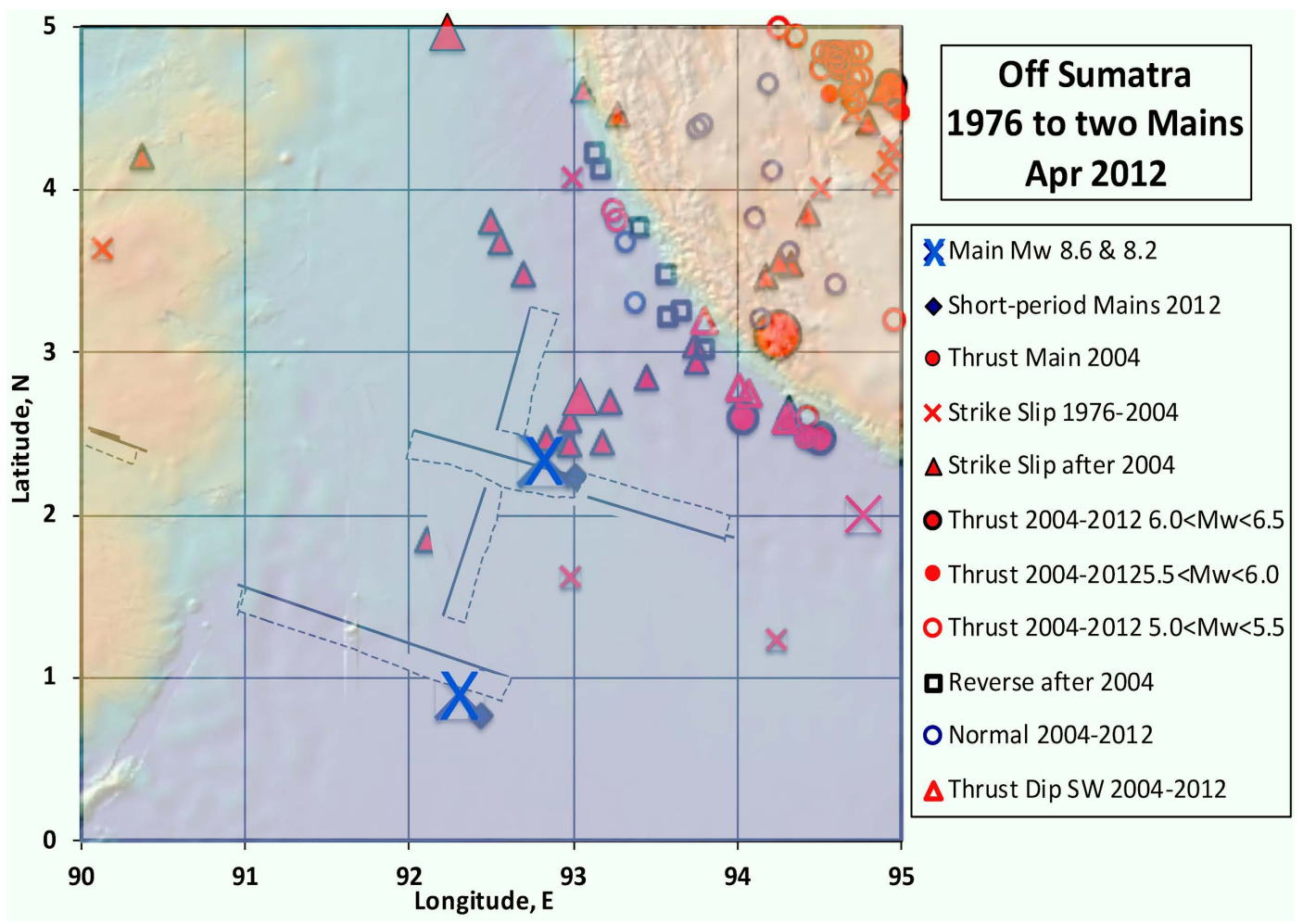

Figure 27. Forerunning activity from 1976 until two mainshocks of 2012 off the coast of Sumatra, Indonesia (Mw 8.6 and 8.2. large blue X's). Computed six fault segments from [61] are shown with updip portions denoted by heavy solid lines. Fault segments dip steepy and involved large strike-slip motion in 2012. Large orange circle denotes centroid of giant 2004 mainshock along the Sumatran subduction zone.

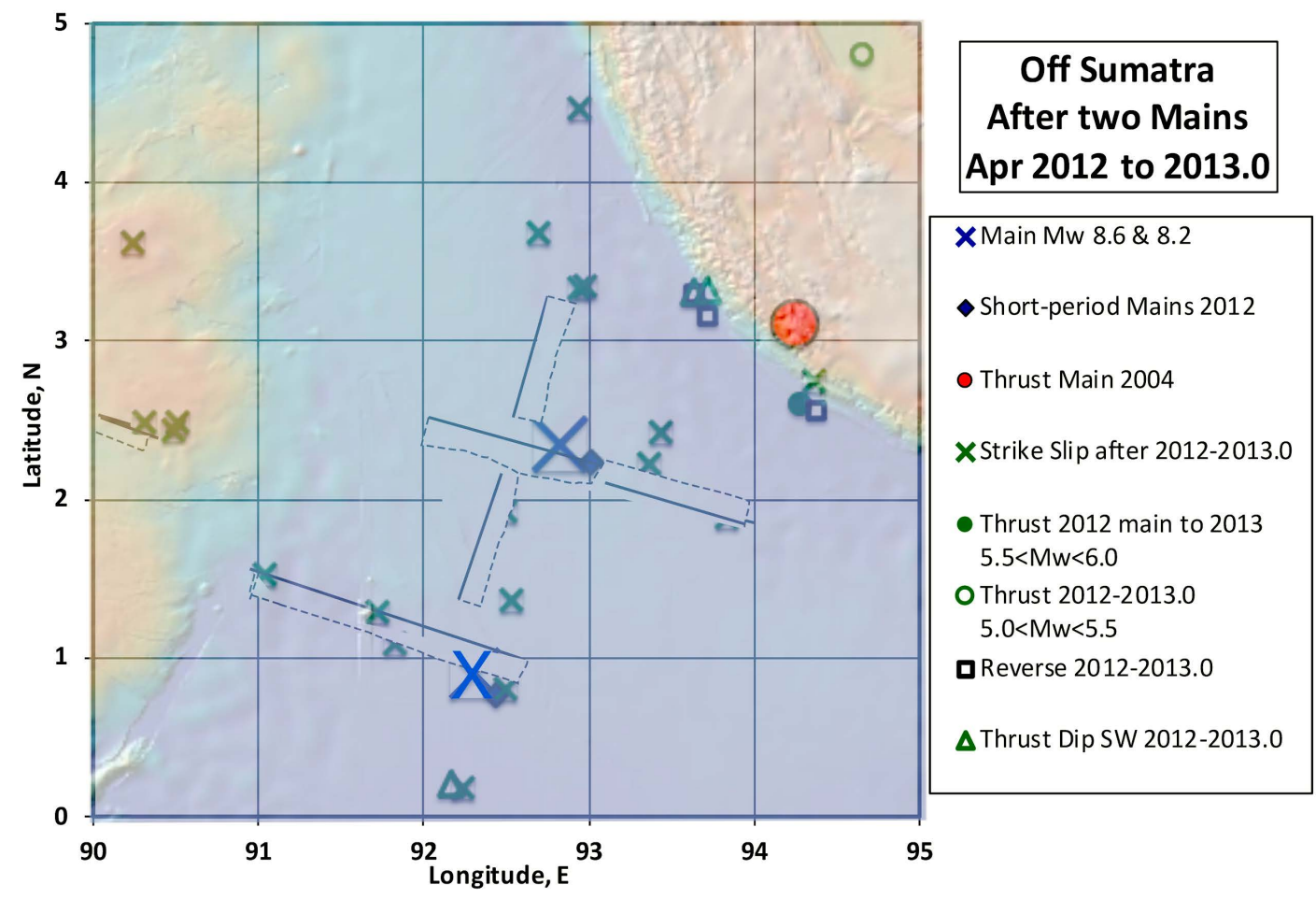

Figure 28. Aftershocks of the 2012 mainshocks off the coast of Sumatra, Indonesia. Symbols same as previous figure. 
Figure 29 indicates that only a few aftershocks occurred following the 2016 mainshock, which was located farther south in the Wharton Bason than the 2012 mainshocks. Only one event took place prior to the 2016 mainshock and it was $200 \mathrm{~km}$ away.

In summary, except for the forerunning shocks, whose stresses likely were boosted after by the two giant Sumatran events of 2004 and 2005, the otherwise low forerunning activity can be ascribed to slow stress buildup along intraplate faults. Those closest forerunning events to the 2012 mainshocks need to be relocated to ascertain if they occurred on or off the faults of the coming great events. The 2016 mainshock had no forerunning events that could be considered related to it and few aftershocks. That intraplate event was located farther from the Sumatran subduction zone than the 2012 mainshocks.

\subsection{Older Great and Large Earthquakes}

\subsubsection{Guatemalan Earthquake of 1976}

The Guatemala earthquake of February 1976 of $\mathrm{Mw} 7.5$ to 7.6 was one of the most destructive shocks in the country's history and caused about 23,000 deaths. It occurred along the Motagua fault, one of the main faults that form the boundary between the Caribbean and North American plates in Central America (Figure 30). The plate boundary within Guatemala is more complex and wider than that farther east within oceanic crust along the transform faults of the same plate boundary in the Cayman trough (Figure 3). Surface faulting on land was the most extensive in the Americas since the San Francisco earthquake of 1906 [62].

The 1976 event occurred so soon after the start of the GCMT catalog that I examined known forerunning shocks of surface-wave magnitude, Ms, greater than 4.6 back to 1956 (Figure 30). Few were found. They were also located more than $100 \mathrm{~km}$ from the western end of the computed rupture zone of the mainshock. The preceding event near $14^{\circ} \mathrm{N}, 92^{\circ} \mathrm{W}$ probably occurred along the subduction zone between the Caribbean and Cocos plates, as did other events in that area after the mainshock (Figure 31). Few aftershocks of $\mathrm{Mw}>5.0$ took place. They were located near the eastern end of the computed rupture zone near the Gulf of Honduras (Figure 31).

Plafker [62] mapped the extent of surface rupture (Figure 31), which was difficult to do along its western end near the volcanic arc and at its eastern end near the Gulf of Honduras. Co-seismic slip of about a meter took place along the segment where Plafker ascertained that clear surface displacement occurred [63]. Smaller slip was computed [63] to its east and west as shown by dashed lines in Figure 31.

In summary, the rupture zone of the 1976 mainshock was devoid of forerunning shocks of magnitude greater than 4.6 from 1956 until its occurrence. It may be regarded as a great asperity that was quiet ahead of time and ruptured almost exclusively during the mainshock. 


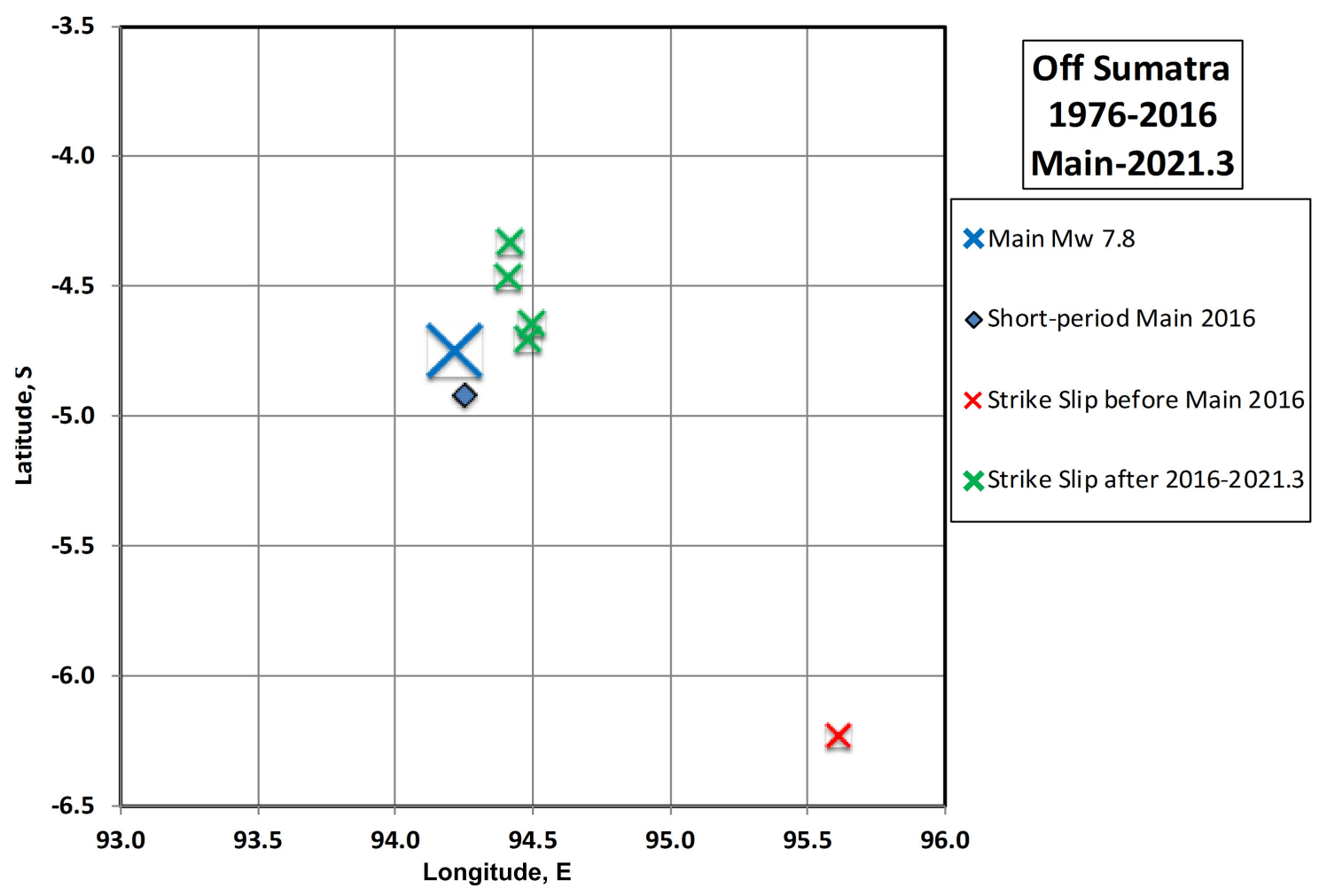

Figure 29. Seismic activity from 1976 to 2021.3 in the vicinity of the 2016 mainshock (large blue X) off the coast of Sumatra, Indonesia.

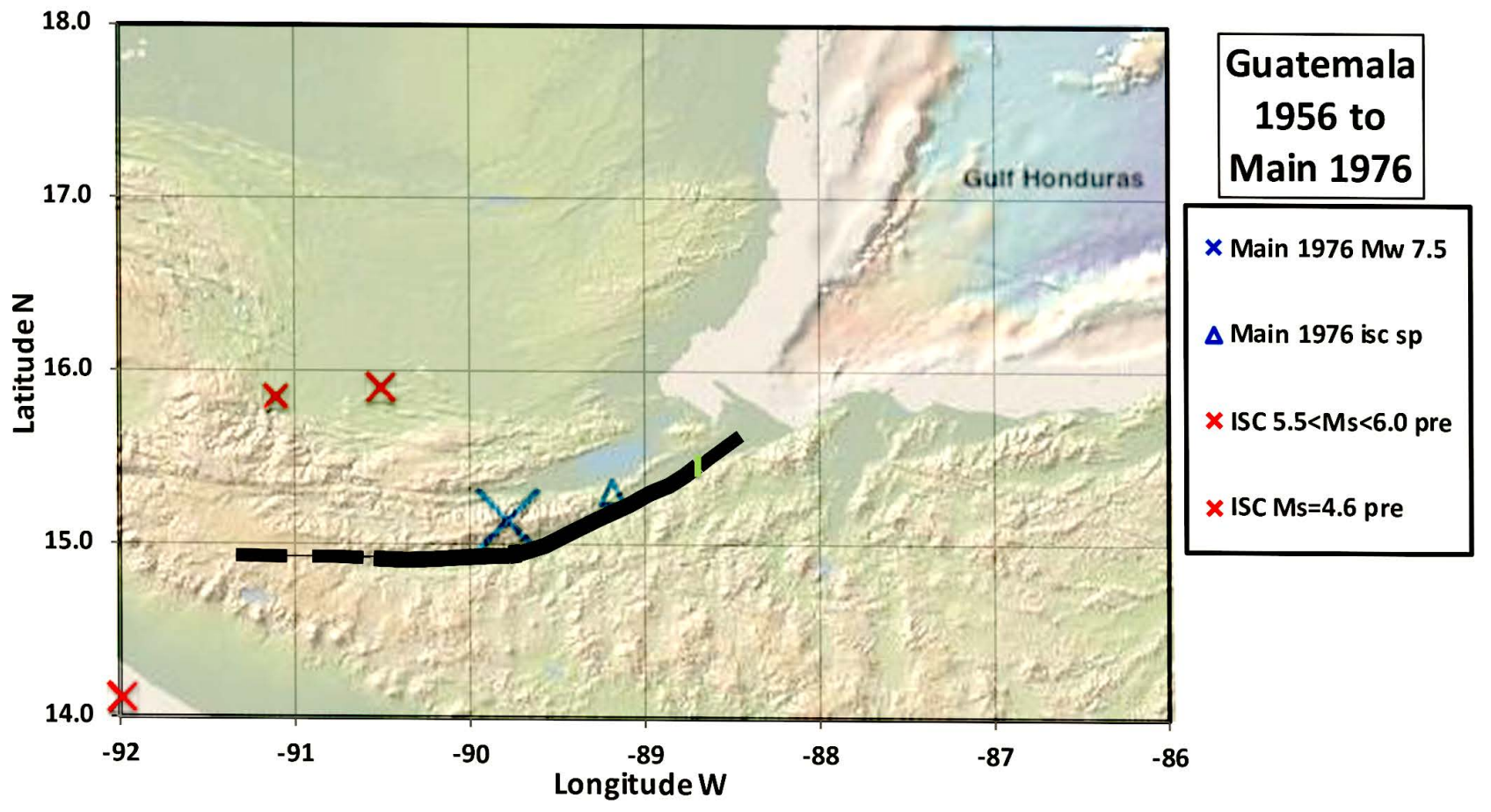

Figure 30. Seismic activity from 1956 until the 1976 Guatemalan mainshock (large blue-green X). Forerunning events of Ms $>4.6$ are from the Bulletin of the International Seismological Centre. Small blue-green triangle denotes epicenter of rupture initiation in 1976. Surface rupture in mainshock along Motagua fault is shown by heavy solid line [62]; additional slip zones computed from seismic data (dashed black lines) are from [63]. 


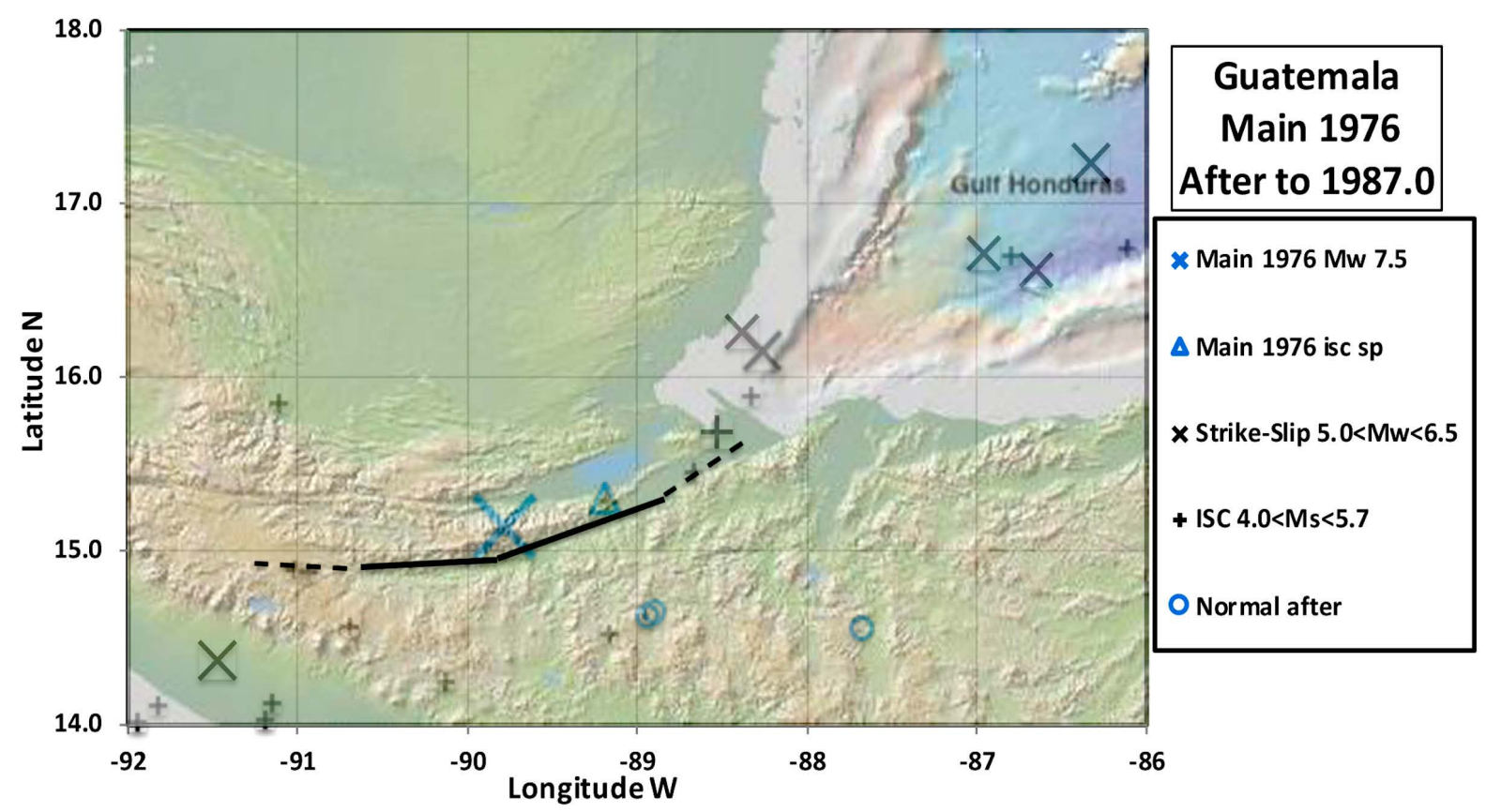

Figure 31. Seismic activity from 1976 to 2021.3 in the vicinity of the 1976 mainshock (large blue-green X).

\subsubsection{Great California Earthquake of 1906}

Strike-slip displacement in the great northern California earthquake of 1906 occurred along the North American-Pacific plate boundary. It was preceded (Figure 1) by a prominent sequence of forerunning shocks and accelerated moment release for magnitudes greater than 5 between 1872 and 1906 [16]. Most forerunning events occurred off the San Andreas fault, the main fault that ruptured in 1906 (Figure 1). Several of those shocks occurred on sub-parallel strike-slip faults in the greater San Francisco Bay area. Some of the largest forerunners took place on mapped thrust faults well to the east of the Bay. These spatial patterns may be helpful for predictions on long-time scales since high-precision depth control is not required, just searches for epicenters of forerunning activity. This is understandable since plate motion in the greater Bay area involves a large strike-slip component and a smaller thrust component. Similar forerunning activity and accelerating seismic moment release with time were described by [16] before the 1868 Hayward, 1948 Desert Hot Springs and 1989 Loma Prieta earthquakes in California (Figure 1).

The parts of the San Andreas fault that broke in 1906 and were quiet ahead of time. They consisted of several great asperities, the southeastern of which broke in the 1989 mainshock of Mw 6.9 (Figure 1). The San Andreas fault to the southeast of the 1989 shock and off the lower part of Figure 1 is known to have a large component of slow deformation and many small shocks, some of which have been as great as magnitude 6.5. That part of the fault is a low-coupled fault segment.

In 1838 the San Andreas fault broke the Loma Prieta zone as well as the Peninsular segment northwest as far as South San Francisco in an event of Mw $\geq$ 
7.2 [64]. It re-ruptured in 1906. The San Francisco mainshock of 1906 broke as far northwest as the Mendocino escarpment and triple junction near $40.2^{\circ} \mathrm{N}$, $124.4^{\circ} \mathrm{W}$ (Figure 32). The 1906 segments, except for Loma Prieta, have been very quiet for shocks of magnitude greater than 5.0 since 1920 (Figure 32). Those segments of the San Andreas fault are surrounded by moderate-size shocks like those described earlier prior to other large continental strike-slip events. The quiet parts of the 1906 rupture zone can be described as two or more great asperities. Much seismicity can be seen where the plate boundary changes to a westerly strike to the west of the Mendocino triple-plate junction.

In summary, quiescence on and near the San Andreas fault that preceded the 1906 California mainshock coincides with several great asperities. Forerunning activity occurred on other faults within the greater San Francisco Bay area, a feature that preceded many large continental strike-slip mainshocks. Forerunning activity to the 1906 mainshock can be ascribed to moderate-size asperities

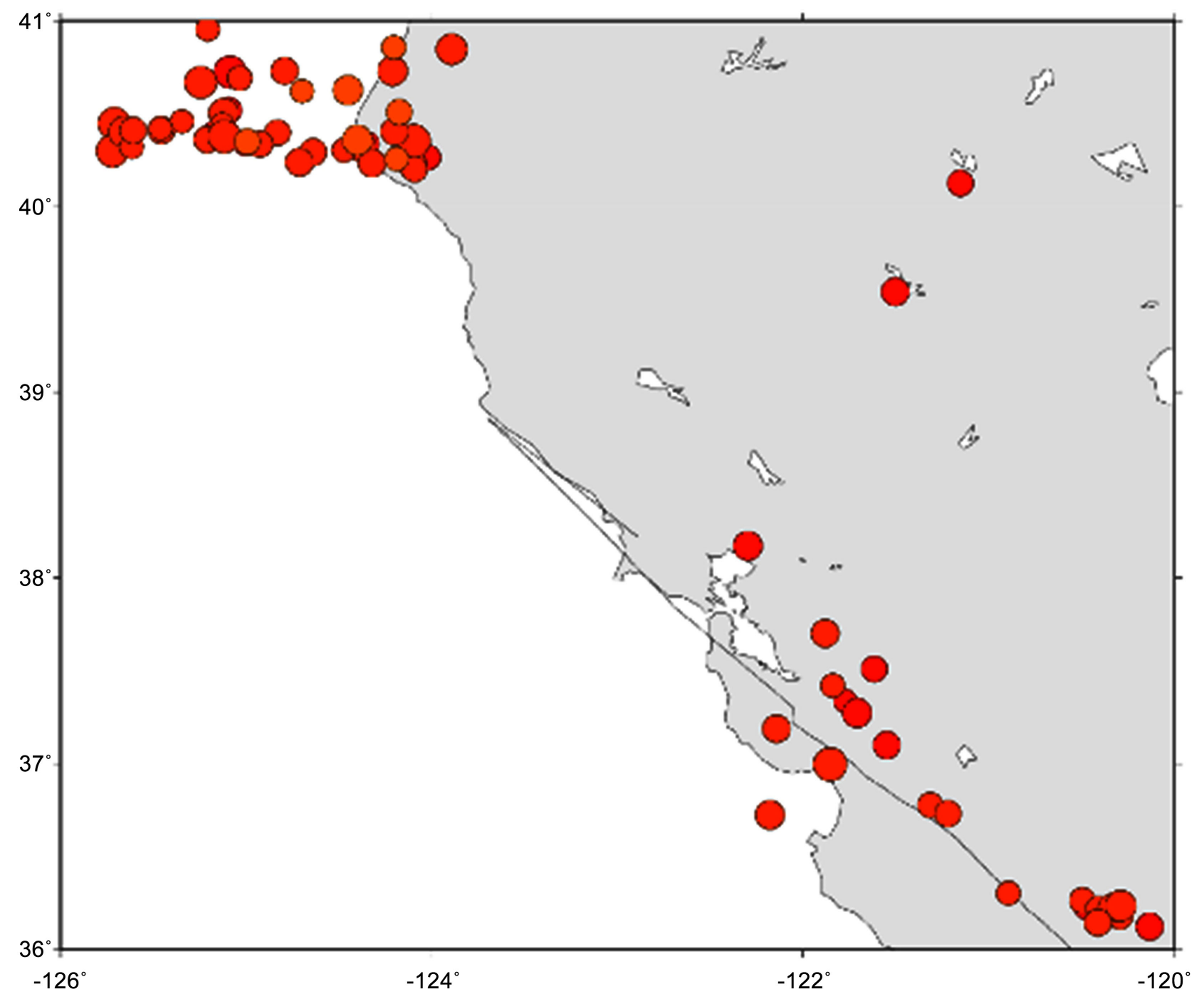

Figure 32. Earthquakes in northern California from 1920 to April 2019 of Ms > 5.0 from the Bulletin of the International Seismological Centre. The San Andreas fault is shown as a long solid line. 
in a zone about $80 \mathrm{~km}$ wide, which were destressed in the previous great earthquake, and then reloaded to failure in the 25 years before 1906. In contrast, forerunning and aftershock activity along oceanic transform faults, like those along the Cayman trough in Figure 3, occurred along very narrow zones and much simpler plate boundaries. Pre-1906 quiescence of the main San Andreas fault resumed after about 1920 and still exists as of June 2021.

\subsubsection{Southern California Earthquake of 1857}

The great southern California mainshock of 1857, largely a strike-slip event, ruptured the surface of the San Andreas fault from near Parkfield to Pallett Creek (Figure 33). It and other fault segments have been sites of many paleoseismic investigations. The 1857 rupture zone has been very quiet for shocks of $M>5.0$ since 1920 but is surrounded by activity at a distance, an indication it consists of two or more great asperities that mainly, and perhaps solely, rupture in great earthquakes. Another major segment of the San Andreas fault last broke in a great shock during 1812 between Pallett Creek and the eastern bend of the fault near San Gorgonio Pass in Figure 34 [65] [66]. The southeastern most part of the San Andreas fault also is quiet in Figure 33 and has not ruptured in a great event for hundreds of years.

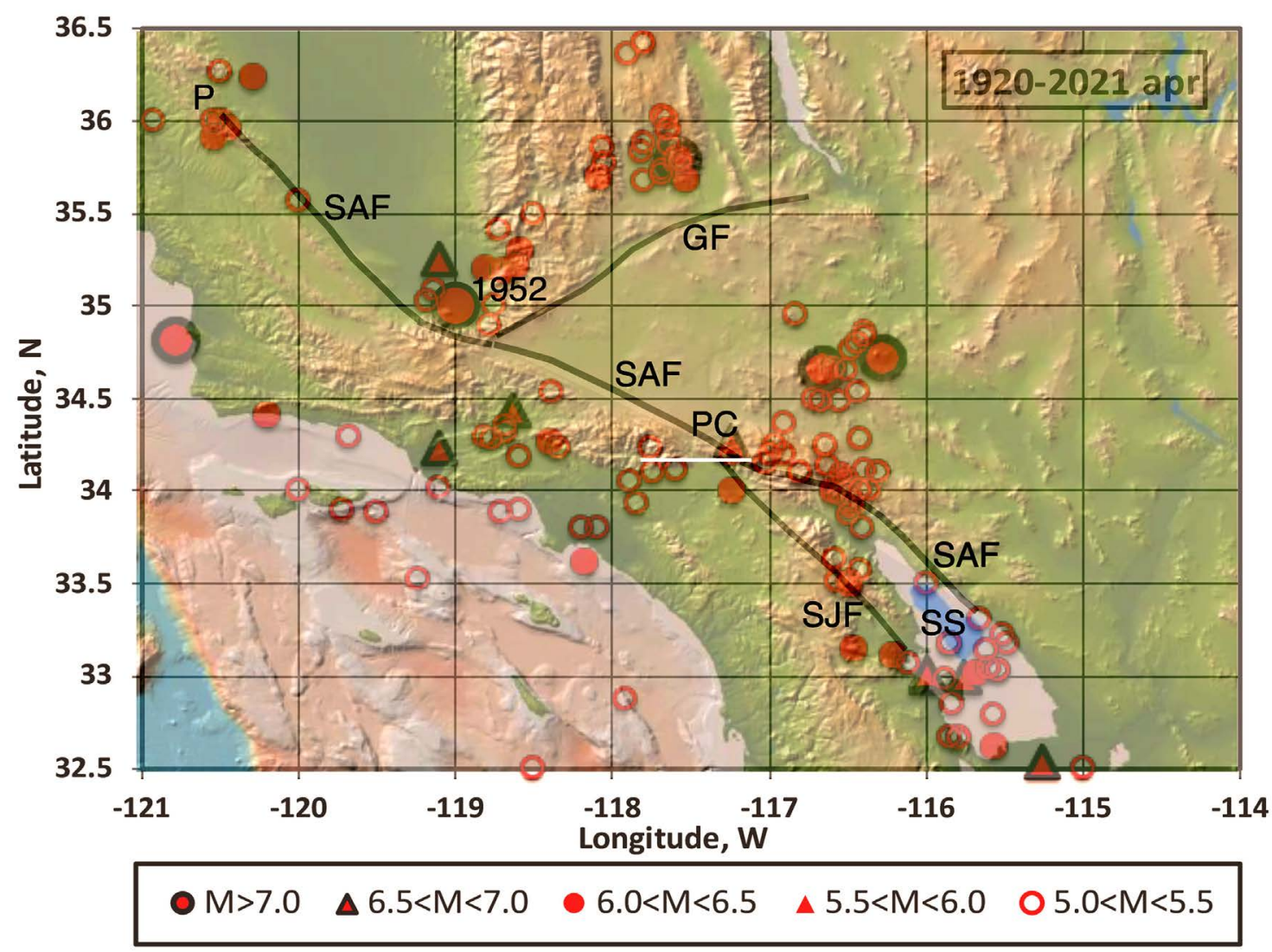

Figure 33. Earthquakes in southern California of magnitudes larger than 5.0 from 1920 to April 2021. Earthquake magnitudes are either Mw, Ms or the local ML. SAF denotes San Andreas, SJF San Jacinto and GF Garlock faults. SS is the Salton Sea. The giant earthquake of 1857 ruptured the San Andreas fault from Parkfield (P) to Pallett Creek (PC). 


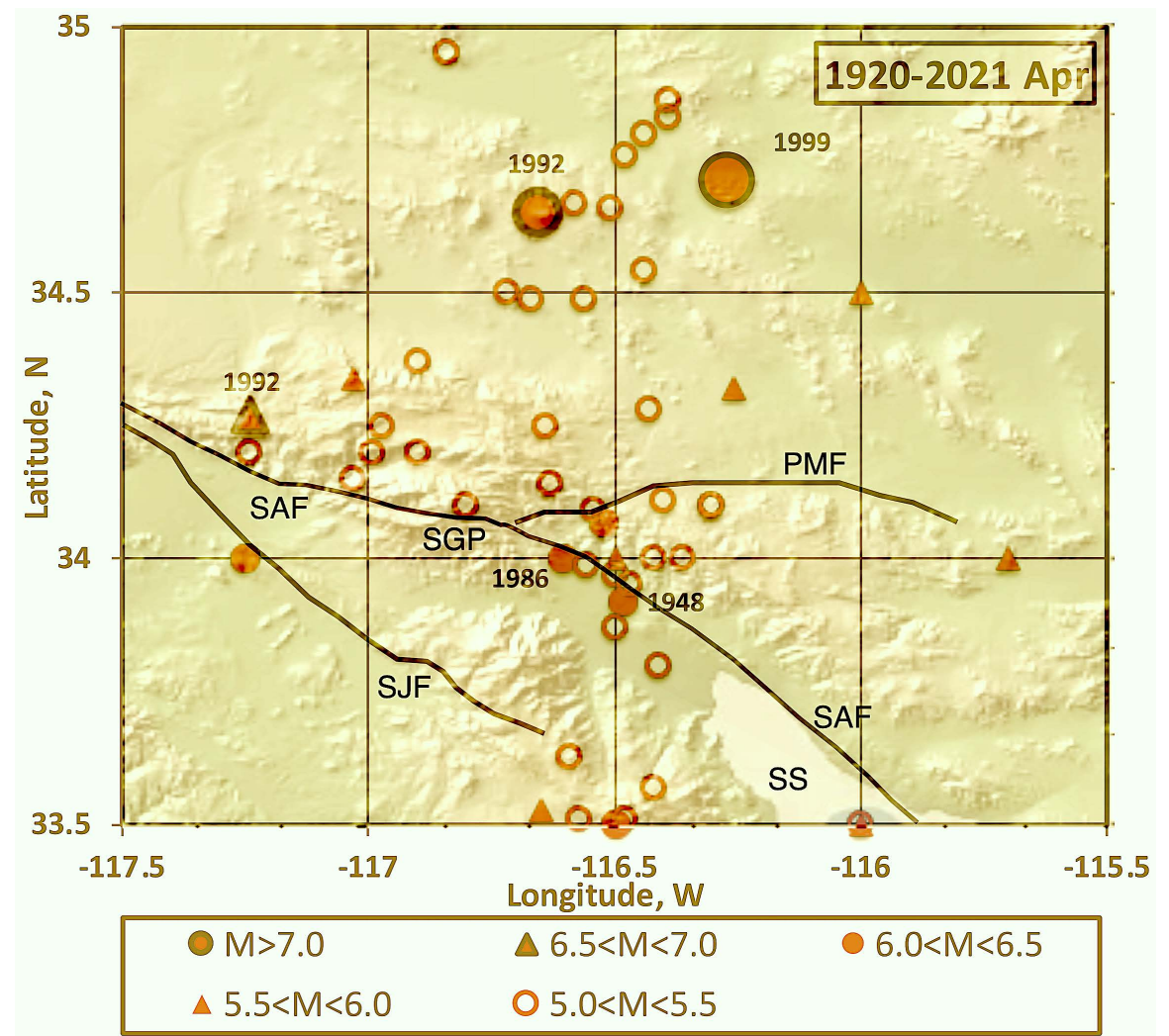

Figure 34. Expanded view of earthquakes in southern California near the eastern bend of the San Andreas fault of magnitudes larger than 5.0 from 1920 to April 2021. Abbreviations same as previous figure. PMF denotes the Pinto Mountain fault; SGP, San Gorgonio Pass.

Several Parkfield earthquakes (P in Figure 33) of about Mw 6 have occurred on the San Andreas fault itself. The rupture zone of the great 1857 Fort Tejon earthquake between Parkfield and Pallett Creek has been particularly quiet for shocks with magnitudes larger than 6.0 since at least 1920. Rupture in the $\mathrm{Mw}$ 7.24 Kern County earthquake of 1952 started near the San Andreas but proceeded along the northeast-striking White Wolf fault. It did not break either the San Andreas or Garlock faults. Its slip consisted of left-lateral strike-slip and reverse components [65].

Several moderate to large earthquakes since 1920 have occurred near the eastern bend of the San Andreas fault in the vicinity of San Gorgonio Pass (Figure 34). The area was described by [67] as a great seismic knot. The 1992 Landers and the 1999 Hector Mine shocks of Mw 7.3 and 7.1 occurred north of the San Andreas fault along the eastern California shear zone. The Big Bear shock of Mw 6.5 occurred the same day as the Landers event but farther west. It involved left-lateral strike-slip displacement oriented $48^{\circ} \mathrm{NE}$ [65]. Hence, it did not rupture the San Andreas. The Joshua Tree event of Mw 6.0 occurred north of the San Andreas fault two months before the Landers earthquake. Jaumé and Sykes [68] interpret it as a left-lateral event like Landers. Thus, it too was not on the San Andrea fault. The Desert Hot Springs event of Mw 6.2 and the 1986 shock of 
Mw 6.1 took place to the east of the eastern bend in the San Andreas along the Banning fault [69] just to the southwest of what is shown as the main fault trace of the San Andreas fault (the Mission Creek strand) in Figure 34. The two rupture zones as inferred from aftershocks by Nicholson strike northwest parallel to the fault. Increased seismic activity occurred about 500 to 530 days prior to and just to the east of the 1948 and 1986 earthquakes [69]. Blisniuk et al. [70] reanalyzed geological data from the Mission Creek and Bannon strands of the San Andreas fault. They report that the Mission Creek strand is by far the more active. The less active Banning strand was the sites of the 1948 and 1986 earthquakes, indicating that they too were not on the main San Andreas fault.

Most, if not all, of the events shown in Figure 34 near the main eastern bend occurred off the main San Andreas fault itself. This indicates that the main fault in much of southern California is locked and consists of one or more great asperities that break in great earthquakes. Those events in Figure 34 are close enough to the San Andreas, however, that their occurrence likely moved it closer to failure. That region should be considered a good place to search for forerunning shocks to great earthquake(s) that will eventually break the San Andreas fault between Pallett Creek and the Salton Sea.

Ben-Zion and Zaliapin [71] describe the localization and coalescence of seismicity before four $\mathrm{Mw}>7$ earthquakes in southern California, one in the adjacent Baja peninsula of Mexico and a 1999 shock along the North Anatolian fault of Turkey. They find that these mainshocks, which they state were locked ahead of time, were preceded about two years by a reduction in the area where low magnitude forerunning shocks occurred on the peripheries of their rupture zones. They also report, "the results for regions around the rupture zones of the $M>7$ earthquakes show that individual events tend to coalesce rapidly to clusters of growing size $\sim 1 \mathrm{yr}$ before the main shocks". They find that activity before the 2004 Parkfield event of M6, however, indicated decreasing average cluster size. They show that the Parkfield section of the San Andreas fault is associated with a well-defined linear zone, which is very different from the more diffuse seismicity in most of southern California. The narrow spatial distribution of activity at Parkfield is like that along the oceanic transform faults in Figure 3. The results of Ben-Zion and Zaliapin represent important directions for work on prediction for yearly to decadal time scales, shorter intervals than studied in this paper.

In summary, few, if any, events of magnitude 6 and larger have taken place since 1920 along the southern San Andreas fault itself between Parkfield and its southern end near the Salton Sea. Seismic activity has occurred on the periphery of those quiet zones since 1920. Some of the closest activity has occurred near the eastern bend of the San Andreas, an area that is recommended for intense study to possibly detect premonitory phenomena of yearly to decadal time scales. The Parkfield area, the site of several shocks on the San Andreas and activity before the 1857 great mainshock, is another area worth extensive monitoring for possible precursory events to a great earthquake. 


\section{Conclusions}

Particular attention is devoted here to the distributions of decadal forerunning earthquakes to large and great mainshocks along transform faults. Forerunning activity is examined for 13 to 45 years before 21 recent large mainshocks that occurred world-wide along strike-slip faults and in the interiors of lithospheric plates (intraplate events). These compliments work by [1] for large to giant earthquakes along subduction zones of the world. Most, and perhaps, all mainshocks were sites of quiet zones for both transform and subduction plate boundaries. Those quiet areas are taken to be major asperities that ruptured in those mainshocks. The locations of surrounding forerunning shocks of smaller size are interpreted to be sites of small to moderate-size asperities. Few to no forerunning events occurred, however, along or near the intraplate mainshocks that were examined, likely because not a long enough time was included in their analyses for regions of very slow stress buildup.

Forerunning events often occurred well off the traces of the main faults that ruptured in strike-slip mainshocks within continents. The 1906 and 1857 rupture zones of great California earthquakes behave similarly and appear to be locked except when they break in great events. Each of those rupture zones has been very quiet for moderate to large earthquakes since 1920 but are surrounded on their peripheries by activity.

Many mainshocks occurred in what had been long-standing seismic gaps for decades to hundreds of years. Forerunning activity might have been used ahead of time to define the approximate rupture zones for the following mainshocks: two oceanic transforms on either side of the Cayman spreading center (Figure 3), the South Scotia transform (Figure 6), New Zealand 2016 (Figure 11) and Sichuan China 2008 (Figure 18). They might have been used but with considerable uncertainty for one end of Pakistan 2013 (Figure 2), Macquarie ridge 1989 (Figure 4), highest moment release area of 2017 Kommandorsky Islands (Figure 10), 1990 Luzon Philippines (Figure 16) and Qinghai China (Figure 20). Forerunning activity since 1976 was not useful in defining the coming rupture zones of intraplate events.

The Parkfield segment of the San Andreas Fault in central California is poorly coupled. It is known to have ruptured in earthquakes of only moderate size and is the site of substantial fault creep and numerous small earthquakes. The adjacent main fault segments farther south and southeast broke, however, in a great earthquake in 1857. The 1857 rupture zone, like that for 1906 San Francisco, is well-coupled and is inferred to consist of two or more great asperities that rupture in great earthquakes [72]. The greater Parkfield area would be a good place to seek forerunning activity and shorter-term precursors to the next great shock just to the south along the San Andreas fault. The Parkfield zone is like low-coupled zones (LCZ) along subduction zones [1]. Many other LCZ have been described as sites of fault creep, smaller earthquakes and slow-slip seismic events. The eastern bend of the San Andreas fault in southern California, the site of many 
moderate-size earthquakes since 1920, is also recommended for intense monitoring and study.

Forerunning earthquakes and aftershocks along oceanic transform faults bordering the Cayman trough were distributed differently than those along several continental transforms. Those oceanic events occurred along narrow bands usually just beyond the ends of the rupture zones of two large earthquakes. The forerunning areas of the 1906 earthquake in California and of large mainshocks along other continental transform faults, however, were broad. Moderate-size shocks also occurred and recurred along some narrow segments of the Gofar transform fault at $4^{\circ} \mathrm{S}$ on the East Pacific Rise while its other segments moved even without moderate-size earthquakes [73]. Some narrow segments of the Eltanin transform fault system in the southeastern Pacific were sites of repeating moderate-size earthquakes whereas other segments were poorly coupled and did not rupture in shocks of $\mathrm{Mw}>5.5$ [74].

The Eltanin transform fault system is situated along the fast-spreading East Pacific Rise. Known shocks along it have not exceeded Mw 6.5; most have been smaller than 6.0. The maximum known size of shocks along the Gofar transform, an even faster-moving fault, was even smaller. Moderate size normal-faulting events are very rare along fast-speading ridges themselves. In contrast, transform faults along slow spreading oceanic ridges-including the Cayman trough and the South Scotia Sea-ruptured in larger mainshocks of $7.5<\mathrm{Mw}<7.8$. The largest strike-slip event along the slow-spreading Southwest Indian ridge was Mw 8.0 [11]. The largest known events along transform faults of the Mid-Atlantic ridge-zones of intermediate-rate spreading-are of $\mathrm{Mw} 7.0$ to 7.1. Great earthquakes in 1906 and 1857 along the continental San Andreas fault were of Mw 7.8 and 7.9. Their long-term slip rate is moderate, about 28 to $33 \mathrm{~mm} / \mathrm{a}$ (Table 1).

Large variations in the sizes of mainshocks among transform faults can be attributed to differences in rock type, the distribution of temperature as a function of depth and geological age (see [15] pp. 307-320). Fast-spreading oceanic transforms like the Eltanin consist of at least three strike-slip segments separated by short spreading ridges [74]. It and other transforms along fast-spreading ridges seem to change their strikes and develop short spreading centers rapidly in response to changes in plate motion. This has prevented the development of very long individual transforms and hence, has restricted the maximum magnitudes of shocks along them. Changing the strike and length of segments of transform faults within continental areas is more difficult. Hence, they rupture in long maximum-size events of Mw 7.8 to 7.9.

The rupture zone of the giant 1906 Ecuador-Colombia earthquake subsequently re-broke in large but not giant shocks in 1942, 1958 and 1979. A similar pattern holds for transform faults, including the rupture zone of the 1906 and 1857 mainshocks in California. Most giant earthquakes-like 1952 Kamchatka, 1960 Chile, 1964 Alaska and 2004 Sumatra-Andaman-likely ruptured two or more great asperities [1]. Each probably broke separately in moderate to great shocks at other times, a common pattern for subduction zones and transform 
faults.

Cumulative seismic moment accelerated about two years before the New Zealand earthquake of 2016 (Figure 13). Cumulative moment accelerated on time scales of about a decade before the giant 2011 Tohoku-oki and the great 2014 Iquique earthquakes along subduction zones. Whether those increases in moment were, in fact, casually related to those coming great earthquakes is uncertain and requires more work. This paper examined mainly the distribution of forerunning activity with latitude and longitude but only a few instances of how it varied with depth.

Several other types of possible precursors-increases in the frequency of small repeating earthquakes, slow slip events and changes in $b$ values-are described briefly here and in [1] along with descriptions of forerunning seismicity and great asperities. We need to understand if precursors of various types occur more often just before great earthquakes.

Some of the mainshocks in this paper along transform faults exhibited short-term precursors. [1] reports similar precursors to mainshocks at subduction zones. [71] describe the localization and coalescence of seismicity on time scales of years before six $\mathrm{Mw}>7$ earthquakes along continental transform faults. These are the start of next steps toward possible earthquake prediction on shorter time scales than decades. I advocate moving from longer to short-term precursory studies. The recent paper [75] indicates strong new interest in the United States in monitoring and studying earthquake precursors.

Quiet zones and sites of forerunning activity in this paper were identified in hindsight. Is it possible to map similar distributions of forerunning activity ahead of time to better determine both the slip regions of coming large to great strike-slip earthquakes and their magnitudes? This will not be easy since hundreds of quiet zones exist today for the subduction and transform-fault plate boundaries of the world. Many repeat times of great shocks exceed 100 years, i.e., longer than detailed seismic observations. A combination of data and calculations could be used to narrow searches for great events of societal interest including ones that are known to have rupture previously in great or giant events. Fault segments could be emphasized that are well advanced in stress accumulation with time compared to their average repeat periods. Slow slip events of a variety of time scales are an important and exciting area of present monitoring and analysis.

Future work needs to include many transform faults and subduction zones worldwide instead of concentrating on just a single or a few areas. In addition to operating more local seismic networks, deployment of permanent GPS observations is needed for additional segments of plate boundaries. Double-difference relocations need to be performed for forerunning shocks, including older and smaller earthquakes. Computer processing of seismograph data to possibly identify forerunning and precursory activity could be done on a continuing basis using probabilistic approaches as soon as new data become available. 


\section{Acknowledgements}

I thank Chris Scholz for critical reading of the manuscript, William Ryan, for advice on bathymetric data.

\section{Conflicts of Interest}

The author declares no conflicts of interest regarding the publication of this paper.

\section{References}

[1] Sykes, L.R. (2021) Decadal Seismicity Prior to Great Earthquakes at Subduction Zones: Roles of Major Asperities and Low-Coupling Zones. International Journal Geosciences. (In Press) https://doi.org/10.5194/egusphere-egu21-1600

[2] Mogi, K. (1962) Study of Elastic Shocks Caused by the Fracture of Inhomogeneous Materials and Its Relations to Earthquake Phenomena. Bulletin of the Earthquake Research Institute, 40, 125-173.

[3] Fedotov, S.A. (1965) Regularities of the Distribution of Strong Earthquakes in Kamchatka, the Kurile Islands and Northeastern Japan. Trudi Institute Fizika Zemli Academy Nauk SSSR, 36, 66-93. (In Russian)

[4] Mogi, K. (1969) Some Features of Recent Seismic Activity in and near Japan (2) Activity before and after Great Earthquakes. Bulletin of the Earthquake Research Institute, 47, 395-417.

[5] Mogi, K. (1969) Relationship between the Occurrence of Great Earthquakes and Tectonic Structures. Bulletin of the Earthquake Research Institute, 47, 429.

[6] Sykes, L.R. (1971) Aftershock Zones of Great Earthquakes, Seismicity Gaps and Earthquake Prediction for Alaska and the Aleutians. Journal of Geophysical Research, 76, 8021-8041. https://doi.org/10.1029/JB076i032p08021

[7] Kelleher, J., Sykes, L. and Oliver, J. (1973) Possible Criteria for Predicting Earthquake Locations and Their Application to Major Plate Boundaries of the Pacific and the Caribbean. Journal of Geophysical Research, 80, 2547-2485.

https://doi.org/10.1029/JB078i014p02547

[8] Dziewonski, A.M., Chou, T.-A. and Woodhouse, J.H. (1981) Determination of Earthquake Source Parameters from Waveform Data for Studies of Global and Regional Seismicity. Journal of Geophysical Research, 86, 2825-2852. https://doi.org/10.1029/JB086iB04p02825

[9] Ekström, G., Nettles, M. and Dziewonski, A.M. (2012) The Global CMT Project 2004-2010: Centroid-Moment Tensors for 13,017 Earthquakes. Physics of the Earth and Planetary Interiors, 200-201, 1-9. https://doi.org/10.1016/j.pepi.2012.04.002

[10] Ekström, G., Tromp, J. and Larson, E.W.F. (1997) Measurements and Global Models of Surface Wave Propagation. Journal of Geophysical Research, 102, 8137-8157. https://doi.org/10.1029/96JB03729

[11] Pacheco, J.F. and Sykes, L.R. (1992) Seismic Moment Catalog of Large, Shallow Earthquakes, 1900-1989. Bulletin of the Seismological Society of America, 82, 1306-1349.

[12] Haxby, W.F. and Ryan, W.B.F. (2019) GeoMapApp. http://www.geomapapp.org

[13] DeMets, C., Gordon, R.C. and Argus, D.F. (2010) Geologically Current Plate Motions. Geophysical Journal International, 181, 1-80.

https://doi.org/10.1111/j.1365-246X.2009.04491.x 
[14] Field, E.H., et al. (2013) Uniform California Earthquake Rupture Forecast, Version 3 (UCERF3): The Time-Independent Model. U.S. Geol. Survey Open File Report 2013-1165, 97 p. https://doi.org/10.3133/ofr20131165

[15] Scholz, C.H. (2019) The Mechanics of Earthquakes and Faulting. Third Edition, Cambridge University Press, Cambridge, 493 p.

[16] Sykes, L.R. and Jaumé, S. (1990) Seismic Activity on Neighboring Faults as a Long-Term Precursor to Large Earthquakes in the San Francisco Bay Area. Nature, 348, 595-599. https://doi.org/10.1038/348595a0

[17] Avouac, J.-P., Ayoub, F., Wei, S., Ampuero, J.-P., Meng, L., Leprince, S., Jolivet, R., Duputel, Z. and Helmberger, D. (2014) The 2013 Mw 7.7 Balochistan Earthquake, Energetic Strike-Slip Reactivation of a Thrust Fault. Earth and Planetary Science Letters, 391, 128-134. https://doi.org/10.1016/j.epsl.2014.01.036

[18] Barnhart, W.D., Briggs, R.W., Reitman, N.G., Gold, R.D. and Hayes, G.P. (2015) Evidence for Slip Partitioning and Bimodal Slip Behavior on a Single Fault: Surface Slip Characteristics of the 2013 Mw7.7 Balochistan, Pakistan Earthquake. Earth and Planetary Science Letters, 420, 1-11. https://doi.org/10.1016/j.epsl.2015.03.027

[19] Tadapansawut, T., Okuwaki, R., Yagi, Y. and Yamashita, S. (2021) Rupture Process of the 2020 Caribbean Earthquake along the Oriente Transform Fault, Involving Supershear Rupture and Geometric Complexity of Fault. Geophysical Research Letters, 48, e2020GL090899. https://doi.org/10.1029/2020GL090899

[20] Braunmiller, J. and Nábêlek, J. (1990) Rupture Process of the Macquarie Ridge Earthquake of May 23, 1989. Geophysical Research Letters, 17, 1017-1020. https://doi.org/10.1029/GL017i007p01017

[21] Hayes, G.P., Furlong, K.P. and Ammon, C.J. (2009) Intraplate Deformation Adjacent to the Macquarie Ridge South of New Zealand-The Tectonic Evolution of a Complex Plate Boundary. Tectonophysics, 463, 1-14. https://doi.org/10.1016/j.tecto.2008.09.024

[22] Kennett, B.L.N., Gorbatov, A. and Spiliopoulos, S. (2014) Tracking High-Frequency Seismic Source Evolution: 2004 Mw 8.1 Macquarie Event. Geophysical Research Letters, 41, 1644-1650. https://doi.org/10.1002/2013GL058935

[23] Ye, L., Lay, T., Koper, K.D., Smalley, R., Rivera, L., Bevis, M., Zakrajsek, A. and Teferle, F. (2014) Complementary Slip Distributions of the August 4, $2003 \mathrm{Mw} 7.6$ and November 17, 2013 South Scotia Ridge Earthquakes, Earth Planet. Science Letters, 401, 215-226. https://doi.org/10.1016/j.epsl.2014.06.007

[24] Eberhart-Phillips, D., et al. (2003) The 2002 Denali Fault Earthquake, Alaska: A Large Magnitude, Slip-Partitioned Event. Science, 300, 1113-1118.

https://doi.org/10.1126/science.1082703

[25] Yue, H., Lay, T., J., Freymueller, T., Ding, K., Riverea, L., Ruppert, N.A. and Koper, K.D. (2013) Supershear Rupture of the 5 January 2013 Craig, Alaska (Mw 7.5) Earthquake. Journal of Geophysical Research: Solid Earth, 118, 5903-5919. https://doi.org/10.1002/2013JB010594

[26] Kogan, M.G., Frolov, D.I., Vasilenko, N.F., Freymueller, J.T., Steblov, G.M., Ekström, G., Titkov, N.N. and Prytkov, A.S. (2017) Plate Coupling and Strain in the Far Western Aleutian Arc Modeled from GPS Data. Geophysical Research Letters, 44, 3176-3183. https://doi.org/10.1002/2017GL072735

[27] Lay, T., Ye, L., Bai, Y., Cheung, K.F., Kanamori, H., Freymueller, J., Steblov, G.M. and Kogan, M.G. (2017) Rupture along $400 \mathrm{~km}$ of the Bering Fracture Zone in the Komandorsky Islands Earthquake (Mw 7.8) of 17 July 201. Geophysical Research Letters, 44, 12161-12169. https://doi.org/10.1002/2017GL076148 
[28] Hamling, I.J., et al. (2017) Complex Multifault Rupture during the $2016 \mathrm{Mw} 7.8$ Kaikoura Earthquake, New Zealand. Science, 356, eaam7194. https://doi.org/10.1126/science.aam7194

[29] Clark, K.J., Nissen, E.K., Howarth, J.D., Hamling, I.J., Mountjoy, J.J., Ries, W.F., Jones, K., Goldstien, S., Cochran, U.A., Villamor, P., Hreinsdóttir, S., Litchfield, N.J., Mueller, C., Berryman, K.R. and Strong, D.T. (2017) Highly Variable Coastal Deformation in the 2016 Mw7.8 Kaikoura Earthquake Reflects Rupture Complexity along a Transpressional Plate Boundary, Earth Planet. Science Letters, 474, 334-344. https://doi.org/10.1016/j.epsl.2017.06.048

[30] Wang, T., Wei, S., Shi, X., Qiu, Q., Li, L., Peng, D., Weldon, R.J. and Barbot, S. (2018) The 2016 Kaikoura Earthquake: Simultaneous Rupture of the Subduction Interface and Overlying Faults, Earth Planet. Science Letters, 482, 44-51. https://doi.org/10.1016/j.epsl.2017.10.056

[31] Lamb, S., Arnold, R. and Moore, J.D.P. (2018) Locking on a Megathrust as a Cause of Distributed Faulting and Fault-Jumping Earthquakes. Nature Geoscience, 11, 871-875. https://doi.org/10.1038/s41561-018-0230-5

[32] Abercrombie, R.E. (2003) The June $2000 \mathrm{Mw} 7.9$ Earthquakes South of Sumatra: Deformation in the India-Australia Plate. Journal of Geophysical Research, 108, ESE 6-1-ESE 6-16. https://doi.org/10.1029/2001JB000674

[33] Allen, C.R. (1962) Circum-Pacific Faulting in the Philippines-Taiwan Region. Journal of Geophysical Research, 67, 4795-4812. https://doi.org/10.1029/JZ067i012p04795

[34] Sitcock, D.M. and Beavan, J. (2000) Geodetic Constraints on Coseismic Rupture during the 1990 Ms 7.8 Luzone, Philippines, Earthquake. Geochemistry, Geophysics, Geosystems, 2. https://doi.org/10.1029/2000GC000101

[35] Velasco, A.A., Ammon, C.J., Lay, T. and Hagerty, M. (1990) Rupture Process of the Luzon, Philippines $(\mathrm{Mw}=7.7)$ Earthquake. Journal of Geophysical Research, 101, 22,419-22,434. https://doi.org/10.1029/96JB02290

[36] Hirano, S., Nakata, T. and Sangawa, A. (1986) Fault Topography and Quaternary Faulting along the Philippine Fault Zone, Central Luzon, Philippines. Journal of Geography, 95, 71-93. https://doi.org/10.5026/jgeography.95.2_71

[37] Daligdig, J.A. (1997) Recent Faulting and Paleoseismicity along the Philippine Fault Zone, North Central Luzon, Philippines. Ph.D. Thesis, Fac. of Sci., Kyoto University, Kyoto.

[38] Lin, A., Ren, Z. and Jia, D. (2010) Co-Seismic Ground-Shortening Structures Produced by the $2008 \mathrm{Mw} 7.9$ Wenchuan Earthquake, China. Tectonophys, 491, 21-34. https://doi.org/10.1016/j.tecto.2009.10.027

[39] Ran, Y., Chen, L., Chen, J., Wang, H., Chen, G., Yin, J., Shi, X., Li, C. and Xu, X. (2010) Paleoseismic Evidence and Repeat Time of Large Earthquakes at Three Sites along the Longmenshan Fault Zone. Tectonophys, 491, 141-153. https://doi.org/10.1016/j.tecto.2010.01.009

[40] Wang, W., Sun, W. and Jiang, Z. (2010) Comparison of Fault Models of the 2008 Wenchuan Earthquake (Ms 8.0) and Spatial Distributions of Co-Seismic Deformations. Tectonophys, 491, 85-95. https://doi.org/10.1016/j.tecto.2009.08.035

[41] Nakamura, T., Tsuboi, S., Kaneda, Y. and Yamanaka, Y. (2010) Rupture Process of the Wenchuan, China Earthquake Inferred from Teleseismic Waveform Inversion and Forward Modeling of Broadband Seismic Waves. Tectonophys, 491, 72-84. https://doi.org/10.1016/j.tecto.2009.09.020

[42] Zhang, G. (2012) Evidence of Sudden Rupture of a Large Asperity during the 2008 
Mw 7.9 Wenchuan Earthquake Based on Strong Motion Analysis. Geophysical Research Letters, 39, 10 p. https://doi.org/10.1029/2012GL052516

[43] Liu, J.-F., Chen, J., Yin, J.-H., Chen, L.-C., Lu, Y.-C. and Yang, H.-L. (2010) Determination of Paleoearthquake Events Using OSL and AMS ${ }^{14} \mathrm{C}$ Dating Techniques at the Leigu Trench along the Longmen Shan Yingxiu-Beichuan Fault Zone. Dizhen Dizhi, 30, 191-199.

[44] Xue, Y., Liu, J., Mei, S. and Song, Z. (2009) Characteristics of Seismic Activity before the Ms 8.0 Wenchuan Earthquake. Earthquake Science, 22, 519-529.

https://doi.org/10.1007/s11589-009-0519-4

[45] Lin, A, Fu, B., Guo, J., Zeng, Q., Dang, G., He, W. and Zhao, Y. (2002) Co-Seismic Strike-Slip and Rupture Length Produced by the 2001 Ms 8.1 Central Kunlun Earthquake. Science, 296, 2015-2017. https://doi.org/10.1126/science.1070879

[46] Lasserre, C., Peltzer, G., Crampé, F., Klinger, Y., Van der Woerd, J. and Tapponnier, P. (2005) Coseismic Deformation of the $2001 \mathrm{Mw}=7.8$ Kokoxili Earthquake in Tibet, Measured by Synthetic Aperture Radar Interferometry. Journal of Geophysical Research, 110, B12408. https://doi.org/10.1029/2004JB003500

[47] Xu, X, Yu, G., Klinger, Y., Tapponnier, P. and Van Der Woerd, J. (2006) Reevaluation of Surface Rupture Parameters and Faulting Segmentation of the 2001 Kunlunshan Earthquake (M 7.8), Northern Tibetan Plateau, China. Journal of Geophysical Research, 111, B05316. https://doi.org/10.1029/2004JB003488

[48] Wen, Y.-Y., Ma, K.-F., Song, T.-R.A. and Mooney, W.D. (2009) Validation of the Rupture Properties of the 2001 Kunlun, China $(\mathrm{Ms}=8.1$ ), Earthquake from Seismological and Geological Observations. Geophysical Journal International, 177, 555-570. https://doi.org/10.1111/j.1365-246X.2008.04063.x

[49] Van der Woerd, J., Tapponnier, P., Ryerson, F.J., Meriaux, A.-S., Meyer, B., Gaudemer, Y., Finkel, R.C., Caffee, M.W., et al. (2002) Uniform Postglacial Slip-Rate along the Central $600 \mathrm{~km}$ of the Kunlun Fault (Tibet), from 26Al, 10Be, and 14C Dating of Riser Offsets, and Climatic Origin of the Regional Morphology. Geophysical Journal International, 148, 356-388. https://doi.org/10.1046/j.1365-246x.2002.01556.x

[50] Henry, C., Das, S. and Woodhouse, J.H. (2000) The Great March 25, 1998, Antarctic Plate Earthquake: Moment Tensor and Rupture History. Journal of Geophysical Research, 105, 16,097-16,118. https://doi.org/10.1029/2000JB900077

[51] Hjörleifsdóttir, V., Kanamori, H. and Tromp, J. (2009) Modelling 3-D Wave Propagation and Finite Slip for the 1998 Balleny Islands Earthquake. Journal of Geophysical Research, 114, B03301. https://doi.org/10.1029/2008JB005975

[52] Robinson, D.P., Henry, C., Das, S. and Woodhouse, J.H. (2001) Two Conjugate Planes of the Wharton Basin Earthquake. Science, 292, 1145-1148. https://doi.org/10.1126/science.1059395

[53] Ruppert, N.A., Rollins, C., Zhang, A., Meng, L., Holtkamp, S.G., West, M.E. and Freymueller, J.T. (2018) Complex Faulting and Triggered Rupture during the 2018 Mw 7.9 Offshore Kodiak, Alaska, Earthquake. Geophysical Research Letters, 45, 7533-7541. https://doi.org/10.1029/2018GL078931

[54] Hall, R. (2012) Late-Jurassic-Cenozoic Reconstructions of the Indonesian Region and the Indian Ocean. Tectonophys, 570-571, 1-41. https://doi.org/10.1016/j.tecto.2012.04.021

[55] Liu, Z.Y.-C. and Harris, R.A. (2013) Discovery of Possible Mega-Thrust Earthquake along the Seram Tough from Records of 1629 Tsunami in Eastern Indonesian Region. Natural Hazards, 72, 1311-1328. https://doi.org/10.1007/s11069-013-0597-y

[56] Pownall, J.M., Hall, R. and Watkinson, I.M. (2013) Extreme Extension across Seram 
and Ambon, Eastern Indonesia: Evidence for Banda Slab Rollback. Solid Earth, 4, 277-314. https://doi.org/10.5194/se-4-277-2013

[57] Meng, L., Ampuero, J.-P., Stock, J., Duputel, Z., Luo, Y. and Tsai, V.C. (2012) Earthquake in a Maze: Compressional Rupture Branching during the $2012 \mathrm{Mw} 8.6$ Sumatra Earthquake. Science, 337, 724-726.

https://doi.org/10.1126/science.1224030

[58] Gordon, R.G., DeMets, C. and Royer, J.-Y. (1998) Evidence for Long-Term Diffuse Deformation of the Lithosphere of the Equatorial Indian Ocean. Nature, 395, 370-374. https://doi.org/10.1038/26463

[59] Delescluse, M., Chamot-Rooke, N., Cattin, R., Fleitout, L., Trubienko, O. and Vigny, C. (2012) April 2012 Intra-Oceanic Seismicity Off Sumatra Boosted by the Banda-Aceh Megathrust. Nature, 490, 240-244. https://doi.org/10.1038/nature11520

[60] Yue, H., Lay, T. and Koper, Y.D. (2012) En Échelon and Orthogonal Fault Ruptures of the 11 April 2012 Great Intraplate Earthquakes. Nature, 490, 245-249. https://doi.org/10.1038/nature11492

[61] Yue, H. and Lay, T. (2020) Resolving Complicated Faulting Process Using Multi Point-Source Representation: Iterative Inversion Algorithm Improvement and Application. Journal of Geophysical Research, Solid Earth, 125, e2019JB018601. https://doi.org/10.1029/2019JB018601

[62] Plafker, G. (1976) Tectonic Aspects of the Guatemala Earthquake of 4 February 1976. Science, 193, 1201-1208. https://doi.org/10.1126/science.193.4259.1201

[63] Young, C.J., Lay, T. and Lynnes, C. (1989) Rupture of the 4 February Guatemalan Earthquake. Bulletin of the Seismological Society of America, 79, 670-689.

[64] Tuttle, M. and Sykes, L. (1992) Re-Evaluation of Several Large Historic Earthquakes in the Vicinity of the Loma Prieta and Peninsular Segments of the San Andreas Fault, California. Bulletin of the Seismological Society of America, 82, 1802-1820.

[65] Deng, J. and Sykes, L.R. (1997) Evolution of the Stress Field in Southern California and Triggering of Moderate-Size Earthquakes: A 200-Year Perspective. Journal of Geophysical Research, 102, 9859-9886. https://doi.org/10.1029/96JB03897

[66] Sykes, L.R. and Menke, W. (2006) Repeat Times of Large Earthquakes: Implications for Earthquake Mechanics and Long-Term Prediction. Bulletin of the Seismological Society of America, 96, 1569-1596. https://doi.org/10.1785/0120050083

[67] Sykes, L.R. and Seeber, L. (1985) Great Earthquakes and Great Asperities, San Andreas Fault, Southern California. Geology, 13, 835-838. https://doi.org/10.1130/0091-7613(1985)13<835:GEAGAS>2.0.CO;2

[68] Jaumé, S. and Sykes, L.R. (1992) Changes in State of Stress on the Southern San Andreas Fault Resulting from the California Earthquake Sequence of April to June 1992. Science, 258, 1325-1328. https://doi.org/10.1126/science.258.5086.1325

[69] Nicholson, C. (1996) Seismic Behavior of the Southern San Andreas Fault Zone in the Northern Coachella Valley, California: Comparison of the 1948 and 1986 Earthquake Sequences. Bulletin of the Seismological Society of America, 86, 1331-1349.

[70] Blisniuk, K., Scharer, K., Sharp, W.D., Burgmann, R., Amos, C. and Rymer, M. (2021) A Revised Position for the Primary Strand of the Pleistocene-Holocene San Andreas Fault in Southern California. Science Advances, 7, 1-14. https://doi.org/10.1126/sciadv.aaz5691

[71] Ben-Zion, Y. and Zaliapin, I. (2020) Localization and Coalescence of Seismicity before Large Earthquakes. Geophysical Journal International, 223, 561-583. https://doi.org/10.1093/gji/ggaa315 
[72] Sieh, K. (1978) Central California Foreshocks of the Great 1857 Earthquake. Bulletin of the Seismological Society of America, 68, 1731-1749.

[73] Froment, B., McGuire, J.J., van der Hilst, R.D., Gouédard, P., Roland, E.C., Zhang, H. and Collins, J.A. (2014) Imaging Along-Strike Variations in Mechanical Properties of the Gofar Transform Fault, East Pacific Rise. Journal of Geophysical Research, 119, 7175-7194. https://doi.org/10.1002/2014JB011270

[74] Sykes, L.R. and Ekström, G. (2012) Earthquakes along Eltanin Transform System, SE Pacific Ocean: Fault Segments Characterized by Strong and Poor Seismic Coupling and Implications for Long-Term Earthquake Prediction. Geophysical Journal International, 188, 421-434. https://doi.org/10.1111/j.1365-246X.2011.05284.X

[75] Pritchard, M.E., et al. (2020) New Opportunities to Study Earthquake Precursors. Seismological Research Letters, 91, 2444-2447. https://doi.org/10.1785/0220200089 